SAND93-0573

Distribution

Unlimited Release

Category UC-515

Printed December 1993

\title{
New Technologies for Item Monitoring
}

\author{
John A. Abbott \\ Sciences Department \\ EG\&G Energy Measurements \\ Albuquerque, NM 87196 \\ Ivan G. Waddoups \\ Insider Technology Department \\ Sandia National Laboratories \\ Albuquerque, NM 87185
}

\begin{abstract}
This report responds to the Department of Energy's request that Sandia National Laboratories compare existing technologies against several advanced technologies as they apply to DOE needs to monitor the movement of material, weapons, or personnel for safety and security programs. We describe several material control systems, discuss their technologies, suggest possible applications, discuss assets and limitations, and project costs for each system.
\end{abstract}

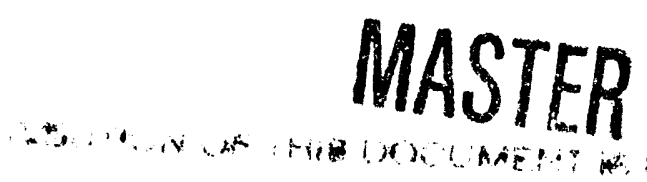


This page intentionally left blank 


\section{CONTENTS}

Summary

1. Introduction

$1.1 \quad$ Background ......................................................... 7

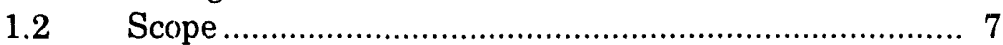

2. WATCH System

$2.1 \quad$ Description ............................................................... 7

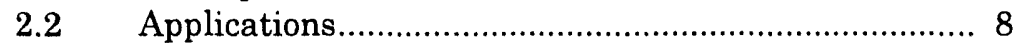

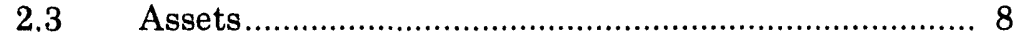

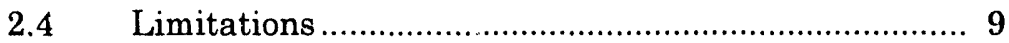

2.5 Projected Cost ............................................ 9

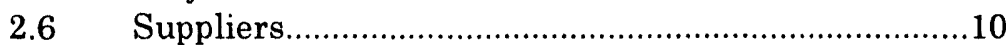

3. Tag System

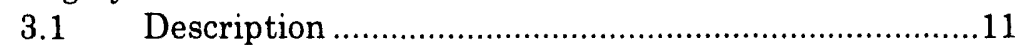

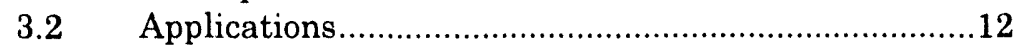

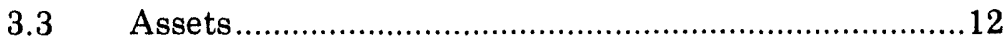

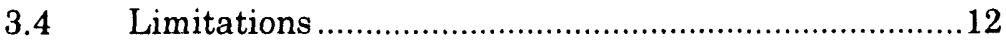

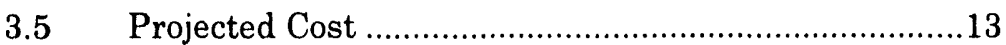

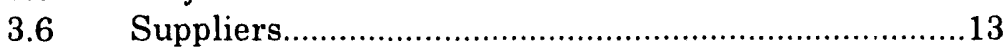

4. PAMTRAK System

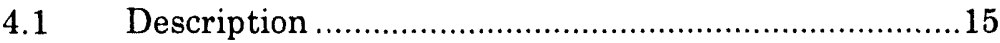

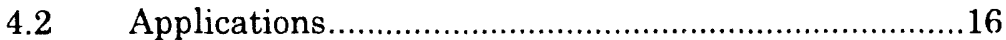

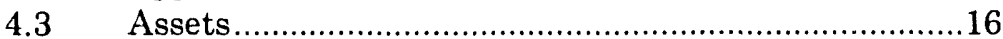

4.4 Limitations ......................................................... 17

4.5 Projected Cost ......................................................

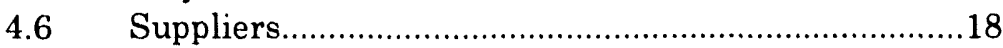

5. VRIS

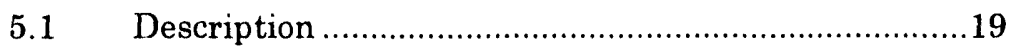

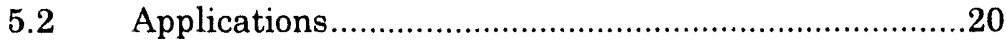

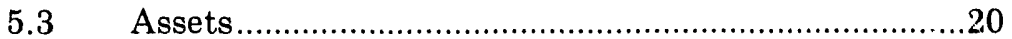

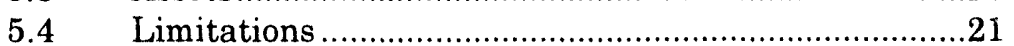

5.5 Projected Cost ......................................................21

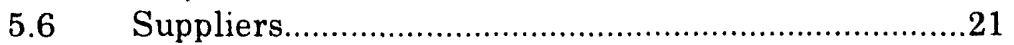

6. VSIS

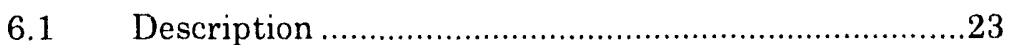

6.2 Applications

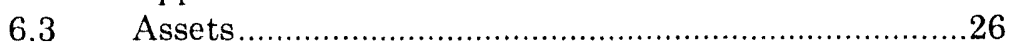

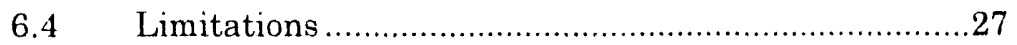

6.5 Projected Cost ......................................................27

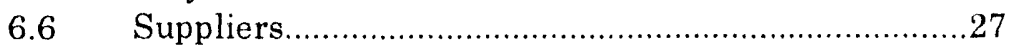


7. AIMS

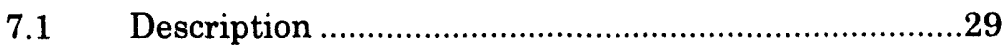

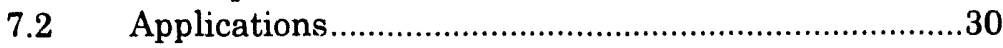

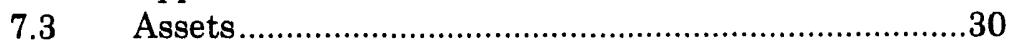

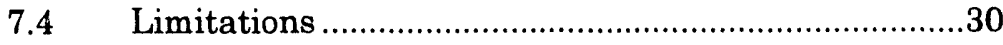

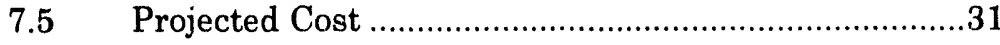

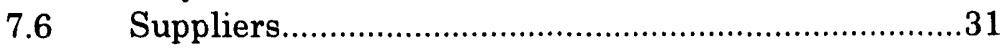

8. EIVS

\begin{tabular}{|c|c|}
\hline 8.1 & Description . \\
\hline 8.2 & Applications..... \\
\hline 8.3 & 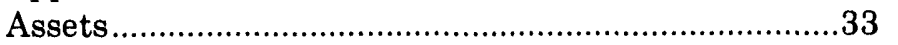 \\
\hline 8.4 & Limitations .. \\
\hline 8.5 & 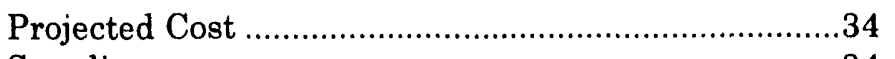 \\
\hline 8.6 & 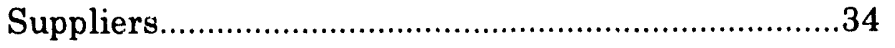 \\
\hline
\end{tabular}

9. Metrox System

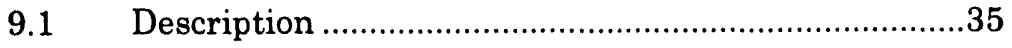

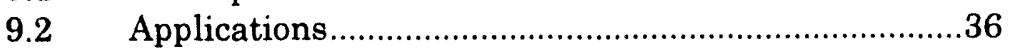

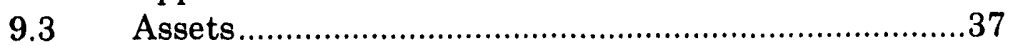

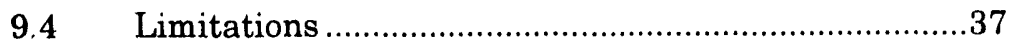

9.5 Projected Cost .......................................................... 37

$9.6 \quad$ Supplier's................................................................... 37

10. TCATS

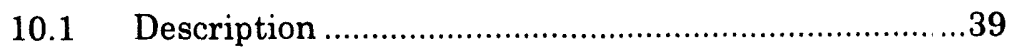

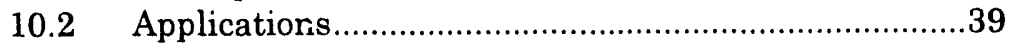

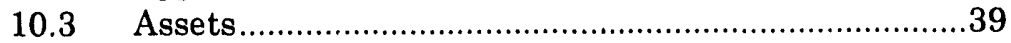

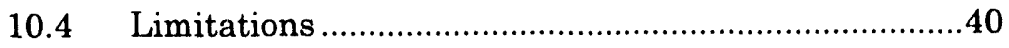

10.5 Projected Cost ...........................................................40

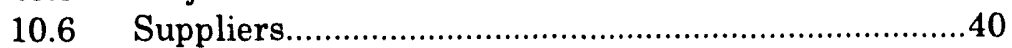

11. LGVSS

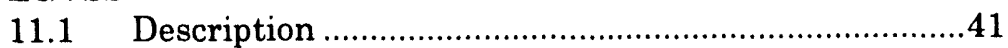

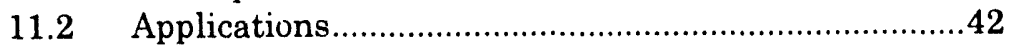

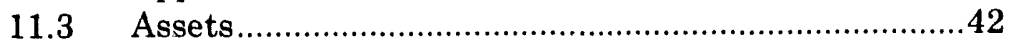

11.4 Limitations ...............................................................

11.5 Projected Cost ......................................................43

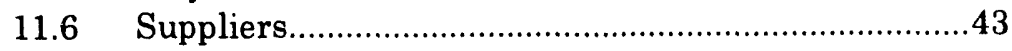

12. CSS

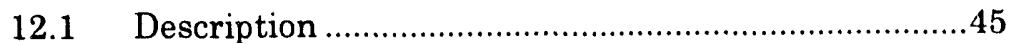

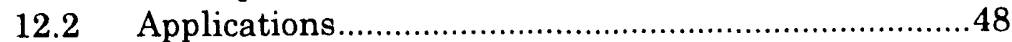

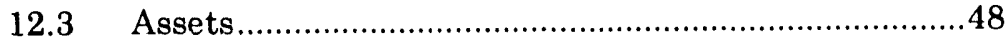

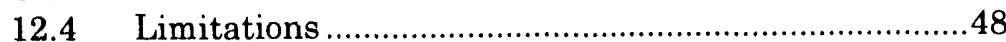

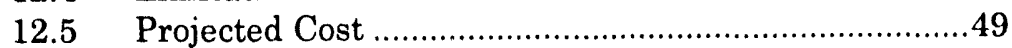

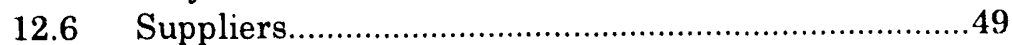


13. SAMMS

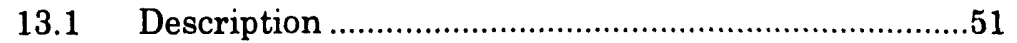

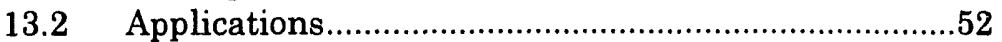

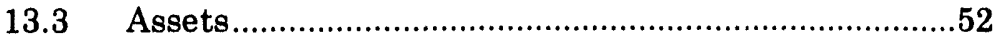

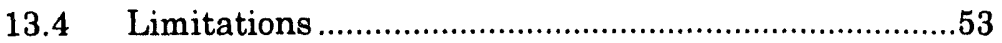

13.5 Projected Cost ..........................................................53

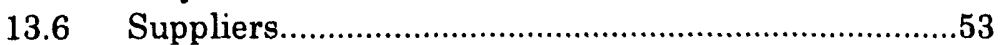

14. FOIDS®

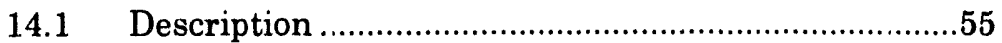

14.2 Applications.............................................................56

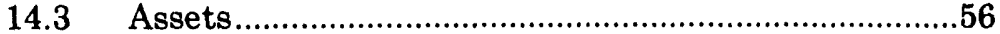

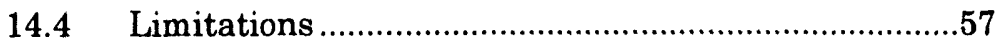

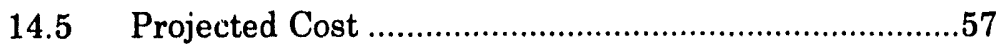

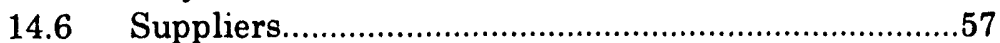

15. GRADS

15.1 Description ..........................................................59

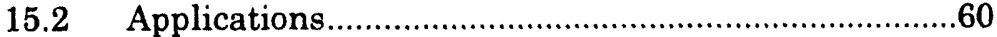

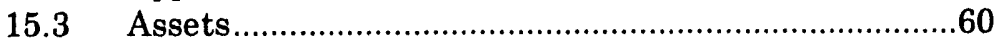

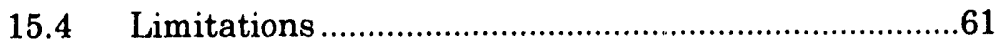

15.5 Projected Cost ........................................................61

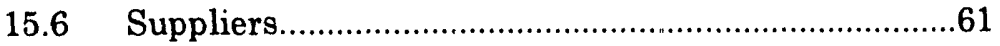

16. PINPAL

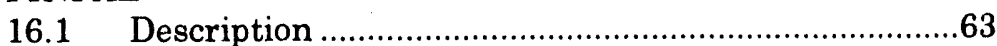

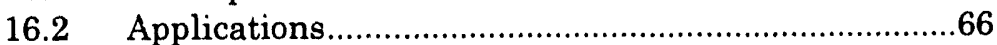

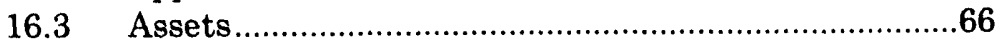

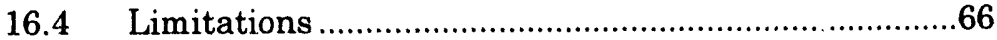

16.5 Projected Cost ........................................................66

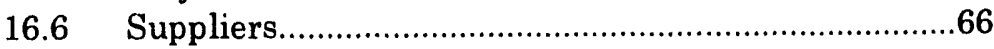

17. Comparison of Technological Systems...................................67 


\section{Figures}

The WATCH System …................................................... 8

System Cost by Number of Sensors ................................... 9

The Tag System ................................................................... 11

System Cost by Number of Monitoring Stations

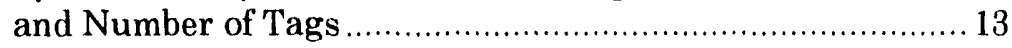

PAMTRAKand Its Subsystems ......................................... 15

Project Costs of the PAMTRAK System ................................ 18

The $\mathrm{WS}^{3}$ Vault Remote Inventory System ........................ 19

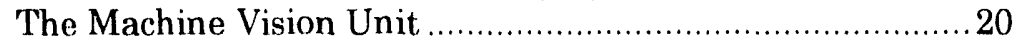

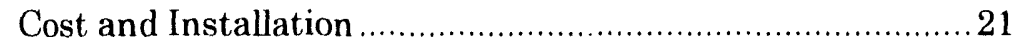

The Vault Safety and Iny ntory System ............................22

The CMUs Five Types of Data ............................................24

Partial Vault Segment with Stored Canisters ......................25

Vault Segment With Complete Set of Stored Canisters ........26

Number of Monitor Stations x 100 ...............................27

A Typical AIMS Installation ..........................................29

Cost by Number of ASTX Packs............................................ 31

Number of Monitoring Stations ............................................. 34

The Metrox Canister Monitoring System …….................... 35

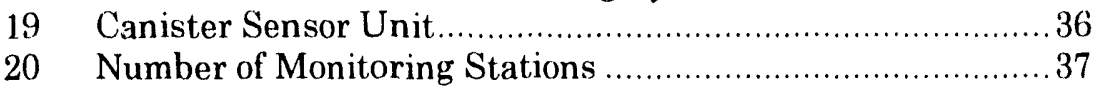

21 Tile, Basket, and Canisters Ready for Insertion

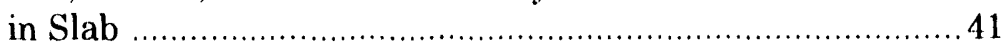

22 Vault Layout................................................................. 42

23 Surveillance Concept for Can Storage Vault ......................44 46

24 CSU on a Rack Within the Vault ......................................47

25 Estimated System Hardware Cost Based on Number ..........

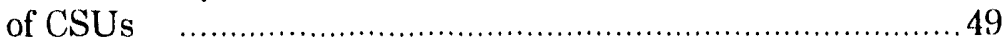

26 SAMMS Storage Area With One Rack Partially

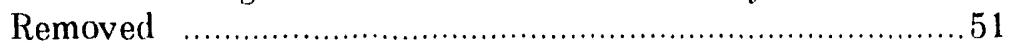

27 ICPP SNM Vault Showing Storage Area …......................... 52

28 FOIDS $₫$ Components ..................................................... 55

$29 \quad$ FOIDS $\circledast$ Sensor Components ........................................... 56

30 Vault Ceiling Mounted Detector Array ................................ 59

31 Item Monitoring Unit..................................................60

32 Physical Inventory Pallet (PINPAL) .................................63 63

33 PINPAL System Level Diagram .......................................64

34 Pantex Síage Right Magazine .........................................65 


\section{Tables}

Comparison of Systems Providing

Location/Containment Attributes

2 Comparison of Systems Providing Continuously

Monitored Item/Material Attributes

3 Item Monitoring Technology Comparison

(Temperature, Weight, etc.)

$4 \quad$ Item Monitoring Technology Comparison

(Cost, Alarm Capability, etc.)

5 Inventory Periods for Alternate Measures

6 System Considerations .73 


\section{Acronyms}

A/D

AIMS

ASTX

BMS

CMU

CPU

CSS

CSU

DOE

EIVS

FOIDS

GRADS

IBM

ICPP

LCA

LED

LGVSS

LVDT

MaxSigma

MaxSP

MB

MCCS

MET

NIM

NMSS

NUCWA

OSS

PAL

PAMTRAK

PC

PIN

PINPAL

PIV

RAM

RF

RPU

SAMMS

S/N

SNL

SNM

$\mathrm{SOH}$

STX

SWIM

TCATS

TCU

VIU

VRIS

VSIS

WATCH

WCU

$\mathrm{WS}^{3}$

WSR
Analog to Digital

Authenticated Item Monitoring System

AIMS Sensor/Transmitter

Balanced Magnetic Sensor

Canister Monitor Unit

Central Processing Unit

Container Safeguards System

Computer Security Unit

Department of Energy

Experimental Inventory Verification System

Fiber Optic Intelligence \& Detection System

Graded Radiation Detection System

International Business Machines

Idaho Chemical Processing Plant

Logic Cell Array

Light-Emitting Diode

Light Grid Vault Surveillance System

Linear Variable Displacement Transformer

A Real-Time Convolution Board

A General Purpose Signal Processing Board

Megabytes

Multiple Code Coded Switch

MCCS Encryption Translator

Nuclear Incident Monitor

Nuclear Material Safeguards and Security System

Nuclear Weapon Accounting System

Office of Safeguards and Security

Permissive Action Link

Personnel and Material Tracking System

Personal Computer

Personal Identification Number

Physical Inventory Pallet

Positive Identity Verification

Random Access Memory

Radio Frequency

Receiver/Processor Unit

Security Alarm and Material Monitoring System

Serial Number

Sandia National Laboratories

Special Nuclear Material

State of Health

Sensor/Transmitter

Special Weapon Inventory Management

Target Cueing and Tracking System

Tag Controller Unit

Vault Interrogation Unit

Vault Remote Inventory System

Vault Safety and Inventory System

Wireless Alarm Transmission of Container Handling

WATCH Controller Unit

Weapons Storage and Security System

Weapon Status Report 


\section{SUMMARY}

\section{Introduction}

The Sandia National Laboratories' (Sandia) Insider Technology Department was tasked by the Department of Energy (DOE) Office of Safeguards and Security (OSS) to develop and demonstrate insider protection technology as it applies to the DOE community. As part of this activity, we identified, characterized, and quantified the trade-offs associated with several existing systems that a site could use for material monitoring. All of these systems provide realtime information on stored nuclear materials and support decreasing the frequency of physical inventories conducted by site personnel. Reducing the frequency of these physical inventories can result in significant cost savings and a reduction of radiation exposure to personnel. This report presents an overview of these systems and examines each system's assets, limitations, possible applications, and projected costs.

\section{System Categorization}

The DOE has published guidance and criteria $^{1}$ for reducing the physical inventory frequency for category I and II special nuclear material storage locations. A site can use three categories of attributes to decrease inventory frequency and still provide assurance of accountability for nuclear materials:

- Area/Environment Attributes that limit or inhibit access to the area and removal of nuclear materials in the inventory;

- Location/Containment Attributes that increase detection of unauthorized access to and/or movement in the storage area; and

- Continuously Monitored Item/Material Attributes that provide qualitative or quantitative assurance that no changes have occurred in the material.

Site specific physical characteristics generally constitute the first category. The technologies presented in the report are the second and third categories.

\subsection{Systems Providing Location/Containment Attributes}

2.1.1 AIMS. The Authenticated Item Monitoring System (AIMS) monitors movement of specified items over time. The AIMS consists of a number of authenticated sensor transmitters (ASTXs) and a receiver/processor unit (RPU) which consists of an RF receiver, a personal computer and an embedded printer. The ASTXs are small, reusable and battery powered. The ASTXs detect and report movement, tamper, and events to the RPU using authenticated RF messages to increase system security. The RPU can store up to 50,000 events between data collection periods. The receivers report the status of the ASTXs to a controller in the RPU that displays and records all alarm information.

1"Nuclear Material Physical Inventory Guidance and Criteria Document," DOE Office of Security Affairs, July 1992. 
2.1.2 EIVS. The Experimental Inventory Verification System (EIVS) is a Los Alamos National Laboratory image-based system which provides timely information on the state of nuclear materials in storage or process. Using video cameras the EIVS acquires baseline image data throughout a monitored area. A host computer digitizes this data and stores it. The system then gathers subsequent image data. The host computer analyzes the subsequent data against the baseline data to detect visually observable changes that occur within the monitored area. The host analyzes these detected events for safeguards significance, archives them for review, and if necessary, triggers an alarm to inform site personnel that an event has occurred.

2.1.3 FOIDS@. The Fiber Optic Intelligence and Detection System (FOIDS®) is primarily designed as a perimeter protection system. The item monitoring system is an adaptation of this system for monitoring stored material using fiber optic technology. This system consists of 1) a control computer that receives, processes, displays, and records all data received from the fiber optic sensors, 2) the FOIDS 3000 fiber optic control interface, and 3) a number of fiber optic loops, used as sensors. The controller is a personal computer using a proprietary operating system with full-color graphic displays that are customized for each site. The system integrates CCTV, access control, and other types of intrusion protection and identification systems. The fiber optic control interface, designed by Mason \& Hanger National is the processing and control point between the computer controller and the fiber optic sensors. The fiber optic loops or sensors are single-mode fiber optic cables. A cable can be 1) molded into a rubber pressure pad and a monitored item placed on top of it, or 2) wrapped around the item to be monitored.

2.1.4 LGVSS. The Light Grid Vault Surveillance System (LGVSS) uses an $x-y$ light beam that monitors nuclear material storage canisters. The concept was proposed by Savannah River, and a mock storage vault was designed and constructed by Oak Ridge National Laboratory. The vault has a below-floor level grid of vertical cylindrical storage locations. The vault floor consists of a grid of metal tiles with aligned holes to allow for the light beam grid. The canister baskets are suspended from the bottom of each metal tile such that the system detects the placement and removal of a canister. The LGVSS consists of a network of light sources, photo sensors, a digital input circuit board that accepts the TTL output from the detector system, and an IBM-compatible PC as the system controller.

\subsubsection{PAMTRAK System. The Personnel and Material Tracking (PAMTRAK)} System consists of a host computer and console, a number of bar-code readers, and three subsystems: an entry control subsystem, a personnel tracking subsystem, and a material monitoring subsystem. The host computer receives information from the users (via the console and bar-code readers) and the various subsystems, and uses the information to maintain an internal representation of the state of the facility. It compares the state against the rules specified for the facility and reports any violations of the rules on the system console. PAMTRAK currently uses the Wireless Alarm Transmission of Container Handling (WATCH) system for its material monitoring subsystem. The WATCH subsystem monitors movement of controlled or stored materials. The WATCHs are small, selfcontained, battery powered devices attached to the material. They detect and report movement, tamper, and low battery alarms to receivers via radio frequency (RF). The receivers report the status of the WATCHs to PAMTRAK or a stand-alone controller that displays and records all alarm information. The WATCHs are basically the same as the ASTXs in the AIMS.

2.1.6 PINPAL. The Physical Inventory Pallet (PINPAL) is a fork truck pallet system used to inventory plutonium pit containers in a storage magazine. It is designed specifically for use at the Pantex Plant. The pallet contains four bar-code laser scanners, four CCD cameras, four VCRs, a video annotator, a supervisory computer and a video quad 
processor. An inventory is conducted by transporting the PINPAL into the magazine and positioning the pallet so it can collect bar-code and video data for each stored item. PINPAL provides inventory reports listing all items scanned, inventor errors and inventory discrepancies.

2.1.7 TCATS. The Target Cueing and Tracking System (TCATS) is a multipurpose, video image, item monitoring or personnel tracking system. The TCATS uses special image processing algorithms to detect purposeful motion while minimizing detection of random motion. The system generates an alarm when the established thresholds are exceeded.

\subsubsection{System Comparisons}

The table below provides a concise summary of some specific details of each system discussed above. Some of the columns need additional definition:

Presence/Movement: The ability to detect movement of the item from a monitored location.

ID: Indicates whether a unique identification of the item is obtained.

Install. Reqmts.: Sandia's judgment of the comparative difficulty in installing the

Tamper: system.

Signal Authent:

Whether the system has tamper protecting features. Whether the commmunications use some form of data authentication.

Table 1. Comparison of Systems Providing Location/Containment Attributes

\begin{tabular}{|c|c|c|c|c|c|c|c|c|c|c|}
\hline SYSTEM & DEVELOPER & $\begin{array}{l}\text { PAESENCE/ } \\
\text { MOVEMENT }\end{array}$ & ID & $\begin{array}{l}\text { WSTALL. } \\
\text { REOMTS. }\end{array}$ & PF & TAMPER & $\begin{array}{l}\text { COST PER } \\
\text { ITEM } \\
\text { MONITOPED }\end{array}$ & $\begin{array}{l}\text { COST PER } \\
\text { MONITORNG } \\
\text { STATION }\end{array}$ & $\begin{array}{l}\text { SIENAL } \\
\text { AUTHENT. }\end{array}$ & $\begin{array}{l}\text { SYSTEM } \\
\text { SECURITY }\end{array}$ \\
\hline AMS & Sandia & YES & YES & LOW & $900 \mathrm{MHz}$ & YES & $\$ 200$ & N/A & YES & NONE \\
\hline EIVS & LANL & YES & NO & MEDIUM & NO & NO & N/A & $\$ 2 \mathrm{~K}$ & YES & PAGSWORD \\
\hline FOIDS $^{\infty}$ & $M \& H$ & YES & No & HIGH & NO & YES & $\$ 5 K$ & N/A & NO & PASSWORD \\
\hline Lovss & $\begin{array}{l}\text { ORNL/ } \\
\text { Bechtel }\end{array}$ & YES & NO & $\mathrm{HIGH}$ & NO & NO & $?$ & $?$ & NO & NONE \\
\hline PAMTRAK & Sandia & YES & YES & MEDIUM & $\begin{array}{l}200 \mathrm{MHz} \\
400 \mathrm{MHz} \\
900 \mathrm{MHz}\end{array}$ & YES & $\$ 300$ & N/A & NO & PASSWORD \\
\hline TCATS & Sandia & YES & NO & MEDIUM & NO & NO & N/A & $\$ 10 K^{\circ}$ & NO & NONE \\
\hline PINPAL & Sandia & NO & YES & LOW & NO & NO & N/A & $\$ 115 K$ & NO & NONE \\
\hline
\end{tabular}

\subsection{Systems Providing Continuously Monitored Item/Material Attributes.}

2.2.1 Metrox System. The Metrox Canister Monitoring System consists of a canister sensor unit, canister sensor interface and control units, and a host computer. Weight, ambient and canister temperatures, canister bulge and canister identification are monitored by the canister sensor unit. Each canister also has an ID unit attached to uniquely identify it. The sensor interface and control unit monitor the individual sensors located in the canister sensor unit. The host computer receives and processes all data from the control units, displays this data, and provides real time visual alarm indications. 
2.2.2 CSS. The Westinghouse Container Safeguards System (CSS) consists of communication nodes and sensor-based modules that monitor the material stored in a sealed metal container. This system obtains weight, temperature, rise, jiggle, ID, and location data for each container. The modules attach and communicate via power line to transceivers. However, when a module is disconnected from the power line, it communicates via RF to portals. The system is intended for situations where materials are stored on shelves in relatively small containers.

2.2.3 GRADS. The Graded Radiation Detection System (GRADS) is a security system designed by LANL to provide a multilayered means of monitoring SNM containers stored in vaults. The first layer of safeguards is a pedestrian radiation portal monitor installed at the entrance to the vault that detects radioactive material moving through the portal. The second layer of safeguardis consists of fixed area monitors configured as an array of neutron detectors installed on the ceiling, storage racks or shelving structure of a storage vault. This monitoring method assumes that the neutron field in a vault produced by a particular configuration of bulk plutonium remains constant as long as the configuration is undisturbed. Changes in the neutron field 1) indicate whether plutonium has been added to, removed from, or moved within the vault, 2) identify the plutonium location, and 3) measure approximately how much plutonium is involved. The third layer of the system is an item monitoring unit that measures mass of and gamma radiation from each container.

2.2.4 SAMMS. The Idaho Chemical Processing Plant uses the Security Alarm and Material Monitoring System (SAMMS) to monitor stored SNM. The SAMMS consists of a series of steel tubes welded into a matrix and set in concrete below the level of the storage area floor. The floor contains circular openings above each steel tube. A steel cap or lid seals each opening in the floor. Suspended from the bottom of each lid is a rack holding SNM containers. When a rack is placed in the storage tube a load cell monitors the weight of the rack and the containers. The SAMMS uses a data acquisition system to continuously monitor the load cell output. Weight tolerance limits are software selectable. The SAMMS generates an alarm when the data acquisition system detects that the weight of the rack exceeds either the upper or lower limit.

2.2.5 VRIS. The Vault Remote Inventory System (VRIS) monitors weapons contained in closed vaults of the Weapon Storage and Security System (WS ${ }^{3}$. The VRIS consists of a 1) machine vision unit that verifies individual weapon serial numbers, 2) detector that monitors and authenticates the collective radiation signature of weapons stored in the vault, 3) vault computer that processes the data received from the vision unit and radiation detector to verify the inventory, and 4) base control computer to conduct inventories of all vaults, store inventory data, and produce weapons status reports.

2.2.6 VSIS. The Vault Safety and Inventory System (VSIS) has monitored approximately 6900 nuclear storage canisters for several years at the Hanford Plutonium Storage Facility. This system consists of canister monitor units (CMUs) that provide data to a central computer over hard wires. The CMUs gather label identification, canister bulge, canister temperature, canister presence, and ambient air temperature data. A minicomputer functions as the control computer for the VSIS, allowing the operator to issue commands and to print reports. It also receives inventory and alarm data for the CMUs from four microcomputers hardwired to the CMUs. 
2.2.7 System Comparisons. The table below provides a concise summary of some specific details of each of the systems discussed above. Additional definitions, beyond those provided for the previous table, follow:

Delta Temp.: The difference between the ambient and canister temperatures.

Bulge: $\quad$ A safety related measurement to indicate an internal pressure increase.

Table 2. Comparison of Systems Providing Continuously Monitored Item/Material Attributes

\begin{tabular}{|c|c|c|c|c|c|c|c|c|c|c|}
\hline SYSTEM & DEVELOPER & WEVEHT & $\begin{array}{l}\text { PPESENCE } \\
\text { MOVEMENT }\end{array}$ & 1D & $\begin{array}{c}\text { DELTA } \\
\text { TEup. }\end{array}$ & maduTion & DULCE & TAMPER & 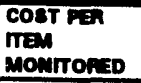 & $\begin{array}{l}\text { SY8TEM } \\
\text { EECUATr }\end{array}$ \\
\hline METhox & Motrox & YES & YES & YES & YES & NO & YES & No & s1k & NONE \\
\hline css & WSTC & YES & YES & $\mathrm{NO}^{\circ}$ & YES & NO & NO ${ }^{\circ}$ & NO ${ }^{\circ}$ & $\$ 700$ & NONE' \\
\hline GADS & LANL & YES & YES & NO & NO & YES & NO & YES & $?$ & PASSWORD \\
\hline SAMMS & WINCO & YES ${ }^{\circ}$ & YES & NO & NO & NO & NO & NO & $?$ & NONE \\
\hline VR1S & Sandia & NO & YES & YES & NO & YES & No & YES & $55 x$ & PASSWORD \\
\hline VSis & Sandia & NO & YES & YES & $\overline{\text { YES }}$ & No & YES & YES & $\$ 700$ & NONE \\
\hline
\end{tabular}

* Still under development, may change.

${ }^{* *}$ Does not measure individual canister weight, measures total weight of rack and canisters.

\section{Conclusion}

There are several technologies available to sites to decrease the frequency of uuclear material physical inventories. These have been developed by both commercial and government organizations. There is a limited amount of testing and actual experience on these systems in general. Potential users should carefully evaluate their specific application and compare their requirements with the various system capabilities in order to obtain a cost effective solution. In many cases potential users may need to do additional development or at least some modification for the system that best matches their needs. 
This page intentionally left blank 


\section{New Technologies for Item Monitoring}

\section{INTRODUCTION}

1.1 Background. The Sandia National Laboratories (Sandia) Insider Technology Department has been tasked by the Department of Energy (DOE) Office of Safeguards and Security (OSS) to respond to the insider threat as it applies to the DOE community. One of the activities within this larger task involves examining current hardware practices in order to identify, characterize, and quantify the tradeoffs associated with using several advanced technologies. These technologies provide real time information on stored nuclear materials. The real time data in turn supports decreasing the frequency of inventories conducted by site personnel.

1.2 Scope. This document examines current technologies as they apply to DOE needs. Wə also examine each íechnology's assets, limitations, possible applications, and projected costs.

\section{WATCH System}

2.1 Description. Wireless Alarm Transmission of Container Handling (WA'TCH) is a system that monitors movement of controlled or stored materials. The WATCH sensors or Sensor/Transmitter (STX) units are compact, self contained, and battery powered. There are currently three types of WATCH sensors in use:

- The Universal Transmitter is designed to be used with an external switch (i.e., a pressure pad, pin switch, infrared or white-light beam, or with any external devices that supplies a switch open or switch closure).

- The Wide Gap or Balanced Magnetic Sensor (BMS) is used for monitoring doors.

- The Jiggle Switch Movement Sensor is attached to an item and detects and reports movements.

The transmitter section of the jiggle switch sensor is modular and interchangeable with other types of sensors currently being developed. The WATCH jiggle switch sensors detect and report movement, tampering, and low battery conditions to the WATCH receivers via $900 \mathrm{MHz}$ radic frequency $(\mathrm{RF})$. All WATCH alarm transmissions are redundant and randomized for high reliability. The $\mathrm{RF}$ receivers process the incoming signals and relay authentic signals to the WATCH controller via an RS-232 cable. Each WATCH receiver is capable of handling 256 WATCH transmitters, and each system can use up to four receivers (see Figure 1). The WATCH controller unit monitors each WATCH and receiver for its state-of-health (SOH). 


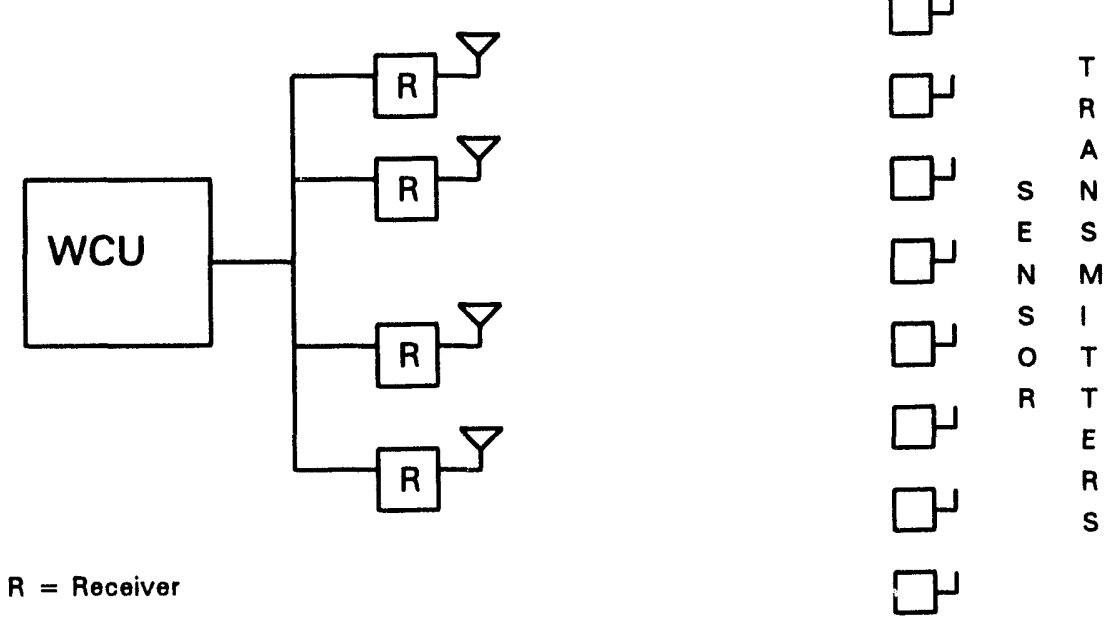

Figure 1. The WATCH System

The WATCH controller unit (WCU) is an IBM compatible PC. Sandia designed and wrote the software using $\mathrm{C}$ programming language. The WCU can be used as a stand-alone system that gathers data and records events inside a controlled area. This data is stored in files on the controller's hard disk and may be downloaded for review or can be converted into permanent records. Access to the WCU's control menus and base operating system is protected by built-in security. The WCU is also designed to be used as a subsystem of the Personnel and Material Tracking System (PAMTRAK) discussed later in this document.

2.2 Applications. The WATCH system is used to monitor sensitive nuclear materials, is ideal in vaults where nuclear materials are stored, and can greatly reduce the need for physical inventory by site personnel. This system also monitors the movement of weapons-related parts and materials in a production facility during nonoperational hours, or when access to these materials is prohibited. The WATCH BMS also monitors entry points in a controlled area.

2.3. Assets. There are many advantages of the WATCH system. This section discusses the system's assets and the advantages of using the WATCH system as an inventory tool or as an internal security system.

- The WATCH system operates on radio frequencies. This substantially reduces the system installation costs. Each system uses from one to four receivers. The number of receivers needed depends on the characteristics of the host facility. The receiver's only installation requirements are one RS-232 communication cable and DC power.

- Only minimal installation modifications are required to existing facilities.

- In comparison with other security systems, this is a very low-cost system.

- The WATCH system used as an inventory tool greatly reduces the frequency of mandatory physical inventory.

- When monitored by security personnel, the WATCH system is capable of providing real time visual alarm indication in the form of highlighted text. 
- Each WATCH sensor is supervised, and loss of signal for any reason is displayed as an alarm.

- Each WATCH sensor is capable of monitoring its internal power supply and indicates low power.

- Each WATCH sensor is tamper-protented, and the WCU displays tamper attempts.

- Low installation requirements allow the WATCH system to be used in storage facilities where nuclear materials are already housed.

2.4 Limitations. Limitations of the WATCH system are:

- The WATCH system only gathers data relative to material access. This system generates real time alarms through the PAMTRAK system when monitored material is accessed. This system does not provide alarms annunciation.

- RF signals from WATCH sensors may impact existing safety and security devices.

- Nine hundred MHz RF signals from WATCH sensors have a range of 600 feet and readily penetrate standard concrete structures. Interception of RF signals is possible if the monitored facility is located near a site perimeter.

- WATCH jiggle switch sensors are sensitive to external vibration and may generate false alarms when installed in facilities where heavy equipment (i.e., robotic stackers) is used.

- Although much has been done to minimize RF collision rates, a potential problem still exists where several hundreds of items are monitored.

- The WATCH system may not be appropriate at sites that restrict or prohibit RF transmissions due to safety concerns when explosives are stored or processed onsite.

2.5 Projected Cost. Figure 2 shows the estimated system cost based on the number of sensors needed.

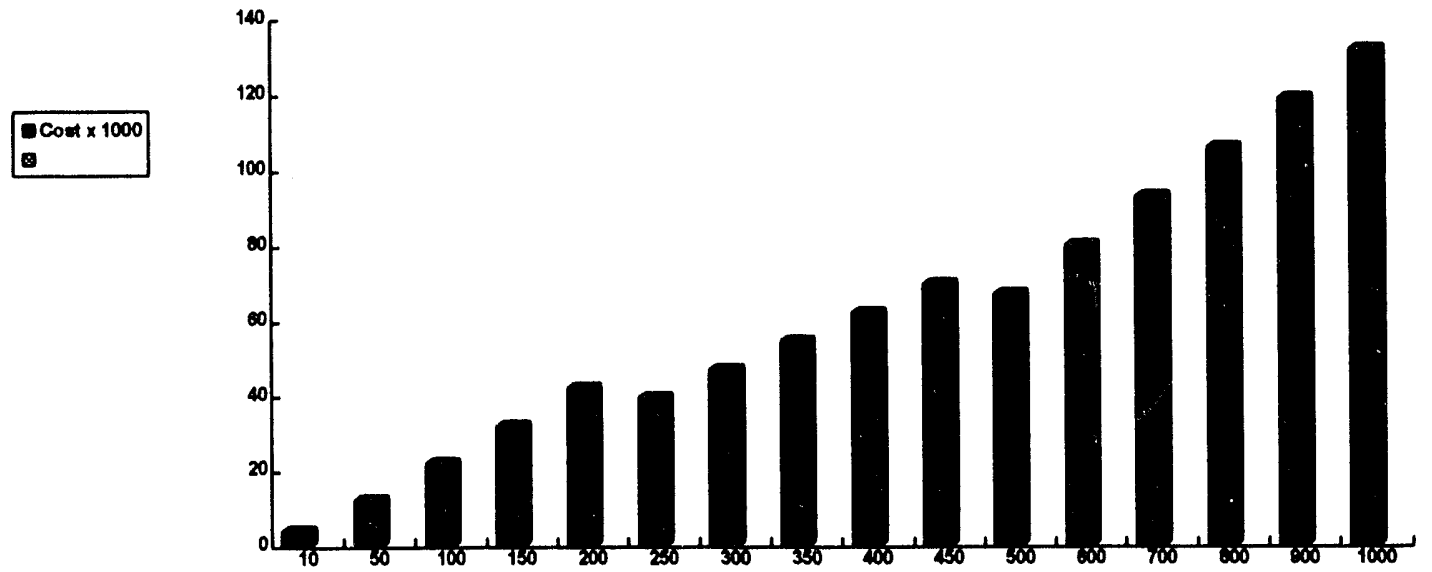

Figure 2. System Cost by Number of Sensors 


\subsection{Suppliers.}

- Sandia National Laboratories, Albuquerque, NM 87185-5800. Contact: Denise A. Anspach (505) 844-8088, or Ivan G. Waddoups (505) 844-1649.

- Inovonics Corp., 2100 Central Ave., Boulder, CO 80301 (303) 939-9336.

- Sentrol, Inc., 10831 S.W. Cascade Blvd., Portland, OR 97223 (503) 620-8540.

- Digiboard Inc., 6751 Oxford Street, St. Louis Park MN 55426 (612) 922-8055. 


\section{Tag System}

3.1 Description. The tag system (Figure 3) is not specifically an item monitoring technology. It can enhance the ability to monitor sensitive materials when used with PAMTRAK.

The tag system is an electrostatic proximity sensor system designed to track personnel or material in controlled-access facilities. The tag system consists of:

- An antenna that generates an electrostatic excitation field.

- A number of proximity tags that transmit a unique 27-bit code when in the presence of the excitation field.

- A second antenna that contains a receiver and signal-conditioning circuitry.

- An antenna interface unit that controls the generation of the electrostatic field, decodes analog signals from the receiver antenna, and outputs these signals to the controller through an RS-232 link.

- A controller that receives, processes, displays, and records all signals received from the receiver antennas.

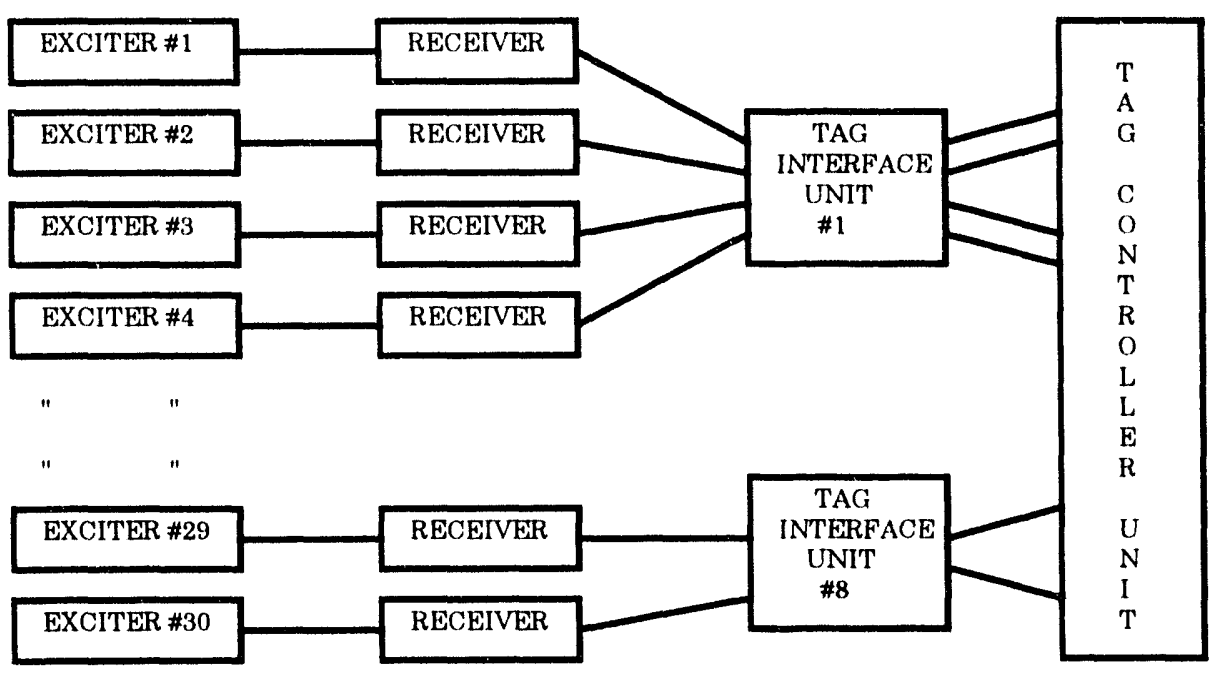

Figure 3. The Tag System 
The tags are compact, self-contained, and battery powered. They transmit their unique ID code only when in the presence of the excitation field from the tag exciter antenna. The receiver antenna is used in tandem with the exciter antenna and receives the signals transmitted by the tags and relays these signals to the antenna interface unit.

The Tag Interface Unit (TIU) supplies power for the exciter and receiver antennas. It also contains circuitry that interrogates a tag transmission for accuracy and authenticity. It then converts the signals to RS-232 and relays them to the controller. Each TIU controls up to four rereiver/exciter antenna pairs.

The Tag Controller Unit (TCU) is an IBM-compatible PC. Sandia designed and wrote the TCU software using $\mathrm{C}$ programining language. The TCU is designed to be used as a standalone system that gathers data and records events within a controlled area. This data is stored in files on the controller's hard disk and may be downloaded for review or for permanent records. Each TCU can handle from one to eight TIUs. Access to the TCU's control menus and base operating system is protected by built-in security.

3.2 Applications. The tag system is designed to monitor personnel with access to sensitive nuclear materials and is useful in nuclear materials storage vaults. The tag system can also monitor personnel in and around weapons production facilities where it is used as a safety device. A tag can be assigned to each individual whose location in a hazardous area can then be pinpointed.

3.3 Assets. The tag system has many advantages. This section outlines the system's assets and defines the advantages of using the tag system to monitor and record controlled-area access by facility personnel.

- The tag system can be used as a safety tool. In the event of an emergency, the number of personnel remaining in a facility can be determined by reviewing the records of those entering or leaving a tag-monitored facility.

- The tag system, when monitored by security personnel, is capable of providing real time, visual indication of tagged personnel entering or exiting a monitored facility as well as any monitored point within the facility.

- Each tag is factory sealed to prevent tampering.

3.4 Limitations. This section identifies the limitations of the tag system.

- The current version of the tags has no mechanism for preventing personnel from removing a tag once it has been assigned. Earlier versions had this capability and new versions of tags with this capability are being considered.

- This system is not designed to annunciate real time alarms when personnel enter a monitored facility except when used with PAMTRAK.

- Additional RF signals from the tags and the exciter antenna may impact existing safety and security devices. 
3.5 Projected Cost. Figure 4 shows the estimated system cost based on the number of monitor stations needed and a separate estimate on the cost of the tags.

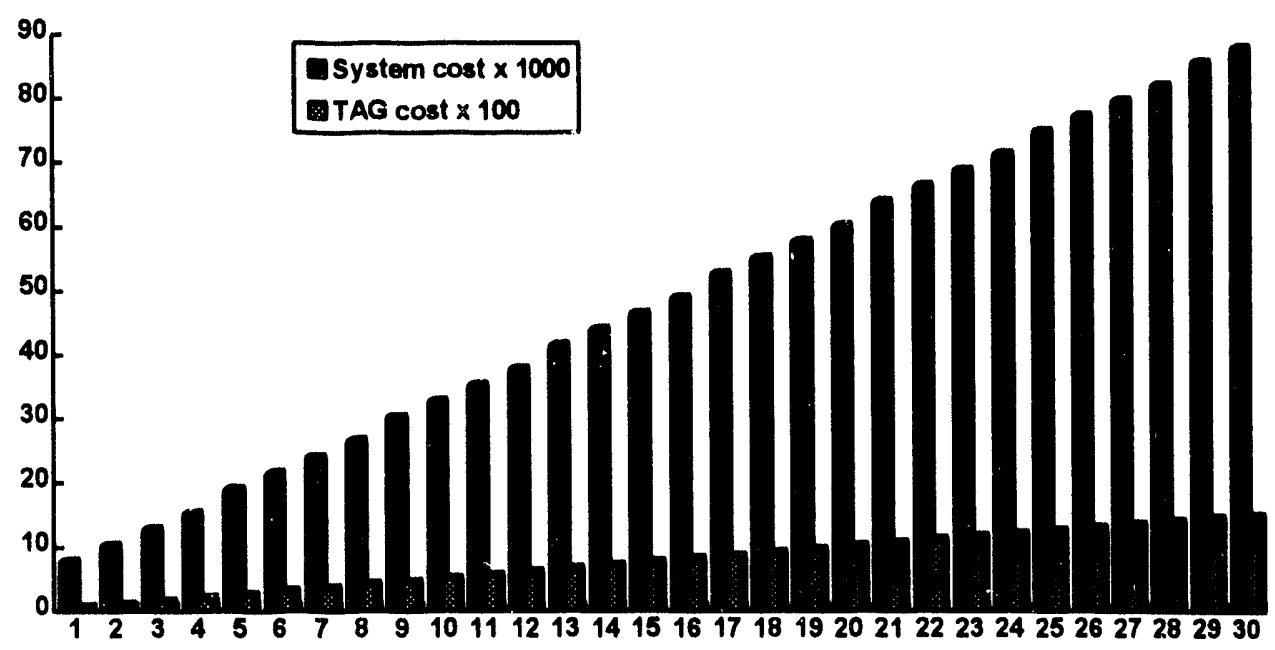

Figure 4. System Cost by Number of Monitoring Stations and Number of Tags

\subsection{Suppliers}

- Sandia National Laboratories, Albuquerque, NM 87185-5800. Contact: Denise A. Anspach (505) 844-8088 or Ivan G. Waddoups, (505) 844-1649.

- Indala Corp., 711B Charcot Ave., San Jose, CA 95131 (408) 434-7010.

- Digiboard Inc., 6751 Oxford Street, St. Louis Park, MN 55426 (612) 922-8055. 
This page intentionally left blank 


\section{PAMTRAK System}

4.1 Description. The Personnel and Material Tracking (PAMTRAK) System is designed as a fully automated means to monitor movement of both material and personnel. Its primary system consists of the host computer, a laser printer, an ink jet printer, a number of bar-code readers, and the system terminal. PAMTRAK as a whole consists of the primary system and three subsystems: material monitoring, personnel tracking, and entry control. A facility can configure PAMTRAK to use any combination or number of material monitoring, personnel tracking, or entry control subsystems with the primary system.

The PAMTRAK host computer is an IBM compatible PC. The laser printer's main function allows site personnel to produce bar-code labels. These labels are attached to all storage containers and are used as identification numbers. These labels also provide a reliable means of controlling the movement of material to and from the vault. The laser printer is used to print reports and any needed log data. The ink jet printer provides a real time log of userselectable events within the monitored area and alarm information.

The bar-code readers scan bar-codes attached to an item before it is stored or moved. Using the bar-code readers, site personnel monitor movement of materials from one area to another.

The system terminal provides access to the PAMTRAK interactive database and windows programs (see Figure 5). The terminal also displays user-selectable events (i.e., entries, exits, movement within the facility, and all alarms).

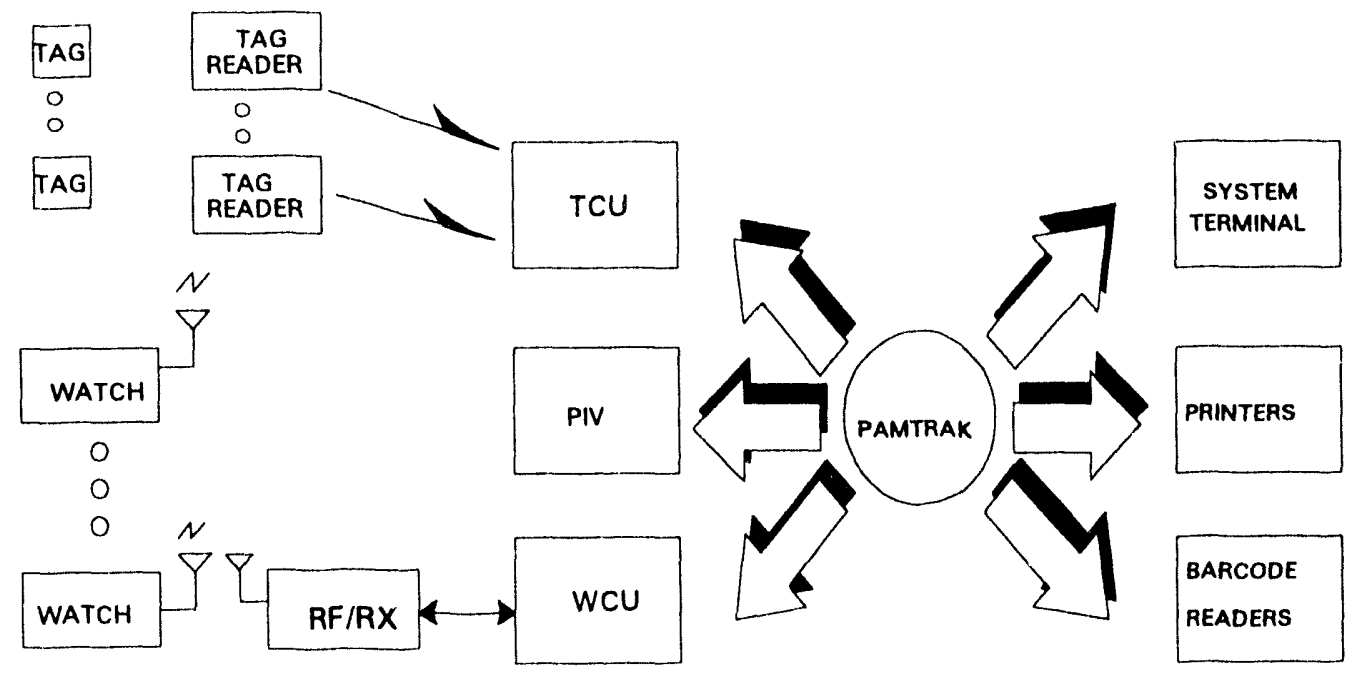

Figure 5. PAMTRAK and Its Subsystems 
The PAMTRAK system uses the WATCH system as its material monitoring subsystem and the tag system as its personnel monitoring subsystem. (See Sections 2 and 3 for further descriptions.)

The PAMTRAK entry control subsystem, Positive Identification Verification (PIV) allows entry into sensitive production or storage areas. When site personnel wish access to monitored areas, a system administrator grants approval. Once access is granted, a template is made of the individual's hand geometry, and a Personal Identification Number (PIN) is assigned and stored in the PAMTRAK database. An individual who wishes to enter a controlled area uses the PIV to scan his/her hand geometry and then inputs a PIN. The PIN is compared with the stored data, and, if correct, entry is granted.

4.2 Applications. The applications for PAMTRAK are unlimited. The PAMTRAK primary system is designed as an interactive, monitoring and tracking system. When interfaced with its subsystems, PAMTRAK provides a safety and security system unique in the DOE community. This system is ideal in nuclear material storage vaults. The system monitors stored nuclear materials for movement or tampering; it also monitors movement of weaponsrelated parts and materials in a production facility during nonoperational hours, or when access to these materials is prohibited. The system is also used to monitor personnel in and around weapons production facilities, and as a safety device. A tag can be assigned to each individual whose location in a hazardous area can then be pinpointed.

4. 3 k issets. There are many advantages to the PAMTRAK system. This section outlines the systems assets and the advantages of using the PAMTRAK system as an inventory tool or internal security device.

A) The PAMTRAK system is very versatile. Its primary computer contains a comprehensive set of rules that may be selectiv ely applied to meet specific site requirements. Examples of the rules that users can select are:

- The types of material allowed in each area

- The types of movement allowed for each material type

- The job designation assigned to each user

- The transactions each job designation is allowed to perform

- The users allowed to enter the facility

- How the facility is divided into areas

- The areas within the facility to which each user has access

- The transactions allowed in each area

- The areas in which at least two users must be present

- Those transactions that require two users to perform

- The amount of time allowed to complete certain transactions

- The events the PAMTRAK primary computer logs 
B) The PAMTRAK primary computer receives and processes information from its various subsystems about movement of users and material throughout the monitored facility. If any movement, access, or attempted transaction violates the facility rules established by site personnel, the PAMTRAK primary system annunciates an alarm. When annunciated, the alarm is displayed on the primary system terminal and logged. The primary computer also sounds a horn and (where appropriate) relays the alarm to a site security system.

C) PAMTRAK enables users to perform transactions using the system terminal or bar-code readers. These readers are placed at convenient locations throughout the monitored site. Some of the transactions that can be performed are:

- Add or delete material

- Ship or receive material

- Add or delete subsystem hardware such as PIVs, tags or WATCHs

- Assign to or remove WATCH from material

- Reset alarms

- Produce reports about the current state of the system

- Provide printout of system rules

- Archive the PAMTRAK primary computer database and log files

- Modify facility rules

- Delegate a job to another user

- Add or delete user accounts

4.4 Limitations. This section outlines the limitations of the PAMTRAK system. When used with its subsystems, PAMTRAK has demonstrated no individual limitations, except for its inherent complexity.

- The PAMTRAK primary system uses RS-232 communication lines to interface with the majority of its subsystems; it limits the distance between PAMTRAK and its subsystems to 100 feet. Conversion to $422 / 485$ is possible with a moderate hardware change; this conversion increases the range to as much as one mile.

- The system has the same limitations as described in the WATCH and Tag systems discussed above.

4.5 Projected Cost. The cost of the PAMTRAK system varies greatly, depending on the type and number of subsystems required. (See Section 2.5 for costs of the WATCH subsystem and Section 3.5 for costs of the tag subsystem.) Figure 6 shows the projected cost of the PAMTRAK system based on the number of bar-code readers and the number of entry control subsystems. 


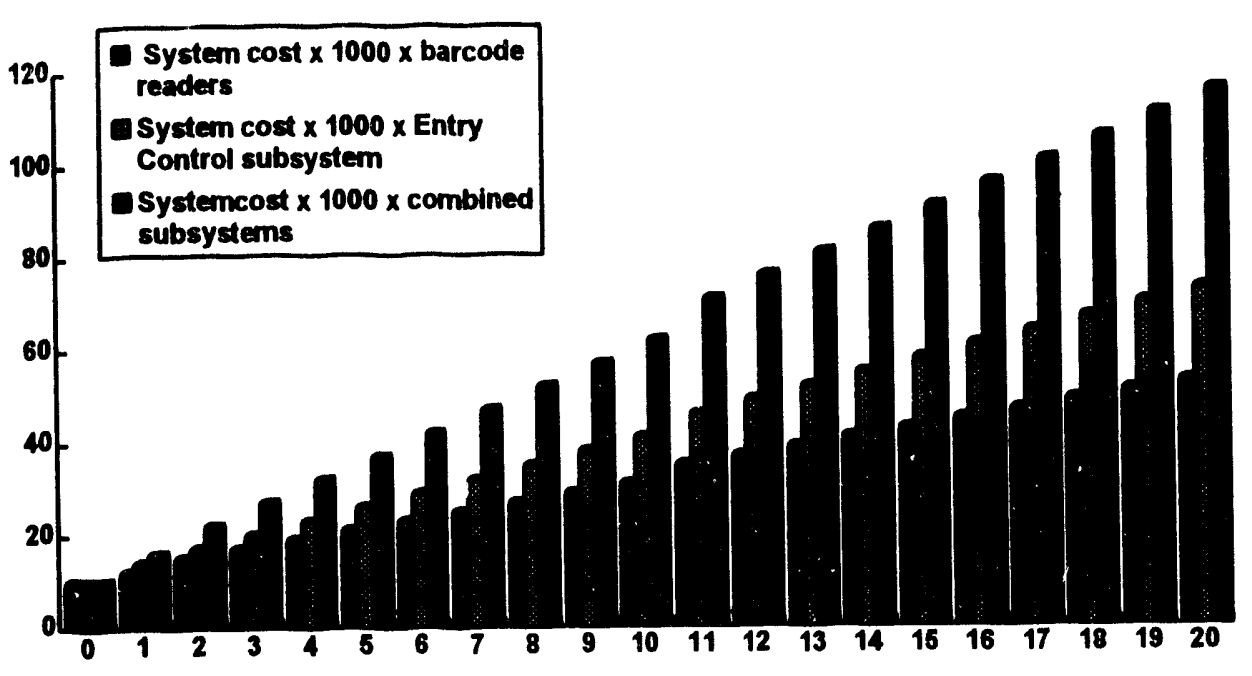

Figure 6. Project Costs of the PAMTRAK System

\subsection{Suppliers.}

- Sandia National Laboratories, Albuquerque, NM 87185-5800. Contact: Denise A. Anspach (505) 844-8088, or Ivan G. Waddoups, (505) 844-1649.

- Inovonics Corp. 2100 Central AVE., Boulder, CO 80301 (303) 939-9336.

- Sentrol Inc., 10831 S.W. Cascade Blvd., Portland, OR 97223 (503) 620-8540.

- Indald Corp., 711B Charcot Ave., San Jose, CA 95131 (408) 434-7010.

- Recognition Systems, Inc., 1589 Provincetown Drive, San Jose, CA 95129 (408) 257 2477.

- Mars Electronics Inc., Westchester, PA 19380 (800) 553-1121.

- Digiboard Inc., 6751 Oxford Street, St. Louis Park MN 55426 (612) 922-8055. 


\section{VRIS}

5.1 Description. The Vault Remote Inventory System (VRIS, see Figure 7) is designed to monitor weapons contained in the closed vaults of the Weapon Storage and Security System $\left(W^{3}{ }^{3}\right.$. The VRIS consists of four basic components: 1) The machine vision unit, 2) the radiation signature detector, 3 ) the vault computer, and 4) the base control computer.

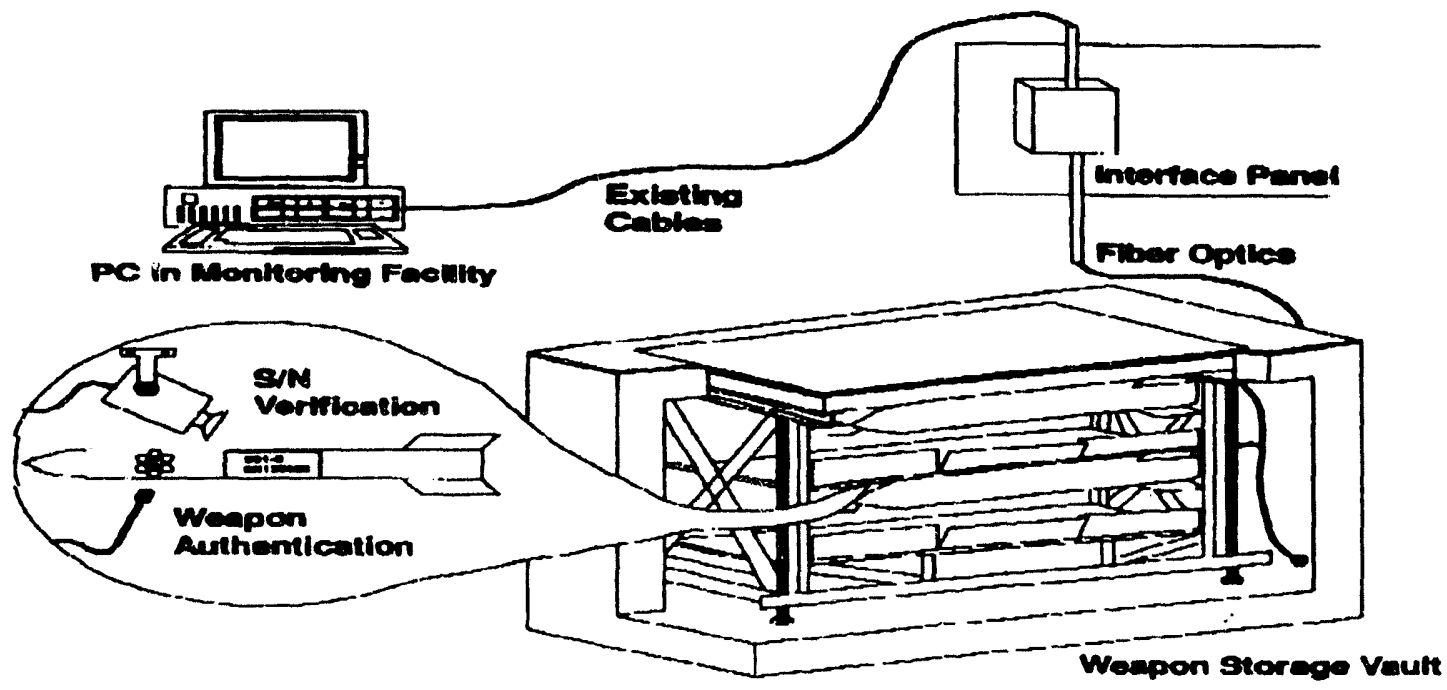

Figure 7. The $\mathrm{WS}^{3}$ Vault Remote Inventory System

The machine vision unit (see Figure 8) is used for weapon serial number verification and consists of a video camera specially modified with an LED ring light. This light provides the only light source in the weapons storage vault and enables the video camera to obtain a reliable image of the weapon serial number. The serial number image is then converted by image processing and optical character recognition) to ASCII text for the control computer database. 


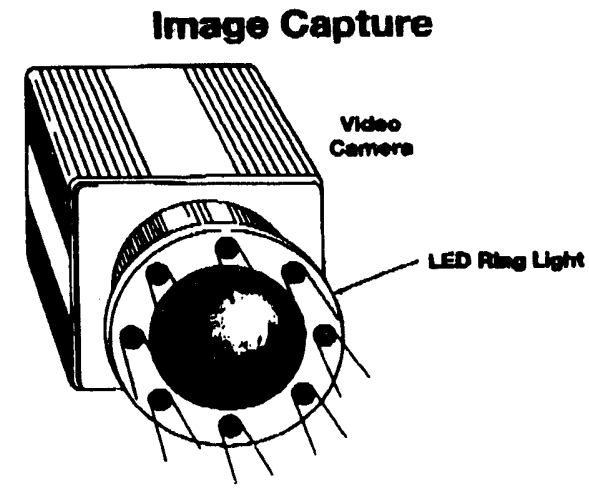

Figure 8. The Machine Vision Unit

The radiation signature detector is a gamma ray scintillation detector and is used to monitor and authenticate the radiation signature of weapons stored in the vault.

Authentication is done by measuring the radiation signature of the stored weapons and comparing it with the initial correct signature stored in the vault computer.

The vault computer also receives data from the video camera. Using image processing and recognition software, the computer verifies the serial numbers of the weapons. The inventories can be performed on command or at preprogrammed intervals. Data is also received from the gamma ray scintillation detector. This data is processed and verified, then signal correlation is done by degree of statistical equivalence to verify correct weapon inventory. The base control computer commands the inventories of all vaults on the base. The inventory data is stored on its database and the results are circulated in weapon status reports (WSRs) or on electronic media.

5.2 Applications. This system is specifically designed for use in the $\mathrm{WS}^{3}$. The current design can be adapted to other weapons storage facilities. Processed data from the control computer can be transported by electronic media and loaded directly into the NUCWA or SWIM databases.

5.3 Assets. There are many advantages to the VRIS system. This section covers the system's assets and defines the advantages of using the system as an inventory tool or as a security device.

- The system design is compatible with existing $\mathrm{WS}^{3}$ inventory systems.

- The required modifications to the $\mathrm{WS}^{3}$ vaults for installation of this system are minimal.

- The system design does not require physical contact with or modification to weapons stored in the vaults. 
- System cost is low.

- Our objective is to make the system compatible with future PAL (MET/SID) systems.

- The system is applicable to other similar weapons storage areas.

- The system enables fast, credible, and accurate weapons inventory.

- System cameras provide their own light source and can accurately verify weapon status without the need to open the vault, which could reduce manpower requirements and minimize vault openings.

- Maintenance should be minimal and could be performed during routine vault maintenance.

5.4 Limitations. This section outlines the limitations of the VRIS system.

- Camera alignment is critical for this system, and requires site personnel to receive training on alignment requirements.

- Cameras must be aligned by hand each time a weapon is replaced or moved.

- Serial number engravings on stored weapons must be backfilled with a dark paint or ink. This provides the camera enough contrast to accurately read serial numbers.

\subsection{Projected Cost. (See Figure 9)}

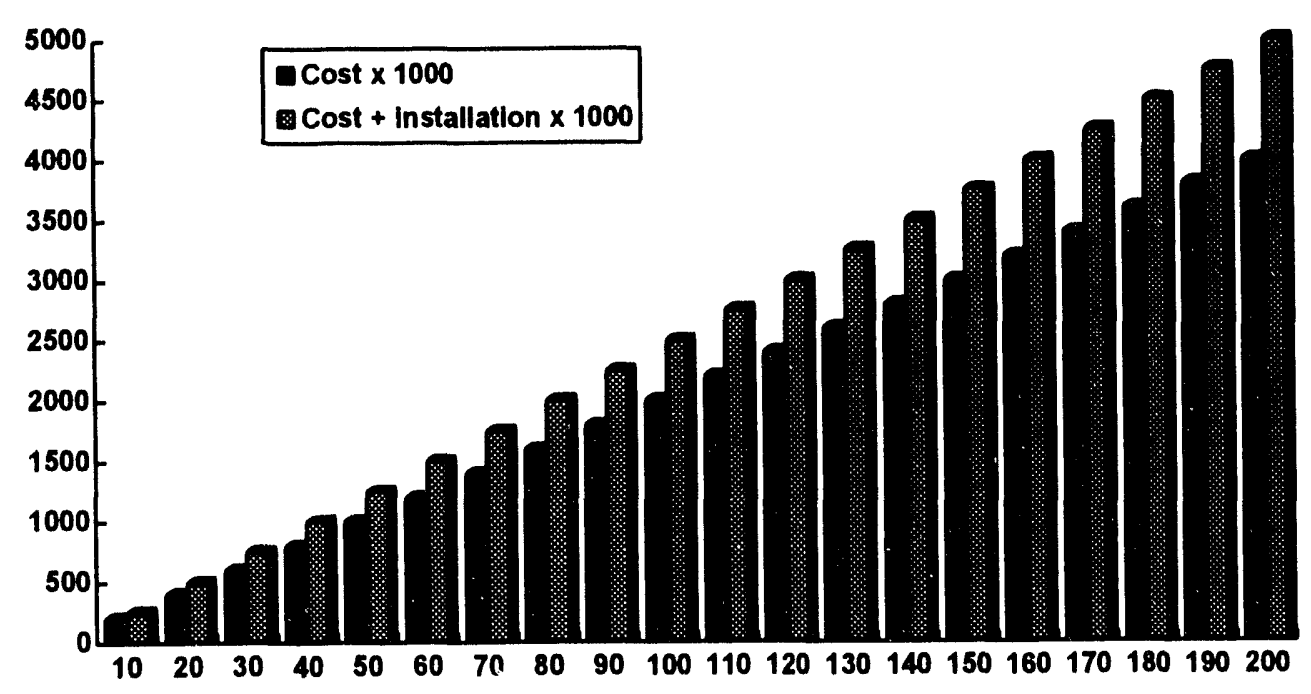

Figure 9. Cost and Installation

\subsection{Supplier.}

- Sandia National Laboratories, Albuquerque, NM 87185-5800. Contact: Carl Schuster (505) 844-8759. 
This page intentionally left blank 


\section{VSIS}

6.1 Description. The Vault Safety and Inventory System (VSIS) is designed to monitor nuclear material storage canisters in Hanford site vaults (see Figure 10). This Westinghouse system, designed by Sandia National Laboratories, consists of:

- Approximately 6,900 Canister Monitor Units (CMUs)

- A prime 2350 minicomputer

- Four Motorola MC6809 microprocessors

- A hardwired communication network to the CMUs

The CMUs provide the system with canister data and consist of a receptacle, a label reader, and four sensors. The CMUs gather five different types of data: label identification, canister bulge, canister temperature, presence, and ambient air temperature (see Figure 11).

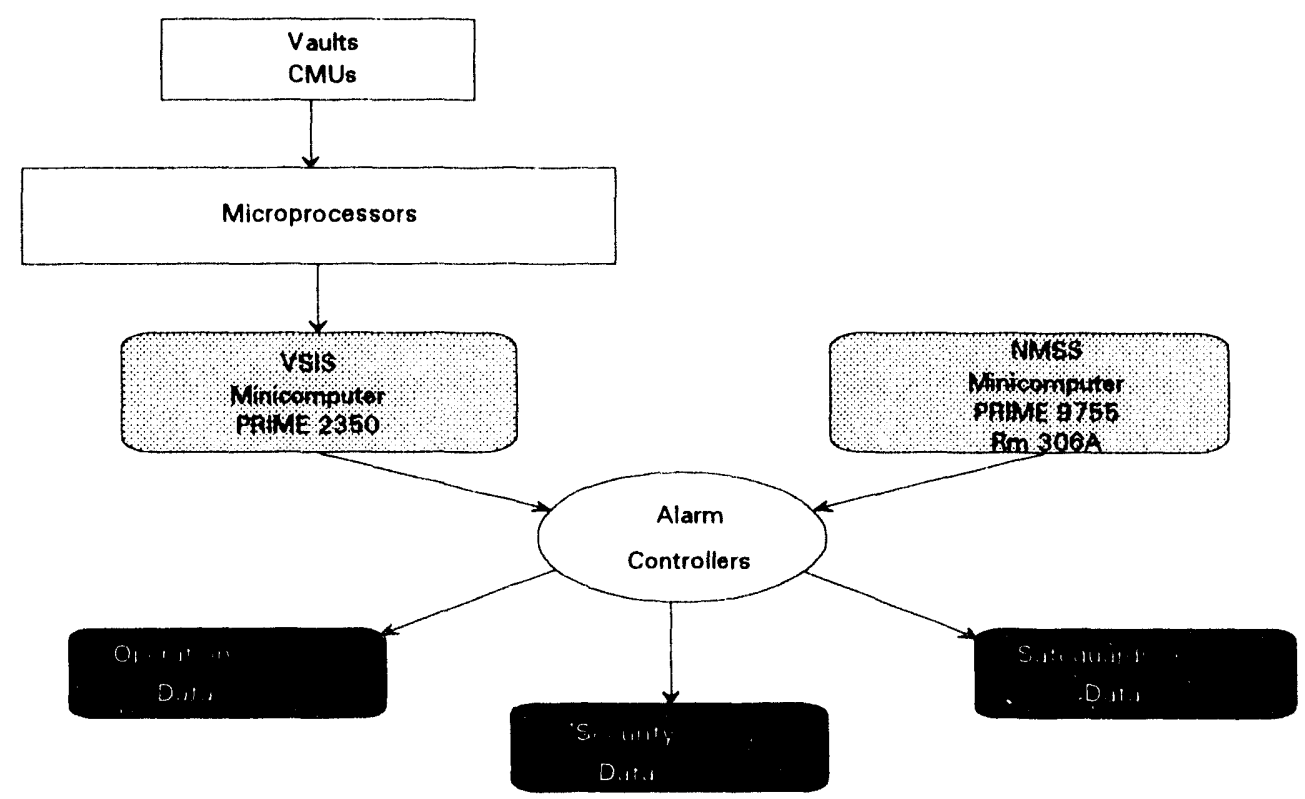

Figure 10. The Vault Safety and Inventory System 


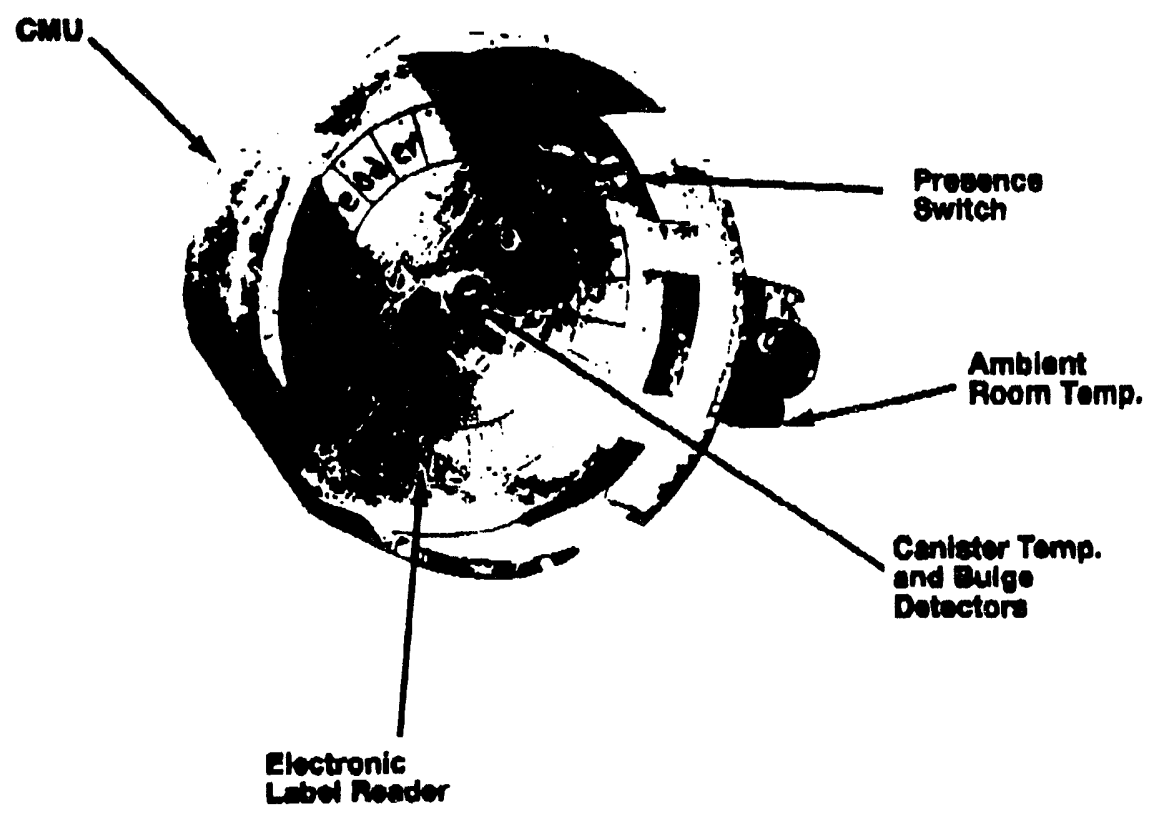

Figure 11. The CMUs Five Types of Data

Label identification data is gathered by the label reader located in the bottom of the CMU. A label that contains a unique electronic signature is fixed to the bottom of each canister. When the canister is in position on the CMU, the label is capacitively coupled to the label reader. The computer then reads the signature at preprogrammed intervals.

Canister bulge data is gathered using a pressure switch positioned in the center of the label reader. This switch detects canister deformation in the event of canister pressurization.

Canister temperature data is gathered using a thermistor also located in the center of the label reader. This thermistor maintains a constant temperature reading on the canister; the computer reads the temperature at preprogrammed intervals.

Canister presence is confirmed using a pressure switch located near the outer edge of the label reader. This switch makes contact with the canister label when the canister is in position; it then confirms that a canister is present.

Ambient temperature data is gathered using a thermistor located on the outside surface of the CMU. This thermistor maintains a constant temperature reading of the ambient air temperature. The computer also reads this temperature at preprogrammed intervals. This data is used to compare an authentic canister against the room temperature near the canister. Figures 12 and 13 show the installation configuration.

The control computer and operator interface for the VSIS system (see Figure 10) is a Prime 2350 minicomputer. This minicomputer is connected to the four MC6809 microprocessors via a fiber-optic multiplexer. The prime 2350 allows the operator to issue commands, print reports, and to receive CMU inventory data and alarm messages from the MC6809 
microprocessors. The VSIS system is also capable of transferring necessary data to the plant central accountability system (i.e., to the Nuclear Materials Safeguards and Security [NMSS] system). The VSIS and NMSS are on the same fiber-optic network and use a vendor-supplied communications protocol called Prime Net. This network creates a backup capability for both computer systems and allows VSIS data viewing by authorized users from any point in the overall network.

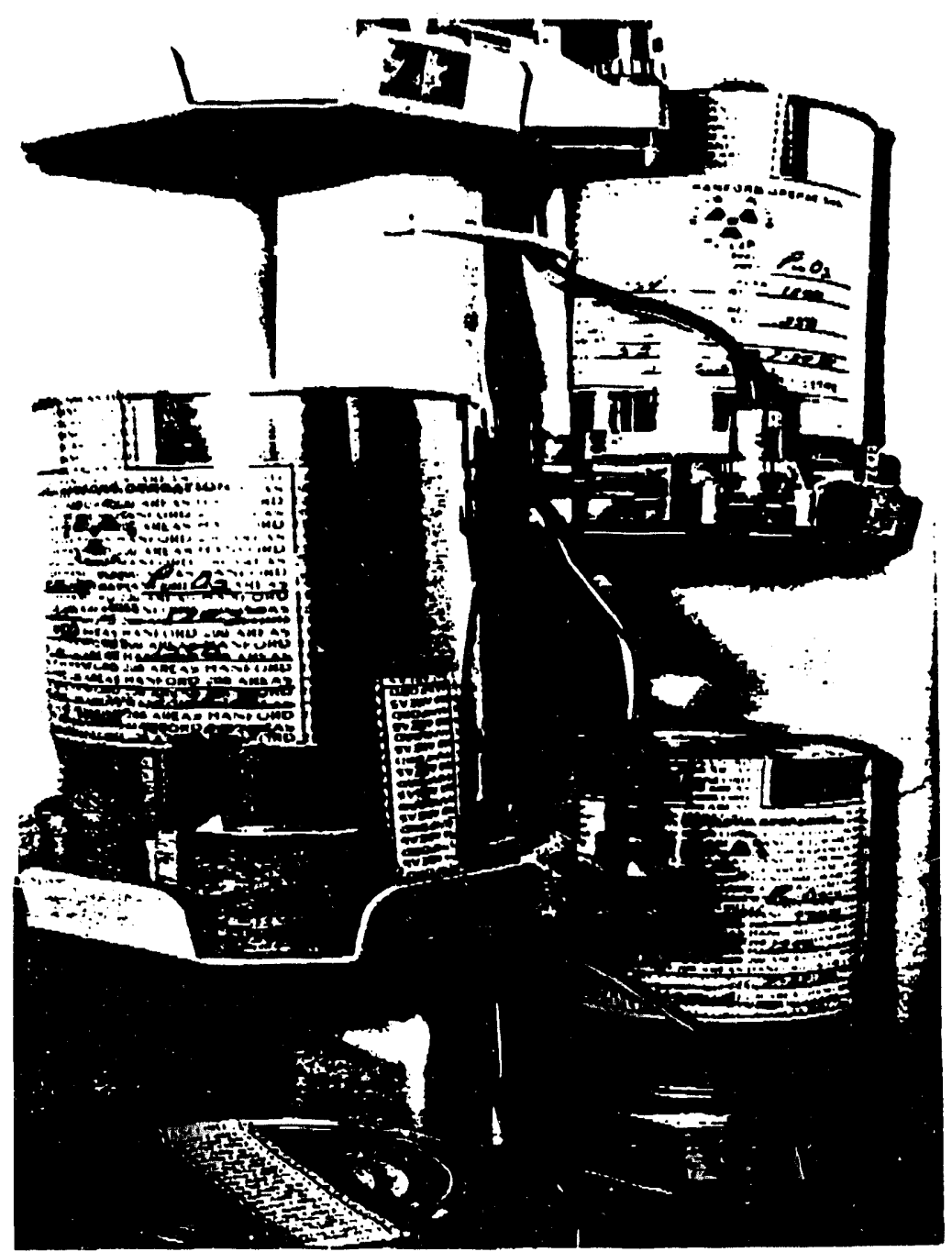

Figure 12. Partial Vault Segment with Stored Canisters

The interface between the computer and the CMUs is a Motorola MC6809 microprocessor programmed to control the CMU sensors according to commands issued by the computer. Since all sensor data is transmitted to the MC6809 microprocessors by wire, an integrated circuit multiplexer is installed in each CMU enabling the system to concentrate the data and to reduce the total number of wires required between the CMUs and the MC6809 microprocessors. 
6.2 Applications. The VSIS system currently monitors nuclear materials storage canisters and is ideal for use in nuclear materials storage vaults. This system greatly reduces the need for physical inventory by site personnel and can also be used as a safety device.

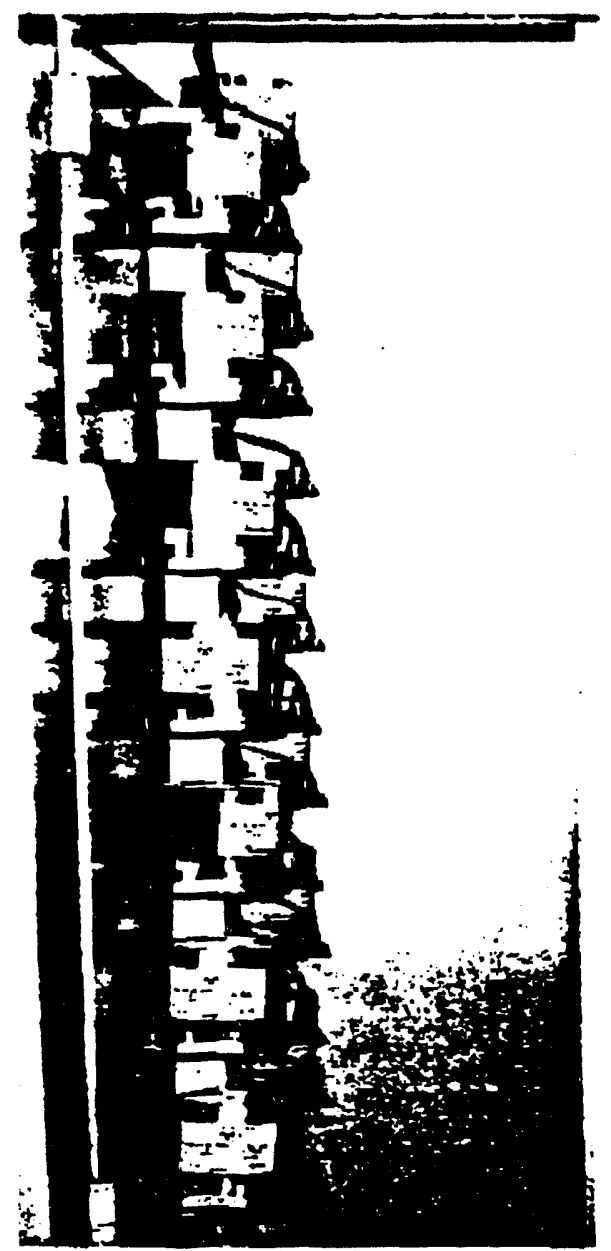

Figure 13. Vault Segment with Complete Set of Stored Canisters

6.3 Assets. There are many advantages to the VSIS system. This section describes the systems assets and defines the advantages of using it as an inventory tool or as an internal security and safety device.

- The VSIS system also can be used as an inventory tool and can greatly reduce the frequency of mandatory physical inventory.

- The VSIS system enhances canister safety and monitors canister temperature. Abnormally high temperature or bulge data may indicate safety concerns that must be reported to MC\&A and plant operations personnel.

- The VSIS system is designed to address the insider threat. Sensors contained in the CMU ensure the presence of the canister and monitor its temperature. Any attempt. to remove the canister itself or remove the contents generates an alarm. 
- The VSIS system uses a communications protocol and fiber-optic network that allows the system to be integrated with the existing plant central accountability system, i.e., with the NMSS.

- The VSIS system verifies correct inventory daily or on user demand. VSIS ensures correct inventory by comparing the results with official NMSS inventory records.

6.4 Limitations. This section outlines the limitations of the VSIS system.

- The VSIS system requires extensive installation and may be impractical in locations already containing nuclear material. The radiation exposure to site personnel during required installation may be prohibitive.

- A recent survey of the maintenance records indicates that approximately 12 $(.001747 \%)$ of the CMUs and $5(.000728 \%)$ of the identification labels will fail each year. While these numbers are low, it indicates that plant personnel may be required to enter each vault 5.66 times per year.

- The VSIS system uses ambient room temperature as the basis for comparing and monitoring canister temperature attributes. Fluctuation in the control of vault temperatures causes faults in the computer logic. If the vault temperature changes too fast, the VSIS system assumes the canisters are being tampered with and issues multiple alarms.

6.5 Projected Cost. (See Figure 14)

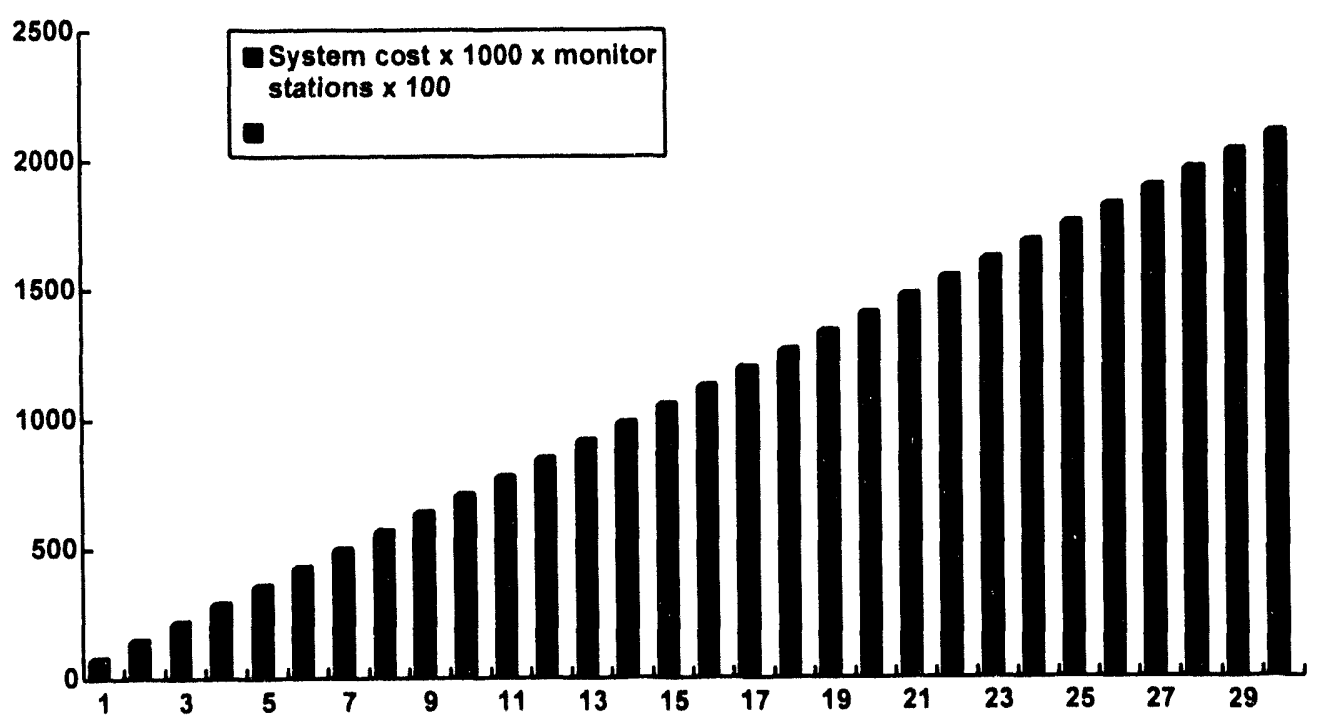

Figure 14. Number of Monitor Stations x 100

\subsection{Suppliers}

- Sandia National Laboratories, Albuquerque, NM 87185-5800. Contact: H. Duane Arlowe (505) 844-3416 or Larry E. Predika (505) 844-5032. 


\section{AIMS}

7.1 Description. The Authenticated Item Monitoring System (AIMS) (see Figure 15) monitors the movement of a number of specified items over a period of time. These items include storage canisters, doors, and overhead cranes. The system consists of a number of ASTX packs or sensor units and a receiver/processor unit (RPU). The unit is composed of an RF receiving module, an IBM compatible $\mathrm{PC}$ for data processing, and a small embedded printer.

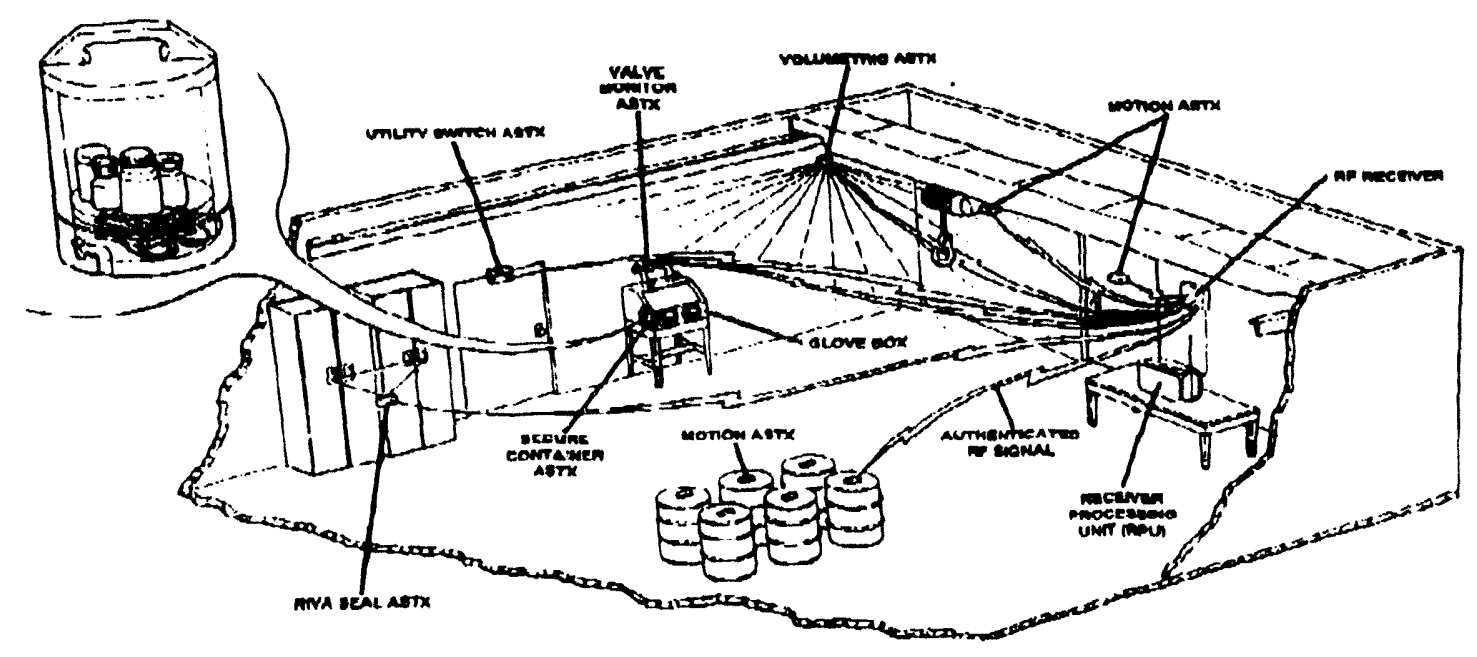

Figure 15. A Typical AIMS Installation

Each ASTX pack is small, reusable, and battery powered. The packs are designed to be placed on an item that has been selected for monitoring. The AS'TX pack detects and reports a variety of event occurrences to the secured and tamper-protected receiver module. The module is capable of storing up to 50,000 events between data collection periods. The ASTX packs contain sensors capable of reporting two different types of physical events. Movement of the ASTX unit triggers a motion sensor embedded in the unit and produces the first type of incident referred to as a "Motion Event." The second type of event, an "Entry Indicating Event," is reported if any tamper attempt is made. These ASTX packs utilize the same circuitry as the WATCH units discussed above.

Each ASTX pack reports an "Authenticated" event and periodic SOH messages back to the receiver via $900 \mathrm{MHz} R \mathrm{~F}$. The receiver receives and stores both authenticated events and SOH messages from each ASTX pack in its group. A receiver group is defined as the receiver plus all programmed and currently operational ASTX packs assigned to it. The receiver has the necessary database information which includes the identification numbers of each ASTX in its group, and how often each should report SOH messages. If $\mathrm{SOH}$ messages are not received from an active ASTX pack, a missing SOH event is recorded with the time and date of the last transmission received, and the time and date of when (if) it begins to transmit again. 
The AIMS receiver module is used in two different configurations:

Configuration 1 is used in systems where a small number of ASTX units will be needed and an unsorted printout of the event history is sufficient. A small embedded printer within the receiver will be used for recording the event history. In this configuration a $\mathrm{PC}$ is not used.

Configuration 2 is used in systems where large numbers of ASTX units are needed and an unsorted printout would be very lengthy and difficult to interpret. In this configuration, a $\mathrm{PC}$ can be connected to the receiver. 'The PC-designed software gives the user the ability to process, sort, and view the event history in several different formats. The use of a PC also allows event histories to be stored on floppy disks for further analysis and archival purposes.

7.2 Applications. The AIMS system is used in monitoring sensitive nuclear materials and would be ideal for use in nuclear materials storage vaults. It greatly reduces the need for physical inventory by site personnel. This system can also monitor movement of weaponsrelated parts and materials in a production facility during non-operational hours, or when access to these materials is prohibited. AIMS also monitors entries into a controlled area. Though it cannot tell who entered, it will indicate that someone entered and when.

7.3 Assets. There are many advantages to the AIMS system. This section describes the system's assets and defines the advantages of using the AIMS system as an inventory tool or as an internal security device.

- The AIMS system operates on radio frequencies and is, therefore, wireless; this substantially reduces the cost of the system and its installation. Each system uses one receiver module designed to be placed in the monitored facility.

- No modifications to existing facilities are required for installation of this system.

- This is a low-cost system when compared with other security systems.

- The AIMS system can be used as an inventory tool and can greatly reduce the frequency of mandatory physical inventory.

- Each AIMS ASTX pack is supervised, and loss of signal for any reason is recorded as an event.

- Low installation requirements may allow the AIMS system to be used in storage facilities where nuclear materials are already present.

- The AIMS ASTX packs use authenticated RF messages; this increases system security.

7.4 Limitations. This section outlines the limitations of the AIMS system.

- When used in Configuration 1, the AIMS system is a data-gathering tool to monitor access to controlled materials; it does not generate real time alarms when monitored material is accessed. See Section 7.1.

- This system does not provide audible alarms and has no alarm relay capabilities.

- Additional RF signals from the AIMS ASTX packs may influence existing safety and security devices. 
- Nine hundred MHz RF signals from the AIMS ASTX packs have a range of 600 feet and readily penetrate standard concrete structures. Interception of RF signals is possible if the monitored facility is located near a site perimeter.

- The AIMS ASTX packs are sensitive to external vibration and may generate false alarms when installed in facilities where robotic stackers are used.

- Although much has been done to minimize RF collision rates, the problem still exists. The AIMS ASTX packs use authenticated messages that increase the length of each message and may increase the collision probability.

- Many sites restrict or prohibit RF transmissions due to safety concerns when explosives are stored or processed on site; thus, the AIMS system may not be appropriate at these sites.

7.5 Projected Cost. The cost figures indicated below are for RPUs with no tamper protection. RPU tamper protection will increase the cost of the system by $6 \mathrm{~K}$ per $1000 \mathrm{ASTX}$ packs (see Figure 16).
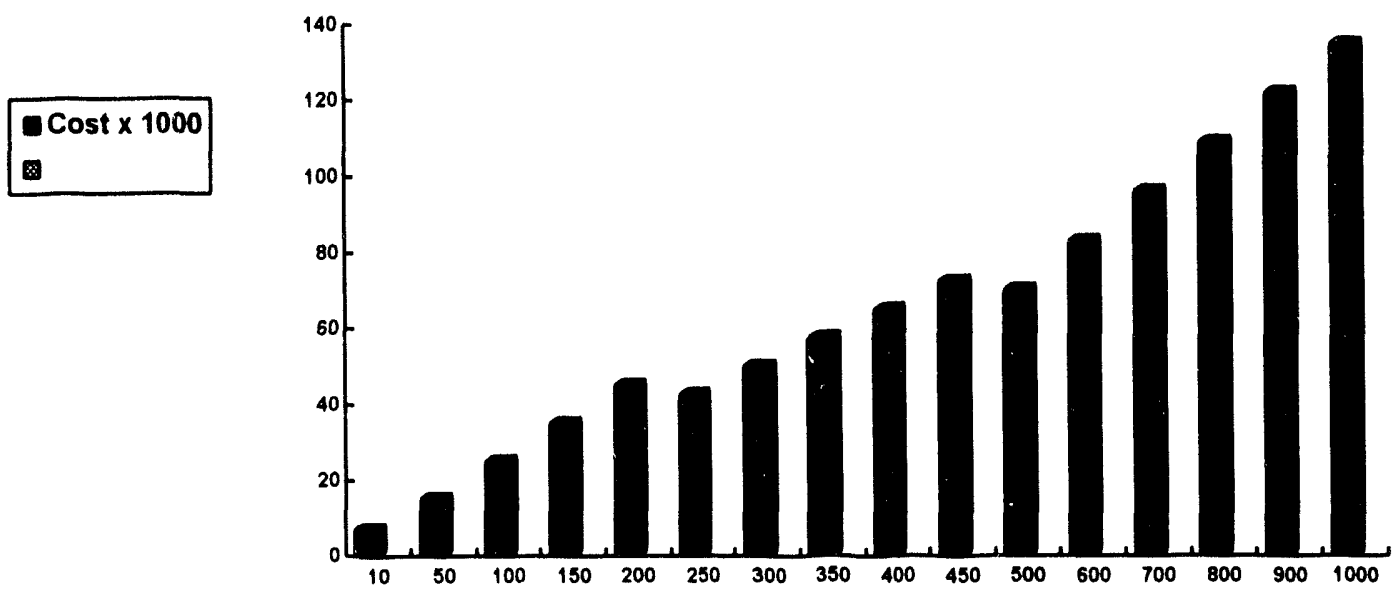

Figure 16. Cost by Number of ASTX Packs

\subsection{Suppliers}

- Sentrol, Inc., 10831 S.W. Cascade Blvd., Portland, OR 97223 (503) 620-8540.

- Sandia National Laboratories, Albuquerque, NM 87185-5800. Contact: J. L. Schoeneman (505) 844-2049.

- Inovonics Corp., 2100 Central Ave., Boulder, Colorado 80301 (303) 939-9336. 
This page intentionally left blank 


\section{EIVS}

8.1 Description. The Experimental Inventory Verification System (EIVS) is an image-based material control system designed to provide timely information about the state of nuclear materials in storage or in process. Using cameras, the EIVS acquires basis imagery describing the area of surveillance. These data are digitized and stored by the host computer; subsequent image data are acquired, compared, and analyzed using image processing and analysis methods designed to detect changes or other events that occur in the monitored area. Detected events are analyzed to determine their safeguards significance; stored for review and archive; and if necessary, trigger audible and visual alarm mechanisms informing site personnel that an event has occurred. The events are also stored for accountability records or for future analysis.

The EIVS is currently in alpha-test at two DOE sites. System hardware includes a Sun Microsystems SPARC 10 host computer configured with up to 512 MB RAM, 1 gigabyte system disk, 2 gigabyte data capacity, and an automatic tape archival system. Image acquisition hardware captures inputs from up to 18 detection cameras and 9 video cameras. The host computer is equipped with a $\mathrm{C}-2$ security level operating system, includes mandatory or discretionary access controls for all system functions, and is housed in tamper-resistant cabinetry.

EIVS software includes an $\mathrm{x}$-window-based user interface with point and click selection of all system functions. Features include camera configuration, live video monitoring, user/system logging and reporting, disk control, system administration, alarm management, and interactive data review/imageprocessing tools.

8.2 Applications. The EIVS monitors sensitive nuclear materials and is ideal for nuclear materials storage vaults. This minimizes the need for physical inventory by site personnel. This system could also monitor weapons-related parts and materials in a production facility during non-operational hours or when access to these materials is prohibited.

8.3 Assets. There are many advantages to the EIVS. This section describes these assets and defines the advantages of using the EIVS as an inventory tool or as an internal security device.

- The EIVS can be used as ar inventory tool; it can reduce the amount of radiation site personnel are exposed to by providing verification data that would extend the physical inventory period.

- The EIVS provides increased protection against insider threats. Traditional nuclear material monitoring systems rely on the absence of signal. These detection systems use bi-level switch alarms only when the switch mechanisms are decoupled. If these and other similar mechanisms are deactivated, the same absence of signal is seen as active, meaning there is no indication of intrusion. Image-based and video-based systems with internal signal verification produce a continuously positive sigial. EIVS provides an enhancement that many systems cannot.

- The ElVS provides defense in depth. When a monitored area is breached, most traditional insider protection systems do not have the ability to identify the person or persons responsible. Image-based and video-based systems provide this information.

- EIVS provides visual and audio alarms. 
- Video signals are supervised; loss or degradation of signal produces an alarm.

- EIVS provides C-2 level computer security features and a tamper-resistant housing is available.

8.4 Limitations. This section discusses the limitations of the EIVS.

- With current image processing software, the EIVS is sensitive to ambient light changes; a sudden change in ambient light can trigger an alarm.

8.5 Projected Cost. (See Figure 17)

Cost per monitoring station $\times 1000$

D.

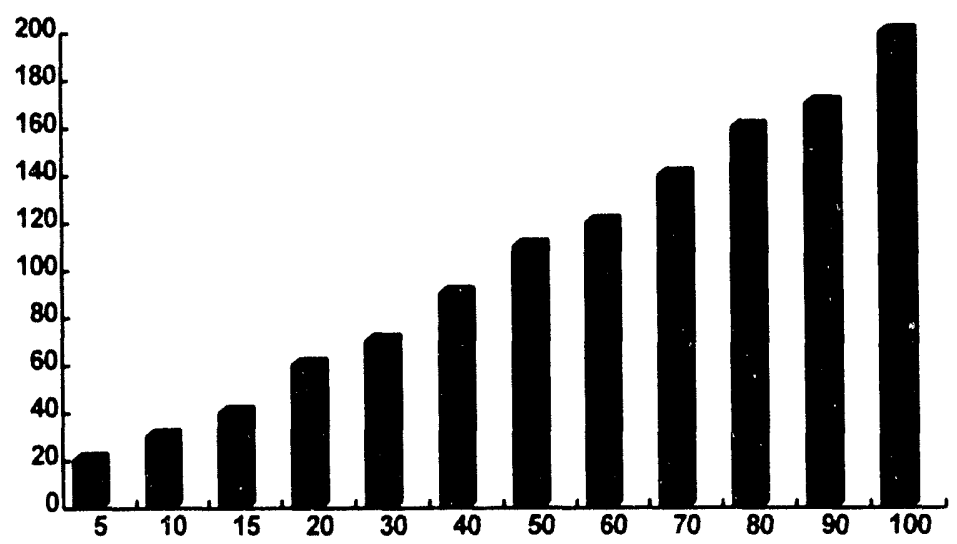

Figure 17. Number of Monitoring Stations

8.6 Supplier.

- Los Alamos National Laboratory, Los Alamos, NM 87545. Contact Cheryl Rodriguez. 


\section{METROX SYSTEM}

9.1 Description. The Metrox Canister Monitoring (METROX, see Figure 18) system provides attribute and location data to monitor the current status of the canister inventory in a canister storage facility. METROX consists of three basic components: the canister sensor unit, the canister sensor interface and control unit, and a host computer.

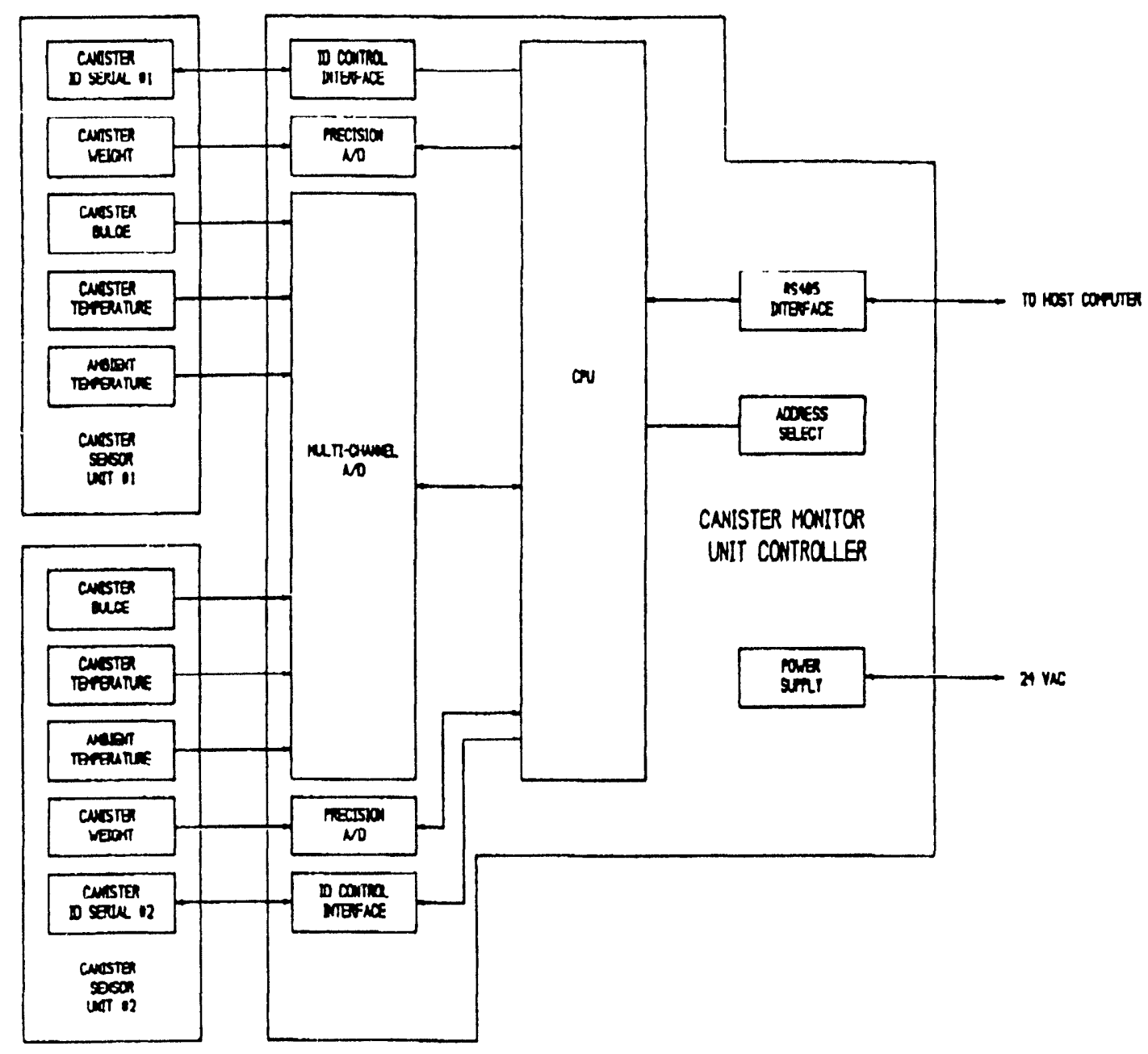

Figure 18. The METROX Canister Monitoring System 
The canister sensor unit (Figure 19) contains sensors to monitor the status of an individual canister. Weight, ambient and canister temperatures, canister bulge, and canister ID are monitored. Individual canisters are prepared by facility personnel by installing a one-touch identification device to the bottom center of each canister.

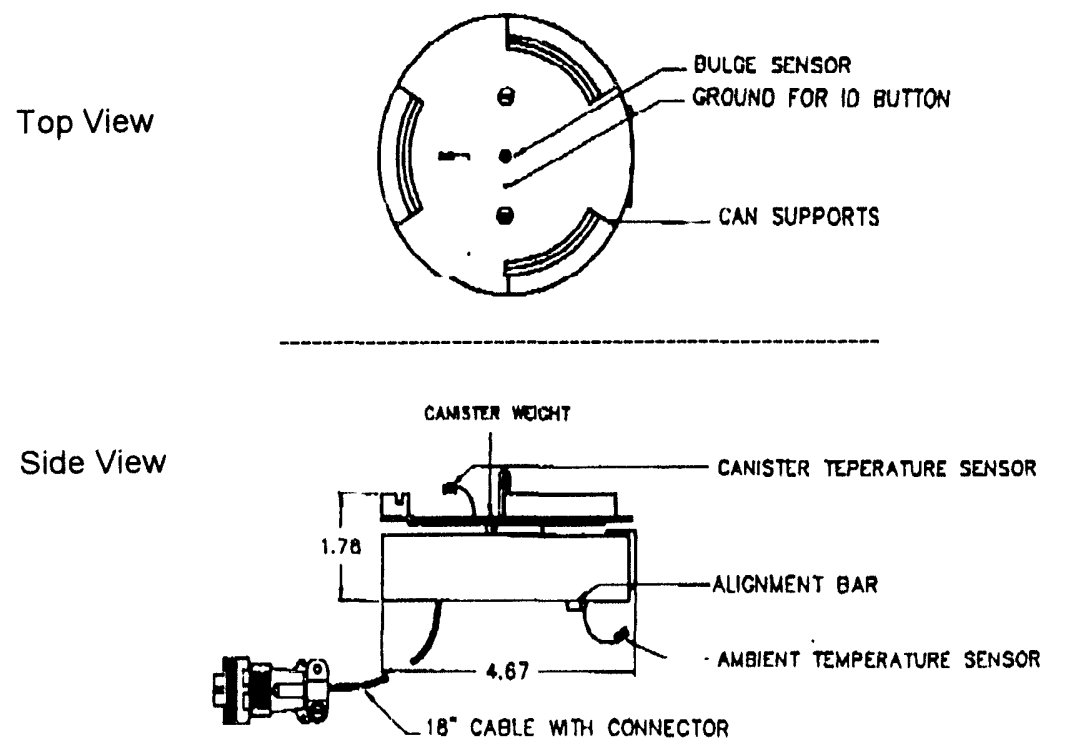

Figure 19. Canister Sensor Unit.

The canister sensor interface and control unit monitors the individual sensors located in the canister sensor unit. ID serial information is transferred from the one-touch to the interface control unit and is processed using a one-wire to three-wire converter. The serial information is then relayed to the main PC controller. Weight data for each canister is monitored by a load sensor and transferred to the interface control unit where it is processed by a 16 -bit analog-to-digital converter. The data is then relayed to the main $\mathrm{PC}$ controller. Canister bulge, ambient temperature, and canister temperature are monitored by separate sensors, and the data is transferred to the interface control unit and processed by a multiple channel analog-to-digital converter. This data is then relayed to the main $\mathrm{PC}$ controller. The host computer receives and processes all data from the canister monitor units, displays this data as requested by the operator, and provides real time visual alarm indications.

9.2 Applications. The METROX system is designed for use in monitoring nuclear materials storage canisters and is ideal for use in vaults where this type of nuclear material is stored. This system greatly reduces the need for physical inventory by site personnel and can be used as a safety device. 
9.3 Assets. There are many advantages to the METROX system. This section describes the system's assets and defines the advantages of using the METROX system as an inventory tool or as an internal security and safety device.

- The METROX system can be used as an inventory tool and would greatly reduce the frequency of mandatory physical inventory.

- The METROX system enhances c anister safety and monitors canister temperature and bulge. Abnormally high temperature or bulge data may indicate safety concerns and are reported to MC\&A and plant operations personnel.

- The METROX system addresses insider threats. Sensors contained in the CSU ensure the presence of the canister, monitor canister weight, and monitor canister temperature. Any attempt to remove the canister itself or remove the contents from the canister generates an alarm.

9.4 Limitations. The METROX system requires extensive installation and may not be practical in locations already containing nuclear material. The radiation exposure to site personnel during required installation may be prohibitive.

- The METROX system uses ambient room temperature as the basis for comparing and monitoring canister temperature attributes. Fluctuation in the control of vault temperatures causes faults in the computer logic. If the vault temperature changes too fast, the METROX system assumes that the canisters are being tampered with and issues multiple alarms.

9.5 Projected Cost. (See Figure 20)

Cost per station $\times 100$

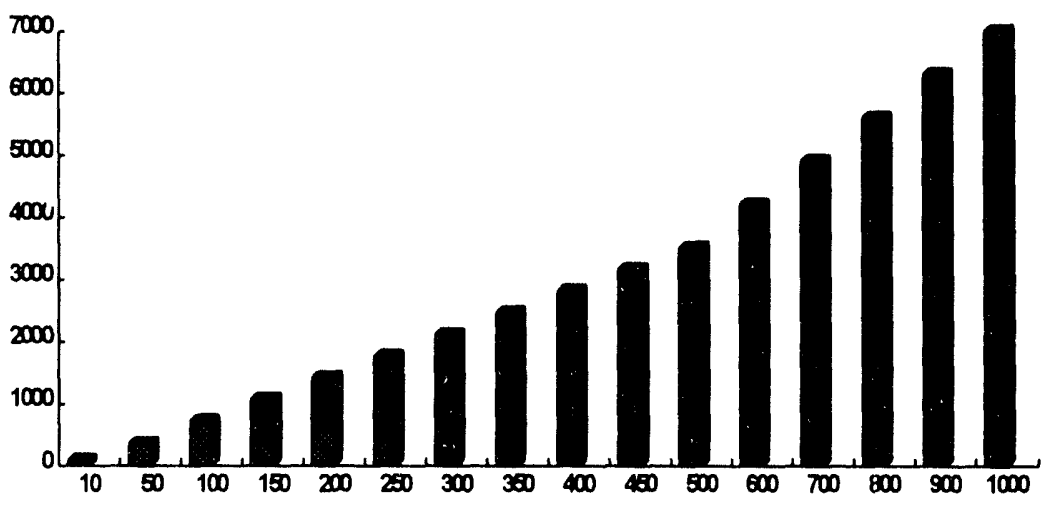

Figure 20. Number of Monitoring Stations

9.6 Suppliers.

- METROX Inc., 7165 Construction Court, San Diego, CA 92121 (619) 271-1731.

- Sandia National Laboratories, Albuquerque, NM. 87185. Contact Ivan G. Waddoups, (505) 844-1649. 
$\infty_{\infty}^{\infty}$

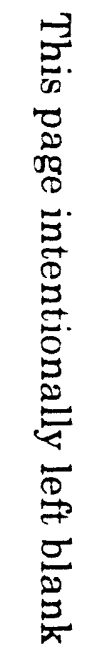
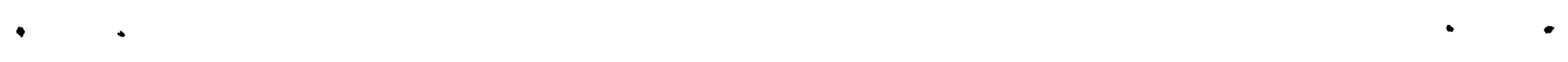


\section{TCATS}

10.1 Description. The Target Cueing and Tracking System (TCATS) is designed as a multipurpose, video image, item monitoring or personnel tracking system. The system can be configured for item monitoring and will generate an alarm when any movement within its field of view occurs. The system can also be configured for personnel tracking and can record the movement of personnel when they are in the field of view.

TCATS uses digital image processing software and hardware to detect and track moving targets in images from standard RS 170 video sources. TCATS uses special image processing algorithms that are most sensitive to a target that displays purposeful motion and that is less sensitive to global image changes or random motion. TCATS uses a multitarget tracking algorithm capable of tracking many objects in any X-Y direction while retaining an identity for each object. The TCATS hardware is optimized for these image processing algorithms.

TCATS consists of:

- a VME dual-height chassis and power supply

- a 68020/688881 CPU and memory board set

- seven Max video image processing boards from Data Cube, Inc.

- either a disk drive or static RAM disk for file storage

- a number of cameras, a monitor, and an input terminal

The Max video boards include a:

- Digimax. The Digimax module is an RS-170 compatible video acquisition and display module that digitizes the signal into $512 \times 512 \times 8$ bit image frames.

- Three Framestores. The framestore module is a digital image storage board.

- A MaxSigma. The MaxSigma module is a large kernel, real time convolution board.

- Two MaxSPs. The MaxSP module is a general purpose signal processing board.

'The output of the TCATS development system is the annotated video image showing the location on the image where the alarm occurred. It is also possible to send alarm signals from the development system to other security equipment. In the present configuration, a prototype alarm box was used to provide relay signals to the other equipment.

10.2 Applications. When the TCATS system is configured for item monitoring, it is used in monitoring sensitive nuclear materials and is ideal for nuclear materials storage vaults. 'This system could also monitor weapons-related parts and materials in a production facility during non-operational hours or when access to these materials is prohibited.

Other potential applications include, but are not limited to: vehicle portal screening, roadway traffic monitoring, industrial process monitoring, and monitoring any avenue of approach. As an intrusion detection system, TCATS is difficult for an intruder to defeat even if the intruder is aware of its existence.

10.3 Assets. There are many advantages to the TCATS system. This section describes the system's assets and defines the advantages of using the TCA'TS system as an inventory tool or internal security device. 
- The TCATS system can be used as an inventory tool and can reduce radiation exposure to site personnel by providing verification data to extend the physical inventory period.

- The TCATS system provides increased protection against insider threats. Traditional nuclear material monitoring systems rely on the absence of signal. These types of detection systems use bi-level switches and alarm only when the switch mechanisms are decoupled. If these and other similar mechanisms are deactivated, the same absence of signal is seen as though it were active; no intrusion is indicated. Image-based and video-based systems with internal signal verification continuously produce a positive signal. TCA'TS provides an enhancement that many systems cannot.

- The TCATS system provides defense in depth. When a monitored area is breached, most traditional insider protection systems do not have the ability to identify the person or persons responsible for the breach. Image-based and video-based systems provide that information.

10.4 Limitations. This section outlines some limitations of the 'TCA'TS system.

- The TCATS system requires extensive installation and may be impractical in locations that already contain nuclear material. The radiation exposure to site personnel during required installation may be prohibitive.

- The user interface is complex and will require extensive training of personnel.

- During testing of the development system, hardware problems required a high level of maintenance. Although improvements are being made and testing has been limited, the complexity of the system indicates that maintenance requirements will be high.

- Development system test results also indicate that false alarm rates are high.

\subsection{Projected Cost.}

Sandia National Laboratories has never calculated the cost of a production 'TCAT'S unit. Some unresolved reliability issues need to be addressed. For a detailed description of these issues. see "SAND92-0396 Overview of the Target (Cueing and Tracking System (ICATS) Appendix B." In order to resolve these issues and produce a small lot of TCATS units would require the following estimated costs:

- Layout/fabrication costs for new circuit boards

- Labor for resolving problem, assembly, and testi

- Enclosure and parts kit (per unit)

$\$ 20,000$

- Total cost for upgraded 'TCATS unit

$\$ 218,000$

- Cost for each additional upgraded unit

$\$ 20,000$

It has been estimated that the initial production unit version of TCATS would cost less than $\$ 10,000$. This estimate is based on proposals submitted to Sandia from private industry during the technology transfer process.

\subsection{Supplier.}

- Sandia National Laboratories, Albuquerque, NM 87185. Contact: Everett E. Schnetzer, (505) 844-8379. 


\section{LGVSS}

11. 1 Description. 'The Light. Grid Vault Surveillance System (LGVSS) is a system designed to monitor nuclear material storage canisters. The concept of using the LGVSS was proposed by Savannah River for use in an oxide storage vault to be constructed at the Savannah River facility. Research and development was completed and a mock storage vault constructed by ORNL under funding from Bechtel. The LGVSS was installed and the mock vault was tested.

The original Savannah River concept was a vault with a below-floor level grid of vertical cylindrical storage locations with a capacity of two nuclear materials storage canisters per location. The floor of the vault would consist of a grid of metal tiles. The canister baskets would be suspended from the bottom of each metal tile (see Figure 21). A magnetic grapple would be used to lift the metal tiles for access to the stored eanisters.

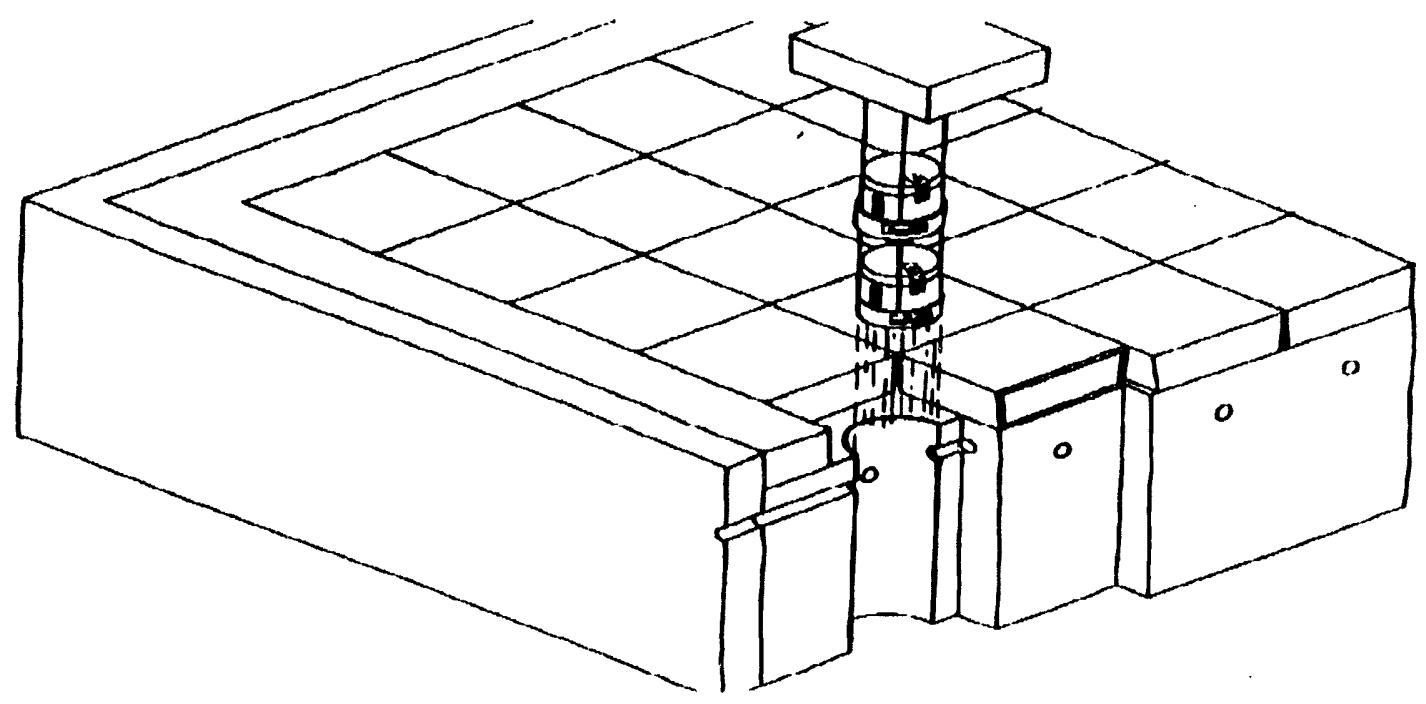

Figure 21. 'Tile, Basket, and Canisters Ready for Insertion in Slab

The LCiVSS would be located below the metallic tile floor of the vault. There are passages between the canister storage positions through which the collimated light beam passes (see Figure 22). The passages in the front-to-rear direction are offset vertically from the passages in the side-to-side direction. As the baskets containing the canisters are inserted or removed from the vertical storage location, they interrupt the light beams. 


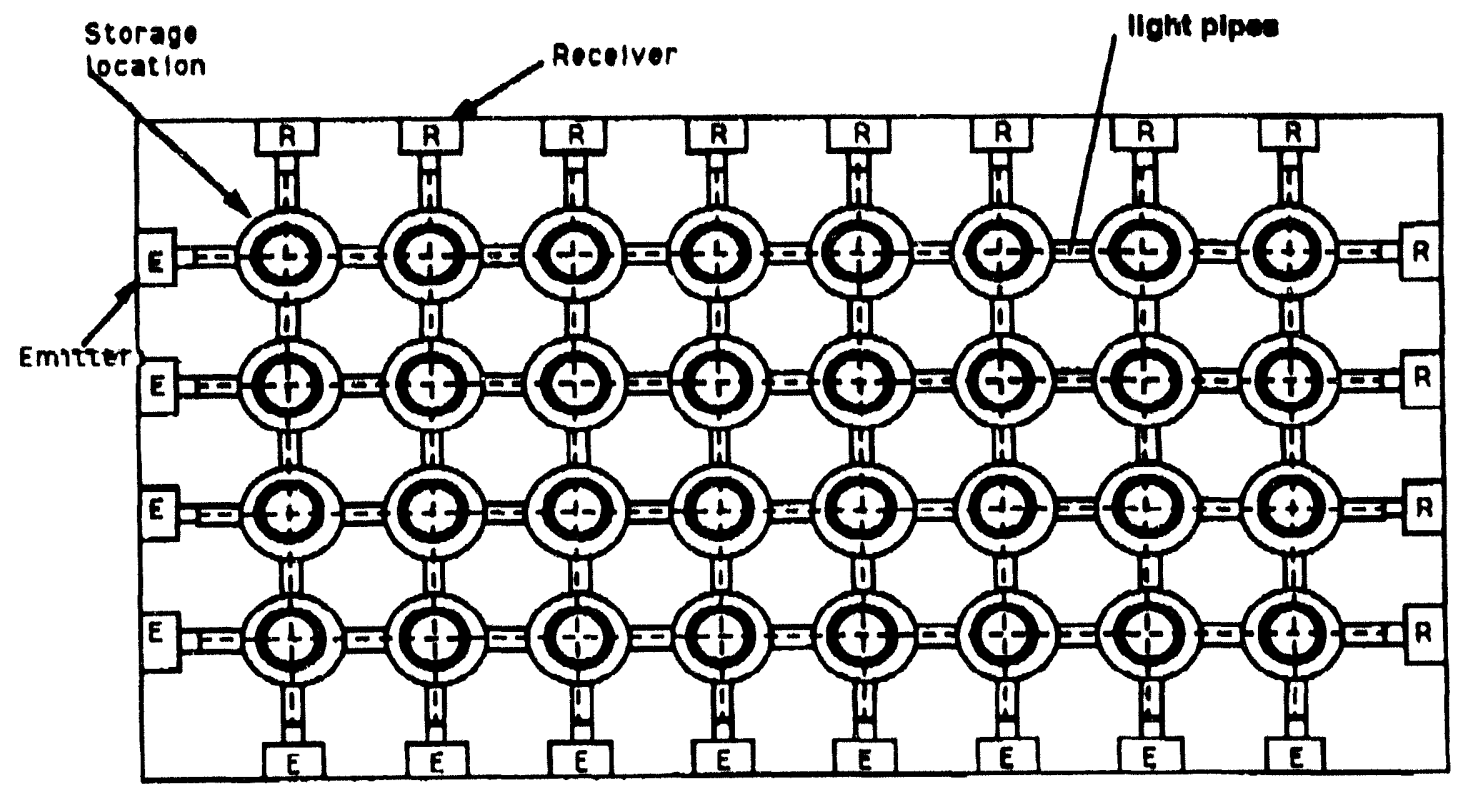

Figure 22. Vault Layout

The LGVSS consists of a network of light sources, photo sensors, a digital input circuit board used to accept the 'TVI, output from the detector system, and an IBM-compatible PC used as the system controller.

11.2 Applications. The LCiVSS system is designed to monitor nuclear materials storage canisters containing uranium oxide. The canisters would be placed in a horizontal array within a borated concrete slab. 'The slab could be placed on the floor of an existing vault, or built into the floor of new vaults. This system could greatly reduce the need for physical inventory by site personnel.

11.3 Assets. There are many advantages to the LGVSS system. This section describes the system's assets and defines the advantages of using the LGVSS system as an internal security device.

- Use of the LGVSS canister monitoring system does not allow access to stored canisters by site personnel. Automated or robotic access to the canisters is monitored by computer. 'This level of security may support the reduction of physical inventories.

- The borated slab that will contain the material canisters reduces the level of radiation in the surrounding vault. This could reduce the radiation exposure to site personnel entering the vault. 
11.4 Limitations. This section outlines some limitations of the LGVSS system.

- The LGVSS system requires extensive installation and may be impractical in locations already containing nuclear material. The radiation exposure to site personnel during required installation may be prohibitive.

- Access to stored canisters requires using an electric hoist/magnetic lift or an automated grapple.

- The LGVSS does not have the ability to verify the presence of stored canisters.

- The LGVSS is not designed to measure canister attributes such as ID or weight.

11.5 Projected Cost. The LGVSS is still in the conceptual phase of its design. Although a smallscale mock system has been constructed for testing and proof-of-concept, no reliable estimate of the cost is available

\subsection{Suppliers}

- Oak Ridge National Laboratory, ()ak Ridge, Tennessee 37831. Contact: Mike II. Ehinger (615) $574 \cdot 7132$.

- Bechtel National. Inc. ('ontact: Dick Philippone (615) 220)-25:37. 
This page intentionally left blank 


\section{CSS}

12.1 Description. The Westinghouse Container Safeguards System (CSS) consists of communication nodes and sensor-based modules that verify the material stored in a sealed metal container. To accomplish this end, attributes of the container are measured. Of the attributes considered, there are several that are meaningful without being impractical (i.e., expensive, unwieldy, short-lived, or unreliable). Accordingly, weight, temperature, rise, jiggle, and location were selected as the parameters to be measured.

For an overall view of the Container Safeguards System see Figure 23. A group of sensor-based modules attach and communicate via power line to transceivers; however, when the modules are disconnected from the power line, they communicate via RF to the portals. Each portal and each transceiver has an RS422 interface and cable. The portal is tied by t'ese to an ISBX-interface card within the Vault Interrogation Unit (VIU).

The existing system is intended for those occasions when materials are stored on shelves in relatively small containers (i.e., in a can with a diameter 4.75 inches and weighs $4 \mathrm{~kg}$ ). The CSU should be attached directly to the material container with adhesive, double-sided tape. Thus, the CSU becomes a part of the stored material until it is detached (i.e., when the stored material is removed for processing, etc.). The CSU module contains a weight sensor, two disturbance sensors (jiggle), two temperature sensors (the container temperature and its differential temperature from ambient), interface for power line-carrier communications, and short-haul RF communications as a means to communicate when disconnected from the power.

An analog timer reactivates (awakens) the module for sensing and communications. That is, most of the circuitry of the CSU is powered down to conserve power and to increase radiation tolerance. During power-down times, the CSU continuously monitors disturbance (jiggle), and records these events for the next interrogation. At the brief power-up intervals, the CSU monitors weight and temperature. Before power down, the CSU communicates with the interrogation unit so that sensor values can be transferred. In addition, the CSU has a watchdog function that has a time out of twice the power-cycling period. The watchdog accounts for the possibility of a latch-up condition that could keep the circuitry powered continuously. (The watchdog's act of powering down eliminates any existing latch-up conditions.) 


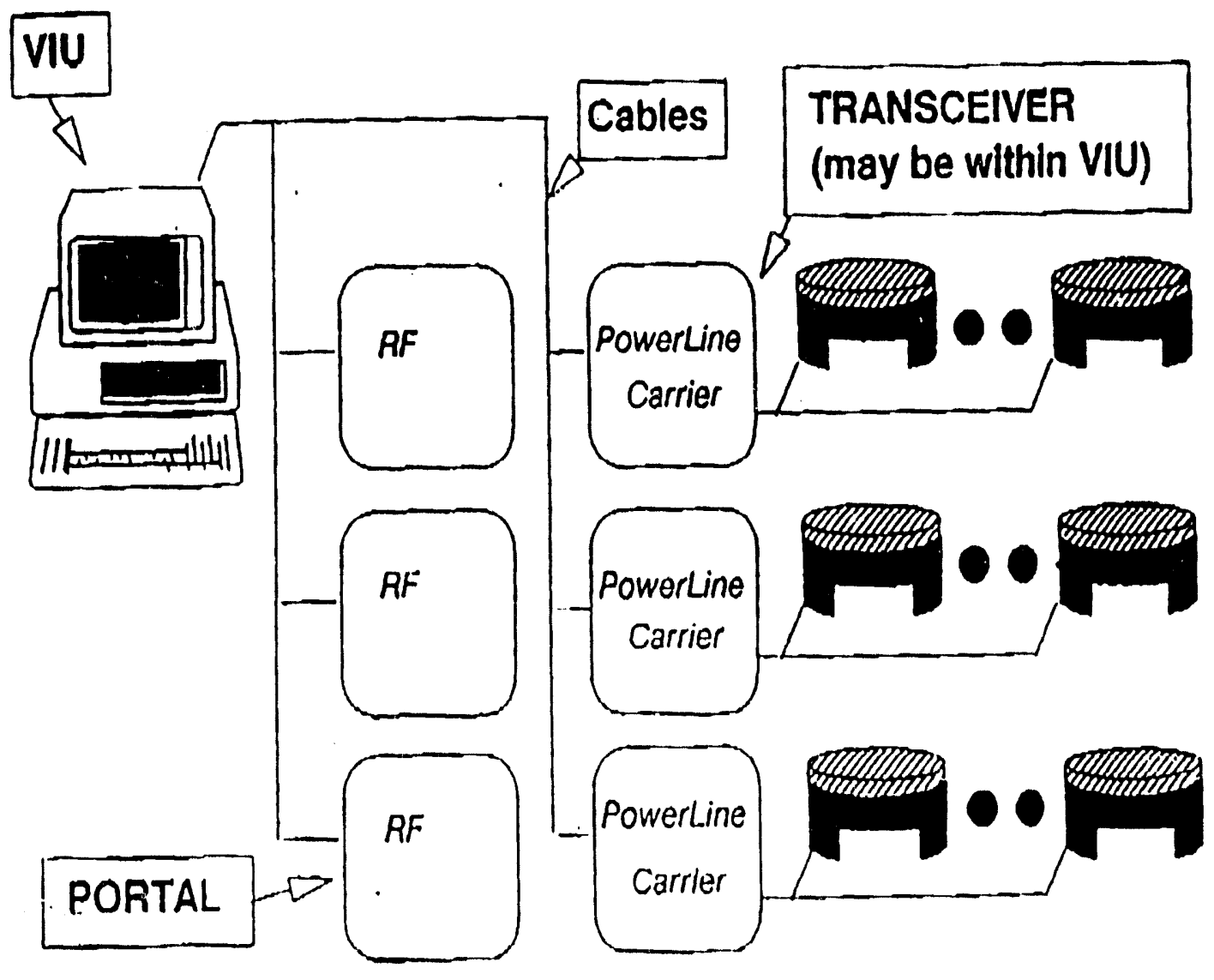

Figure 23. Surveillance Concept for Can Storage Vault

12.1.1 The CSU. The CSU is circular and approximately 4.25 inches in diameter (Figure 24). It is less than 3 inches high and is constructed so that the CSU elevates the container about 2 inches above the existing vault racks. The container itself is supported by a stainless bellows whose position indicates the container's weight. In the prototype, a portion of the CSU must hang over the edge of the rack to ease the connection of power. In addition to on-rack operation, the CSU must be constructed so that it also operates on any flat horizontal surface. 

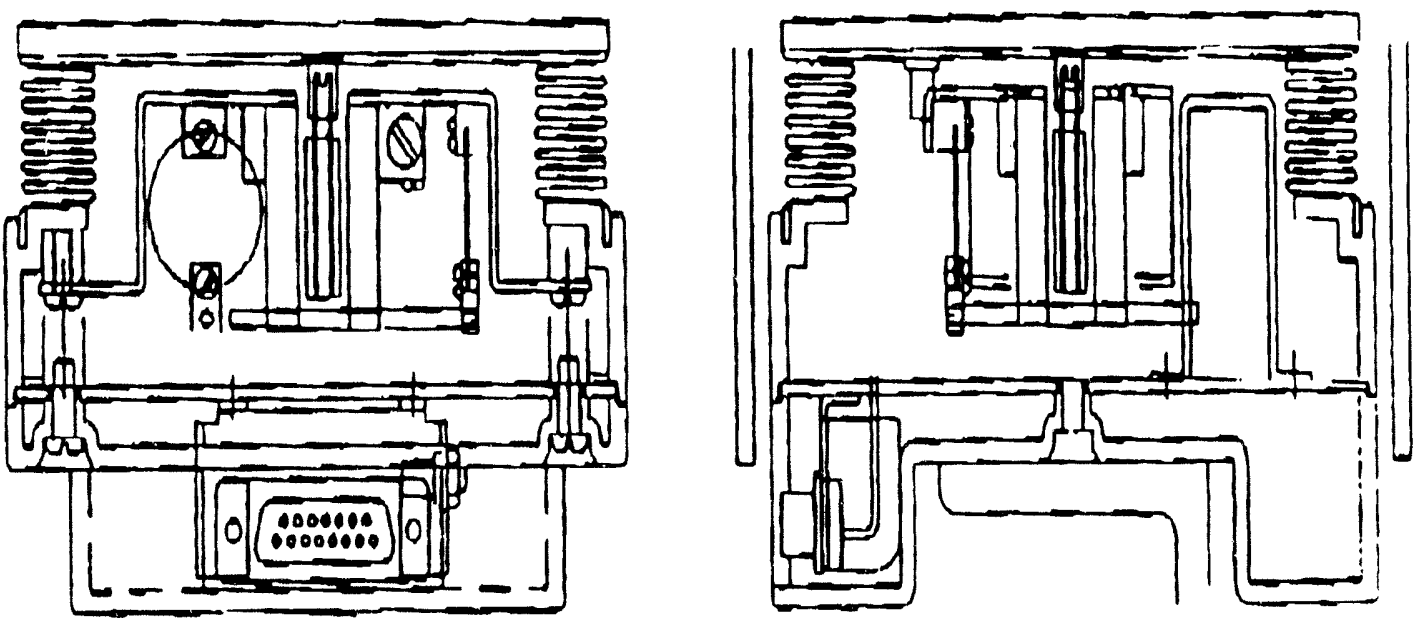

Figure 24. CSU on a Rack Within the Vault

12.1.2 The VIU. The VIU is an ISA-bus compatible computer. Slots with in the computer chassis must be occupied with one or more ISBX boards. Each board can contain three interface cards that are connected to it. Finally, each ISBX-interface card must have a ribbon cable that provides a connector at the rear of the computer. Therefore, each portal or transceiver must be tied to the computer via a cable that attaches to the computer. Alternatively, transceivers may reside within the PC chassis.

12.1.3 ISBX Interface (ards. Up to three interface cards can reside on each ISBX board within the computer chassis. The computer communicates with the interface cards as $1 / O$ through the ISBX board. Each card has an Intel ISBX connector (Part Number: 103109-001) that attaches to the ISBX board two X/inx Logic (ell Arrays (LCAs) that implement the communications protocol, and two RS422 compliant transceivers with a $1(1)$ pin connector that permits the ribbon cable to be attached.

There are two different types of interface cards. While they are physically identical, the programming of the X/inx LCAs is quite different. One LCA design is for RF communications and therefore receives demodulated data from the portal. The other LCA design for the powerline carrier must demodulate a DPSK signal as the CSU does and account for half-duplex operation. Both LCA designs transmit DPSK data that is compatible with the CSU receiver.

12.1.4 Transceivers. For powerline carrier application. the transceiver is a half-sized PC-bus compatible board that will plug into an IBM-PC, AT, or compatible computer. The transceiver serves as a power supply and communications center for the CSUs. Those CSUs not attached to the powerline must communicate through $\mathrm{RF}$ portals; however, they will do so only within approximately 5 feet. A 9 pin D-type connector ties the transceiver to the rear of the VIU chassis. An alternative 10-pin connector is provided on the transceiver to attach it to an ISBX-interface card within the same PC chassis. The use of the 10-pin connector avoids the need for an external 9-pin cable.

12.1.5 Portals. For RF application, the portal is an 11 inch $\times 15$ inch $\times 5$ inch box that can be mounted over a doorway. The box has only a standard 110-volt power cord and a 9-pin D-type connector for communication with the ISBX-interface card within the VIU. Those CSUs not attached to the powerline must communicate tinrough the RF portals. Since the CSUs can only communicate within approximately 5 feet, the portal must be capable of receiving beacons from a much greater distance. 
12.2 Applications. The CSS was designed to monitor sensitive nuclear material storage canisters. This system is ideal for use in vaults where nuclear material is stored. The CSS greatly reduces the need for physical inventory by site personnel.

12.3 Assets. There are many advantages of the Container Safeguards System. This section covers the system's assets and defines the advantages of using the CSS as an inventory tool or as an internal security device.

- The CSS can be used as an inventory tool and would greatly reduce the frequency of mandatory physical inventories.

- The CSS addresses the insider threat. Sensors contained in the CSU detect motion, a change in weight, temperature, and location. Any attempt to remove the canister itself or to remove the contents from the canister will generate an alarm. In addition, CSU design is modular so that additional sensors (such as a bulge or tamper detection) could be accommodated.

- Lifetime cost is minimized since the units have been designed for a 50 -year life with no scheduled maintenance. Cost of unscheduled maintenance is reduced by a modular design that allows quick replacement of the electronics.

- The CSUs have been designed for radiation tolerance and tested for a lifetime gammaradiation dose of $10^{5} \mathrm{RAD}$.

- System communications are over a single pair of wires that also provide CSU with 12 volts. This method assures reliable communications and freedom from interception with minimum wiring needs. Data integrity is assured because normal communications are with individual units. Wiring may be made modular for ease of installation

- In the event of power supply failure, the CSUs can operate for several days from a selfcontained standby battery.

- The CSUs have the option of low-power RF communications that have proven benign to other electronic systems, including Nuclear Incident Monitors (NIMs).

12.4 Limitations. Limitations of the Container Safeguards System are:

- Currently, the CSS is a data-gathering tool for use in monitoring access to controlled materials. No software has been written to generate real time alarms when monitored material is accessed.

- Currently, the system software is not complete; therefore, the system provides neither audible alarms nor alarm-relay capabilities.

- The CSUs have the option of a low-power, $900 \mathrm{MHz}$ RF signals with a range as far as 200 feet. Interception of these RF transmissions is possible.

- Each CSU includes a disturbance sensor whose sensitivity is adjustable; however, false alarms may still be possible from external vibration.

- The CSU design does not currently read an identification from an individual can; rather, the unit itself has a unique identification. 
12.5 Projected Cost. The following chart shows the estimated system hardware cost based on the number of CSUs with all of its sensors. Less costly alternatives could be considered for the sensor that measures weight using a radiation-tolerant Linear Variable Displacement Transformer (LVDT) and stainless bellows.

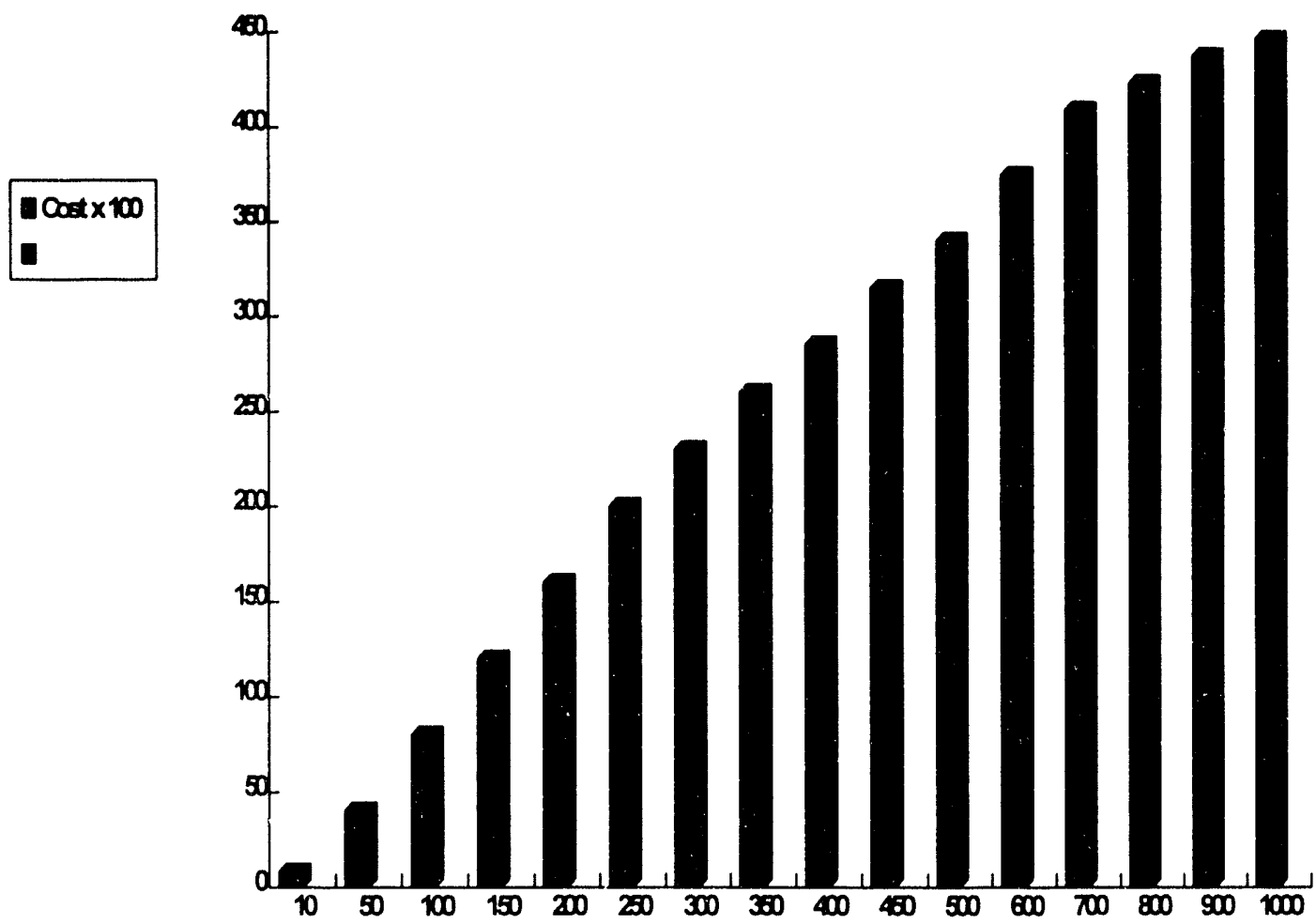

Figure 25. Estimated System Hardware Cost Based on Number of CSUs

\subsection{Suppliers.}

- Westinghouse Science and Technology Center, Pittsburgh PA 15235-5098. Contact Roger W. Cox: (412) 256-2173.

- Westinghouse Savannah River Company, Aiken SC 29808. Contact Mary Rodriguez, MC\&A Manager: (803) 725-5028. 
This page intentionally left blank 


\section{SAMMS}

13.1 Description. 'The Security Alarm and Material Monitoring System (SAMMS) is designed as a means of storing Special Nuclear Material (SNM) at the Idaho Chemical Processing Plant (ICPP). The system consists of a series of steel tubes welded into a matrix and set in concrete below the level of the storage area floor. The storage area floor contains a number of circular openings, one above each steel tube. A steel cap or lid seals each opening in the storage area floor. Suspended from the bottom of each lid is a rack designed to hold a number of SNM containers. When the rack is placed in the storage tube, a load cell monitors the weight of the rack and the containers (see Figure 26). A PC-based data acquisition system is used to continuously monitor the output of the load cells. Weight tolerance limits are assigned in software, and if the weight of the rack exceeds either the upper or lower limit, an alarm is generated. The SAMMS is connected to the plant security alarm system via dry contact relays, and to the plant safeguards system via an RS-232 communication link. When SAMMS generates an alarm, it will close the appropriate relay to alert security forces, and will send pertinent data to safeguard systems regarding weight. deviations being registered by the SAMMS.

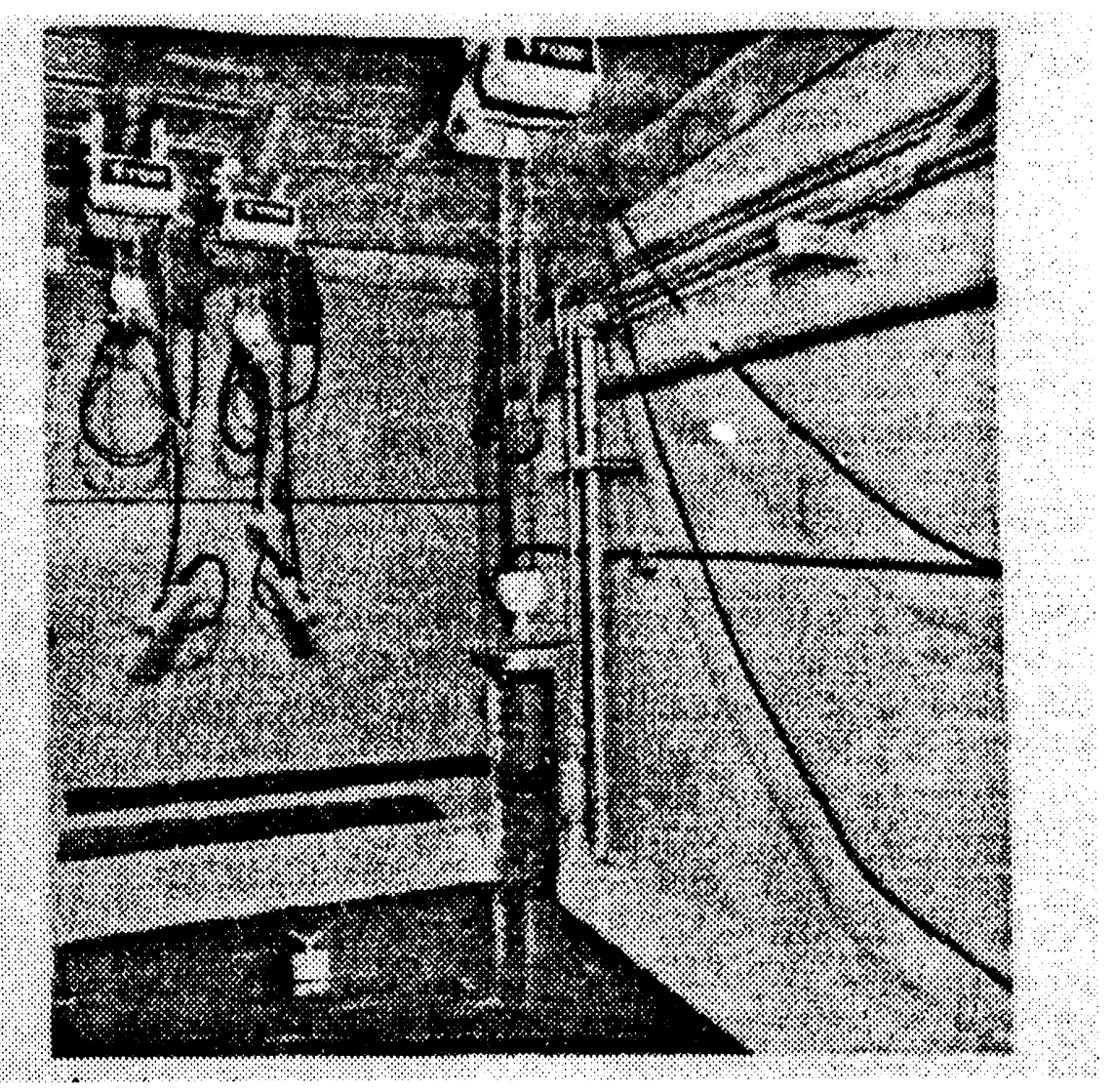

Figure 26. SAMMS Storage Area With One Rack Partially Removed 
13.2 Applications. The SAMMS is designed to monitor Special Nuclear Material storage canisters at the ICPP. This system is applicable for use in vaults where nuclear material is stored and limited storage space is available. The SAMMS greatly reduces the need for physical inventory by site personnel.

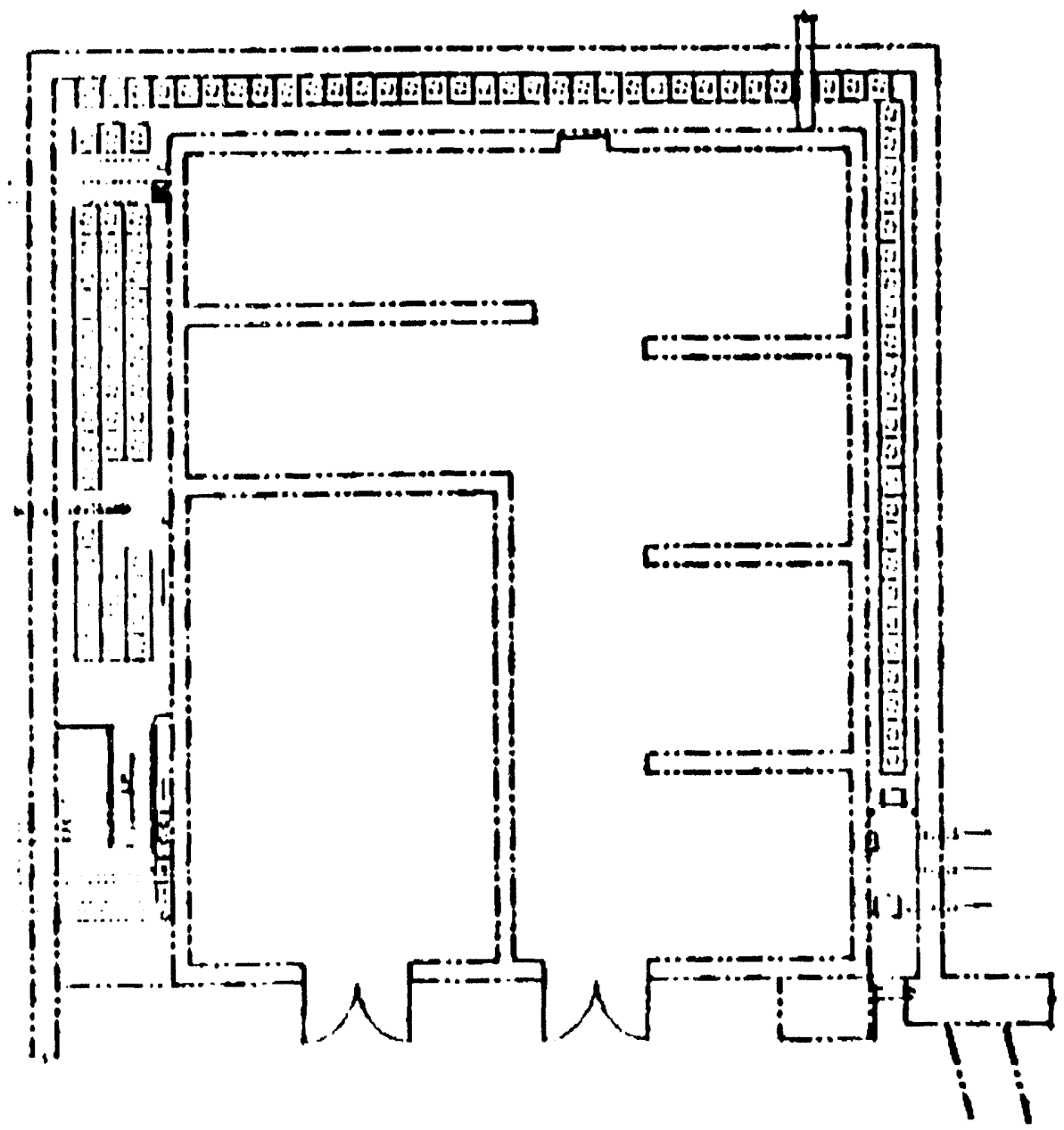

Figure 27. ICPP SNM Vault Showing Storage Area

13.3 Assets. There are many advantages of the Security Alarm and Material Monitoring System. This section covers the system's assets and defines the advantages of using the SAMMS as an inventory tool or as an internal security device.

- The SAMMS can be used as an inventory tool and would greatly reduce the frequency of mandatory physical inventories.

- The SAMMS addresses the insider threat. Sensors contained in the SAMMS detect any change in weight. Any attempt to access the racks or remove the canisters themselves or to remove the contents from the canister will generate an alarm. 
- System communications are over a single pair of wires. This method assures reliable communications and freedom from interception with minimum wiring needs. Data integrity is assured because normal communications are with individual units. Wiring may be made modular for ease of installation.

13.4 Limitations. This section outlines some limitations of the SAMMS system.

- The SAMMS system requires new construction and extensive installation and may be impractical in locations already containing nuclear material. The radiation exposure to site personnel during required installation may be prohibitive.

- Access to stored canisters requires using an electric hoist, magnetic lift, or an automated grapple.

- The SAMMS does not have the ability to verify the presence of stored canisters.

- The SAMMS is not designed to measure canister attributes such as ID, weight, or bulge. The weight attribute SAMMS provides applies to the total weight of the rack and any canisters stored in the rack

1:3.5 Projected Cost. 'The SAMMS is a site specific system. Although a system has been constructed and is in use, no reliable estimate of the cost is available.

\subsection{Supplier.}

- Westinghouse Idaho Nuclear Company, Inc., Safeguards and Security, Idaho Falls, ID 8340:3. Contact: Randon C. Anderson. 
This page intentionally left blank

H. 


\section{FOIDS(}

14.1 Description. The Fiber Optic Intelligence \& Detection System (FOIDS®) model 3000 is primarily designed as a perimeter protection system. The proposed item monitoring system is designed as a means of monitoring stored material using fiber optic technology. This system consists of:

- A control computer that receives, processes, displays, and records all data received from the fiber optic sensors (see Figure 28)

- The FOIDSN 3000 fiber optic control interface (see Figure 28).

- A number of fiber optic loops, used as sensors.
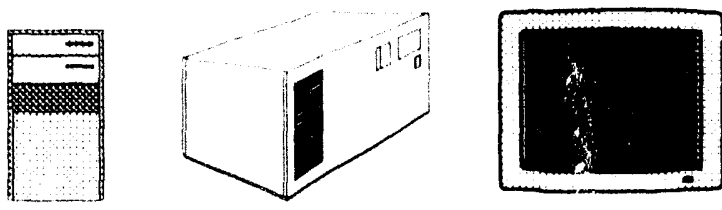

Figure 28. FOIDSW (omponents

- The F(OIDS(R) model $3(1) 00$ cont roller is an IBM compatible computer using a proprietary operating system with full-color graphic displays customized for each site. The system is designed for ease of use and readily integrates with (CTV, access cont rol and other types of intrusion protection and identification systems. Command and control of the entire system is conducted from the F(OIDS console at a central monitoring point. The FOIDS system also displays the status of the sensors, trunk lines and power supplies. The operator is able to conduct a complete continuity check of each sensor on command or can direct the FOIDS( $)$ to conduct automatic self checks. Any non-standard condition detected by the system can be displayed on the screen and accompanied by an audible alarm. After the initial alarm, the operator can suppress the audible alarm but the visual alarm will remain until the cause of the alarm has been resolved. The system will also store all event signals received. The system will record all adjustments or changes, all alarm conditions by time and date, and all non-standard conditions detected during self-test. This information is stored in the system's memory for later review or retrieval.

- The FOIDS model 3000 microprocessor-based fiber optic cont rol interface, designed by Mason \& Hanger National, Inc. is the processing and control point between the computer controller and the fiber optic sensors. Each fiber optic interface contains all the necessary hardware for 8 complete fiber optic sensor loops. The support hardware for the sensor loops consists of a power supply, a (class I) continuous wave laser, an optical splitter, a photo diode, and a signal processor (see Figure 29). The laser is connected to one port of the four port optical splitter and the photo diode is connected to the second port on the same side. Each end of a single mode optical-fiber loop is connected to the two ports on the other side of the optical splitter. The light beam from the laser is split into two sub signals which travel in opposite directions around the fiber optic loop and are recombined in the optical splitter and exit through the port being 
monitored by the photo diode. The level of amplitude interference that is achieved becomes the baseline which is monitored for change. The level of interference can range from constructive interference, where the original beam is restored, to destructive interference, where the beam is lost and a null condition is created, or to some condition between the two extremes. Touching or moving the sensing loop, or changes in the surrounding air pressure will cause the light sub signals to take a different route through the core of the fiber optic cable and cause a change in the baseline amplitude interference.

- The fiber opt ic loops or sensors are single-mode fiber optic cable. These sensors are entirely passive in operation. emitting no electronic signals which may be detected by any intruder, and can be used in close proximity to radar or other security systems and communications equipment. Sensors are not affected by electro-magnetic interference. radio transmissions or any other electronic emanations. These sensors produce no $\because r$ tive emissions, will not int roduce hazards into the area being monitored and can be used safely in explosive handling, pet roleum storage or other hazardous areas. Sorvice life of the sensors exced 10 years and are maintenance free unless physically damaged Repair of damaged or broken sensors is easily accomplished with proper equipment and does not require replacement of the damaged sensor. The fiber optic cable is very versatile and can be used in many forms. The cable can be molded into a rubber pressure pad and a monitored item placed on top of it. The cable can be used as is by wrapping it around the item to be monitored. The cable can be installed on doors. imbedded into concrete floors at access points and commonly traveled areas, can be installed into walls and ceilings to prevent covert ent rance to cont rolled areas.

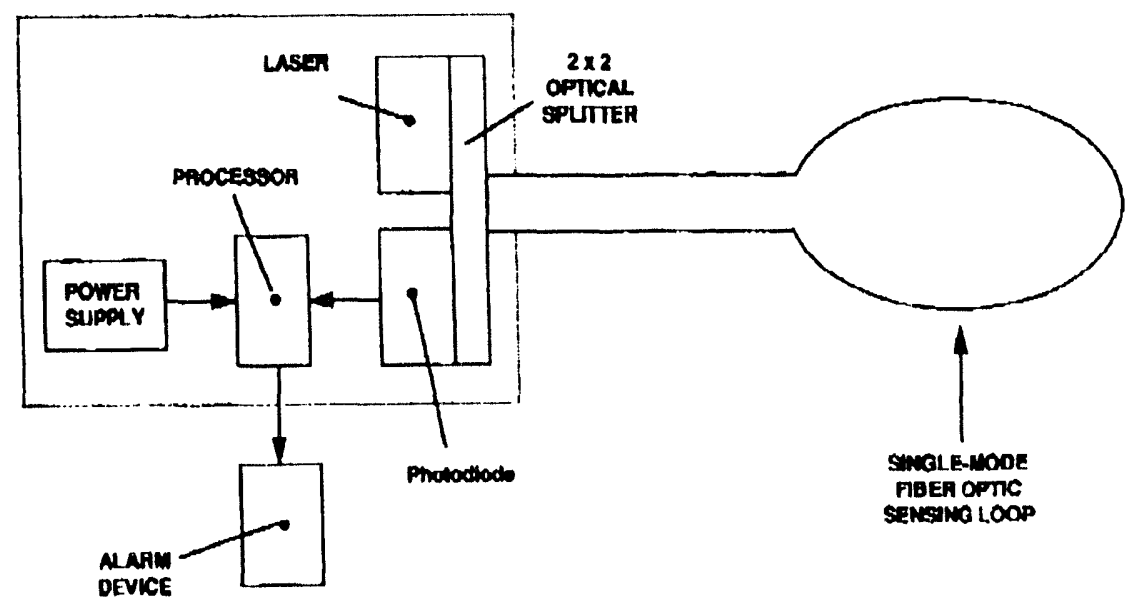

Figure 29. FOIDS( Sensor Components

14.2 Applications. This system is applicable for use in vaults where nuclear material is stored. The FOIDS( $)$ reduces the need for physical inventory by site personnel. 'The system can be used for item monitoring, intrusion detection, perimeter security and inventory.

14.3 Assets. There are many advantages of the Fiber Optic Intelligence \& Detection system. This section covers the system's assets and defines the advantages of using the FOIDS( $(\mathbb{A})$ as an inventory tool or as an internal security device. 
- The F(OIDS( can be used as an inventory tool and could reduce the frequency of mandatory physical inventories.

- The F(OIDSk system is an int rinsically safe monitoring system.

* No power sources in the storage areas

* No active emissions

* No lighting hazards

* Safe for use with radionetive materials

- The follosin system is capable of providing real time visual and audible alarm indication

- The entire Follos system is tamper proof.

- The F() (I)S s system reduces nuisance alarms by using automatically cont rolled zone sensitivity and alarm discrimination features 10 adjust for abnormal conditions. 'This enables the system to distinguish between most environmentally caused alarms and those caused by an artual intrusion.

- The Follose system uses self-diagnostic software foverify all system and sensor functions.

- The F()IISS system is capable of supporting fiber optic sensors at distances up to 19) miles without the need for additional support hardware such as amplifiers or repeaters

- The Foll)s system onhances security by allowing an operator to confirm an intrusion by furthur aceessing the sensors. listening to sounds emanating from the sensing zones via the single-mode fiber optic cable.

- The F()IDSk sensors have a long expected service life (10+ years)

14.4 Limitations. 'This section outlines some limitations of the F(OIDSe system

- The F(OIDS system requires extensive installation and may not be practical in locations already containing nuclear material. The radiation exposure to site personnel during required installation may be prohibitive.

- The F(OII)S system is hardware intensive, the space required in the security monitoring station would be considerable. For every 8 it ems monitored an interface unit $101 / 2$ inches high by 17 inches wide and 14 inches deep would be required.

\subsection{Projected Cost.}

Estimated cost of this system is approximately $\$ 5,000.00$ per item monitored. This cost is based on an initial purchase of the model 3000 system and enough equipment for 16 sensors. The price of the system will be considerably less when large quantities are purchased.

\subsection{Supplier.}

- Mason \& Hanger National, Inc., 2227 Drake Avenue, Suite 2. Huntsville, AL 35805 (205) 881.2728 Contact: Éric L. Wagner 
This page intentionally left blank 


\section{GRADS}

15. 1 Description. 'The Graded Radiation Detection System (GRADS) is a security system designed to provide a multilayered means of monitoring SNM containers stored in vaults.

- The first layer of safeguards for the stored SNM is installed at the ent rance to the vault. A pedestrian radiation portal monitor insures that any removal of radioactive material generates an alarm.

- 'The second layer of saleguards are fixed area monitors, an array of neutron detector: installed on the ceiling of a storage vault (see Figure 30). 'The neutron detectors can also be attached to the storage racks or shelving structure depending on the configuration of the vault. 'These detectors are designed to detect the movement of plutonium inside the storage vault. 'This method of monitoring plutonium has been investigated by Los . Namos National Laboratory ( $L A N L$ ) and provides continuous surveillance of a typical large storage vault. 'Th is monitoring method assumes that the neutron fiekt in a vaule produced by a particular configuration of bulk plutonium will remain constant as long as the configuration is undisturbed. (Changes in the neutron field are measured, using an appropriate array of neutron detectors and indicate whether plutonium has been added to or removed from the vault, identify the location. and measure approximately how much plutonium is involved.

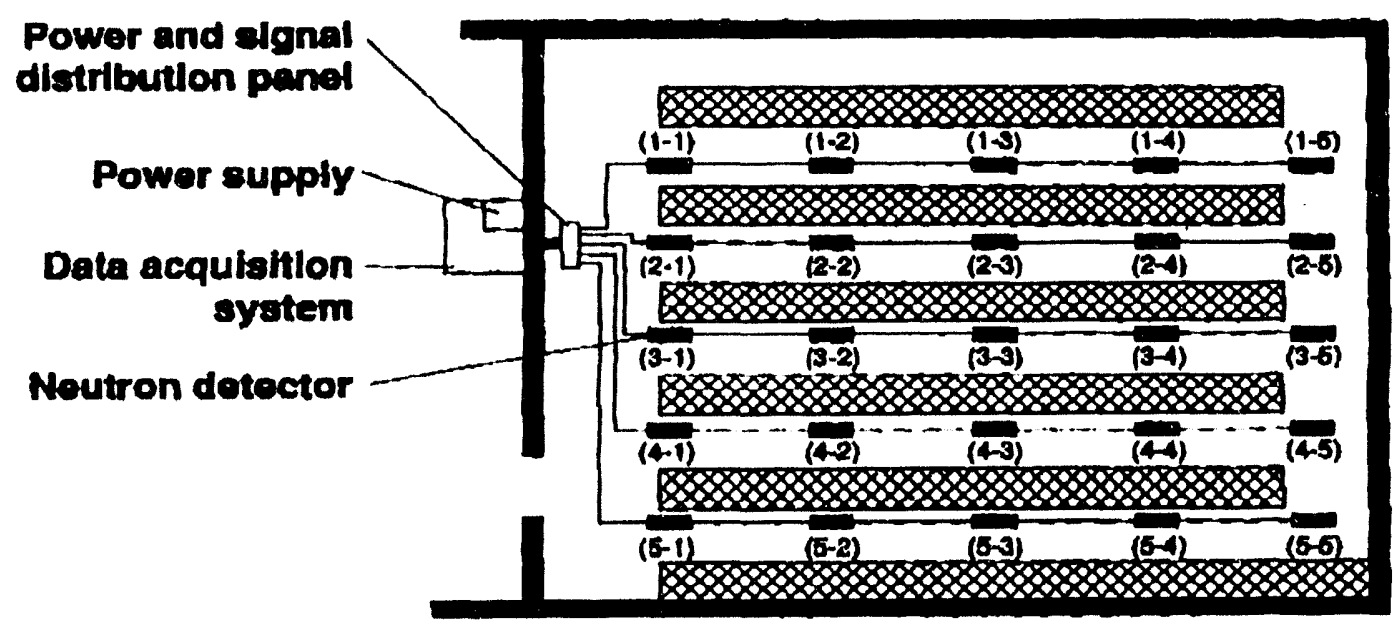

Figure 30. Vault Ceiling Mounted Detector Array

- The third layer of safeguards, and the most elaborate, measures two unique attributes for each item in the storage vault. The item monitoring units developed by LANL. monitor both mass and gamma ray emissions (see Figure 31 ). 


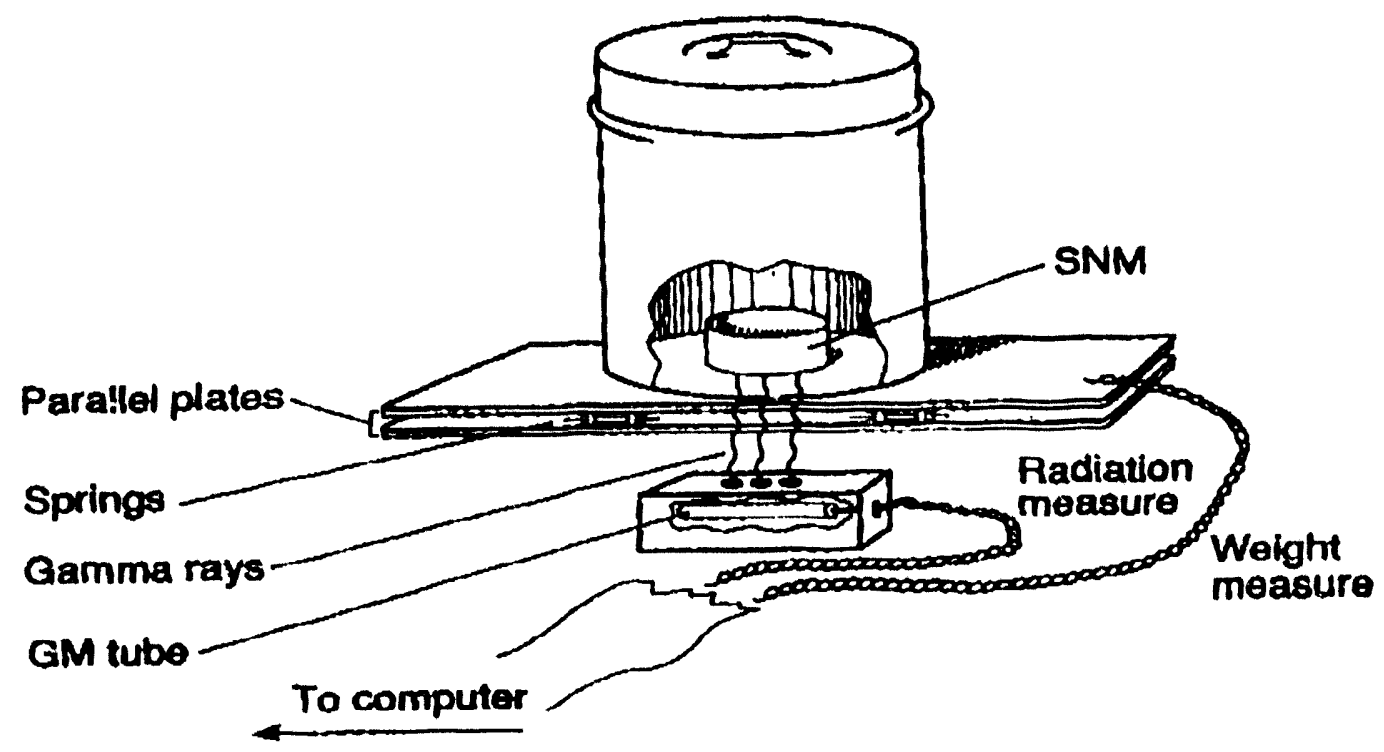

Figure 31. Item Monitoring Unit

This system. developed by LANL, requires each container to rest on an item monitor. which senses its mass and gamma ray emissions and transmits the information to the host computer for analysis. The monitoring units use a shielded and collimated (ieiger-Muller tube placed below the parallel plates of the mass sensor to detect the gamma radiation. A pair of parallel plates separated by springs serves as a mass sensor to monitor the combined mass of the container and its contents The host computer compares data gathered at intervals to the previously acquired data. Iny significant deviation results in an alarm

15.2 Applications. The GRADS is designed to monitor Special Nuclear Material storige canisters. This system is applicable for use in vaults where nuclear material is stored. The (iRAISs greatly reduces the need for physical inventory by site personnol.

15.3 Assets. There are many advantages of the (iraded Radiation Detection System. 'This section covers the system's assets and defines the advantages of using the (iR.ll)s as an inventory tool or as an internal security device.

- The (ARADS system can be used as an inventory tool. The system provides information on two attributes unique to each cont ainer being monitored. 'Th is will reduce the frequency of mandatory physical inventories.

- The GRADS system is capable of providing real time visual and audible alarm indication.

- The GRADS system can provide continuous surveillance of stored nuclear material and generate an alarm if the configuration or amount of nuclear material changes.

- The GRADS system enhances the safety of stored canisters by monitoring both the mass of, and the gamma ray emissions from each item being monitored.

- The GRADS system provides defense in depth. 
15.4 Limitations. This section outlines some limitations of the GRADS system.

- The GRADS system requires extensive installation and may not be practical in locations already containing nuclear material. The radiation exposure to site personnel during required installation may be prohibitive.

- The (XRADS neutron area monitoring sub-system is primarily designed to monitor stored plutonium. Because of the very low spontaneous fission rate of uranium this subsystem radiation detection concept would need to be modified to monitor uranium.

- The GRADS is not a quantitative monitoring system. It will detect changes in the mass or radiation level, but will not provide absolute measurements.

15.5 Projected Cost. The GRADS system is still in the conceptual phase, although some preliminary fabrication and testing has been done in the laboratory for proof-of-concept purposes. There is no accurate data on projected cost available.

\subsection{Supplier.}

- Los Alamos National Laboratories, Nuclear Technology \& Engineering Division, Advanced Nuclear Technology. N.2, P.O. Box 1663, Mail Stop J-562, Los Alamos, NM 87545. Contact: Don A. Close (505) 667-4839. 
This page intentionally left blank 


\section{PINPAL}

16.1 Description. The Physical Inventory Pallet (PINPAL) is designed as an integrated platform for the automated inventory of plutonium pit AL-R8 containers (see Figure 32). The PINPAL consists of four bar-code laser scanners, four CCD cameras, four super VHS VCR recorders, a video annotator, a supervisory computer, and a video quad processor.

The laser scanners collect bar-code data and transmit this data via RS-232 to the supervisory computer through a buffered multiplexer. The camera video images are captured by the super VHS VCR recorders. These video images are annotated with data sent by the supervisory computer to the video annotator over RS-232 data link. The four video channels are passed on through a quad multivision processor that allows all four channels to be viewed simultaneously or selected individually. The PINPAL has two video monitors to allow viewing of all channels collectively or separately. The user interface to the PINPAL is by text screen prompts on the supervisory computer monitor with operator inputs via a hand held scanner or by keyboard entry.

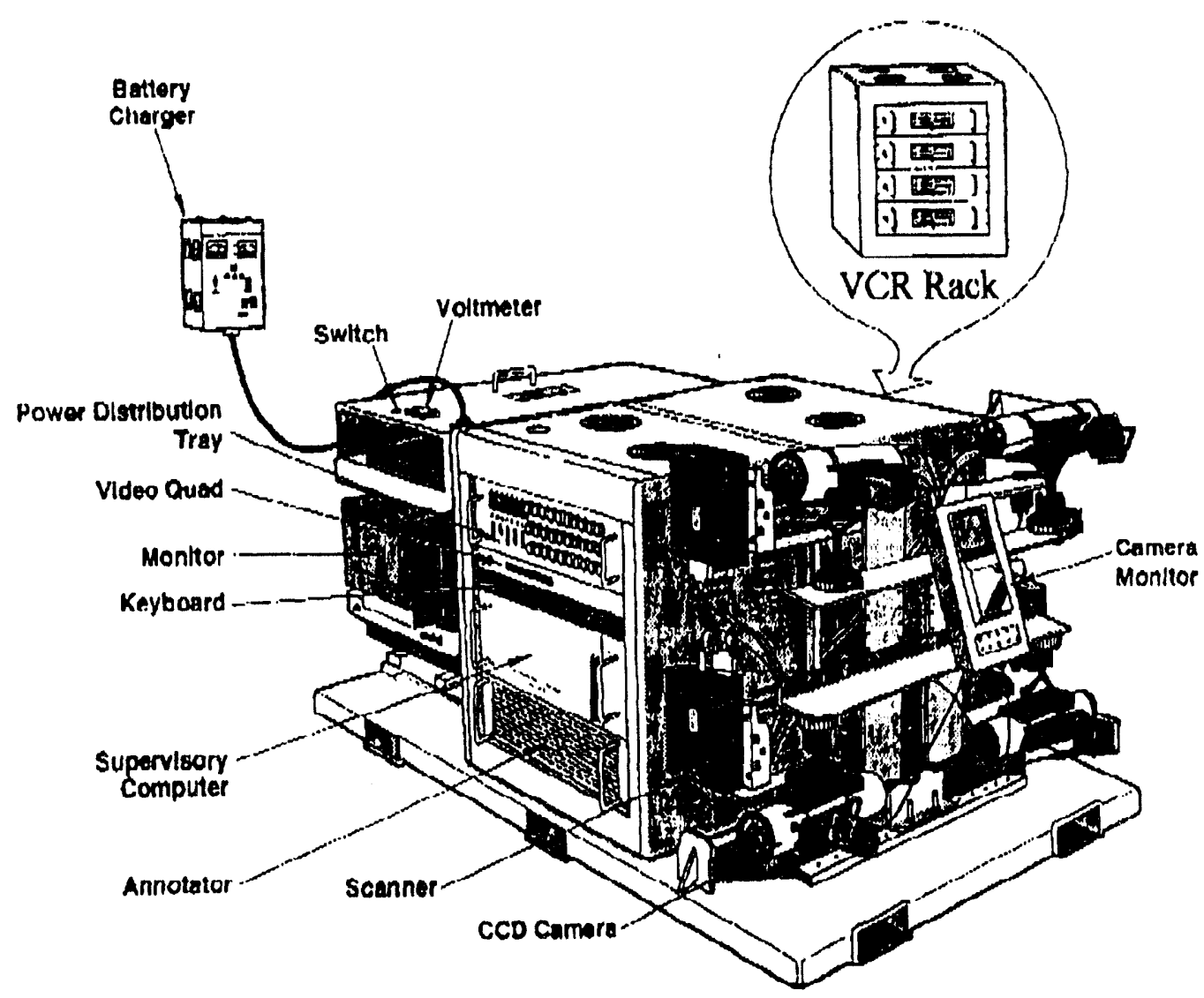

Figure 32. Physical Inventory Pallet (PINPAL) 
The bar-code readers are Microscan MS-4280 long-range raster sweep visible light diode laser scanners. The MS-4280s on the PINPAL have been configured to read three distinct bar-codes. Two successful reads are required before the bar-code data is decoded and transmitted to the supervisory computer.

The PINPAL cameras are environmentally sealed COHU 4810 monochrome CCD cameras with an auto focus lens.

The video is recorded with Panasonic Super VHS model AG-7400 video cassette recorders. Video annotation is accomplished by the HEI model $523 \mathrm{~A}$ video data system. The quad multivision is provided by the ROBOT MV45 video quad processor. The video monitors used on both the PINPAL and the shielded lift truck cab are Sony FDM-402A watchcam black and white monitors.

The supervisory computer is a Prolog 486 DX with one megabyte of flash memory and a single 3.5 inch floppy disk drive. RS-232 buffered multiplexing is accomplished using the Baytech $525 \mathrm{H}$ modified for DC operation (see Figure 33).

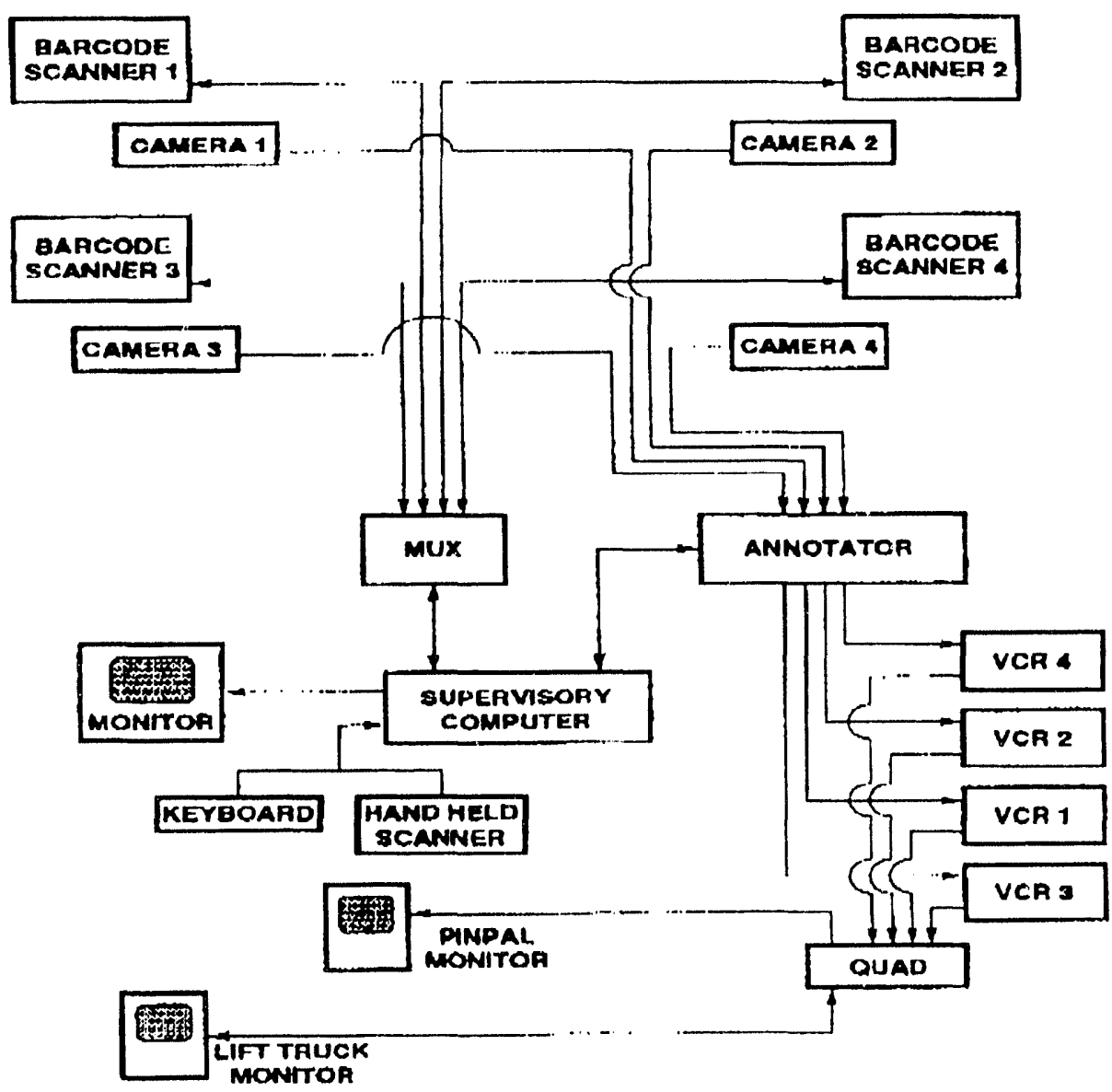

Figure 33. PINPAL System Level Diagram 
An inventory is performed by transporting the PINPAL with a radiation shielded lift truck through the magazine's center aisle (see Figure 34). The PINPAL conducts the automated bar-code data and video acquisition of the magazine's contents as it passes by each item stored in the vault. The PINPAL annotates the video record during the inventory with time and date, camera ID, magazine number, current bar-code data, and total item count. The lift truck operator is provided a monitor with real time video feedback from the PINPAL to observe system operation as well as assist in positioning of the PINPAL. The inventory is complete when PINPAL has passed by all stored items, and is then removed from the magazine. Upon completion of the inventory the PINPAL supplies three forms of useful data.

- An Inventory Summary Statement is displayed on the PINPAL monitor to alert the operator of any deviation from the pre-recorded magazine inventory.

- Inventory Data Files:

- Inventory Record file. 'This file contains a listing of all the items scanned during the inventory.

- Inventory Error File. This file contains a listing of inventory errors which were found, such as missing or additional items.

- Inventory Discrepancy File. This file contains a listing of discrepancies found between scanned inventory data and magazine record data such as differences in part numbers or serial numbers.

- Scanner Read Test File. This file contains a listing of all inventory data and how many times the bar-code was scanned, decoded and transmitted to the PINPAL supervisory computer.

- Magazine Video Record: This recorded video allows site personnel to conduct a visual inspection of the magazine contents outside the high radiation environment. During this inspection site personnel can check the integrity of the AL-R8 drums and the TID attached to each one, as well as PINPAL annotated information.

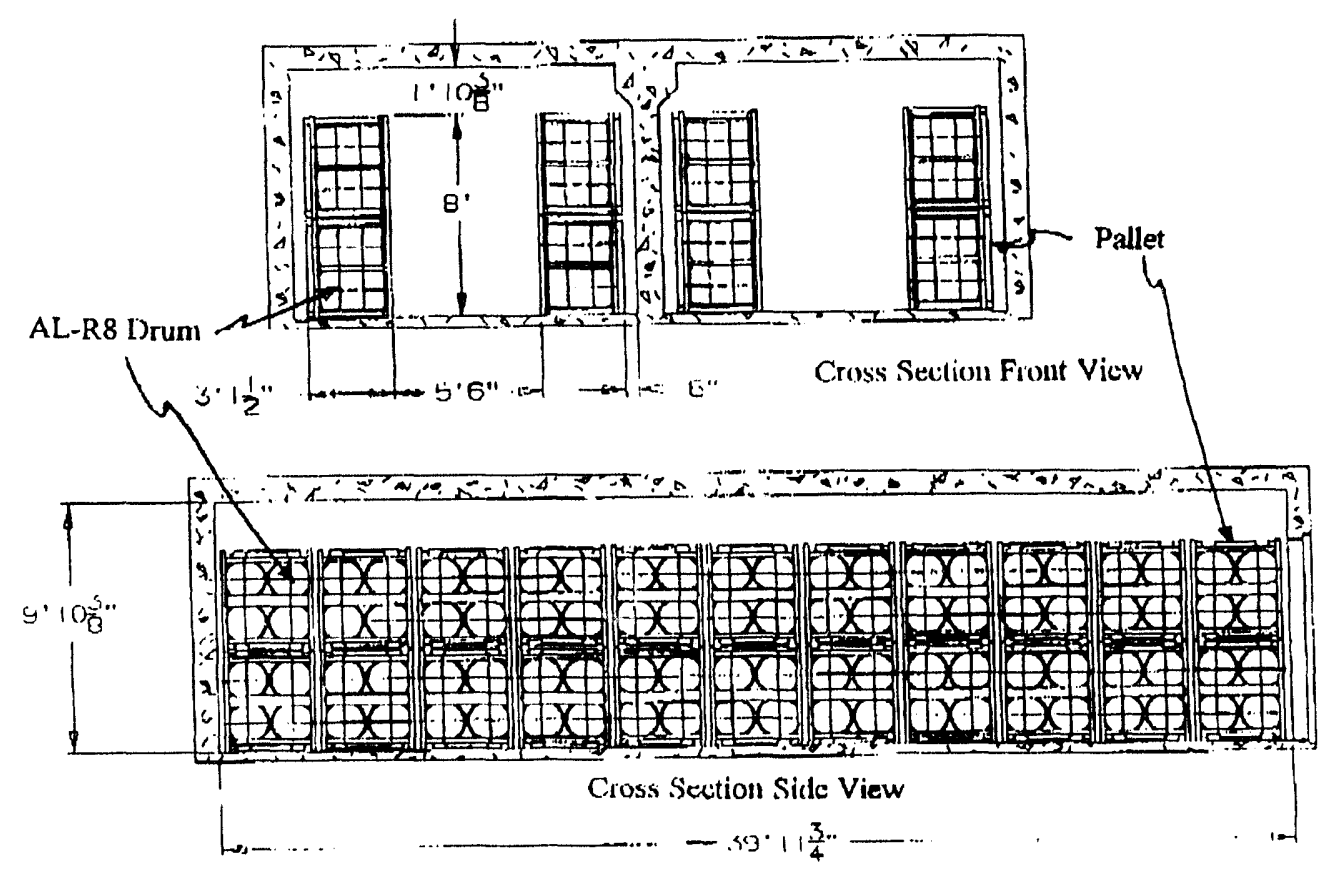

Figure 34. Pantex Stage Right Magazine 
16.2 Applications. The current version of PINPAL is site specific. The PINPAL was designed to facilitate the inventory of AL-R8 drums at the Pantex plant in Amarillo, Texas. Due to the increase in the number of weapons being dismantled and the high amounts of nuclear materials being stored, an automated method of inventory was needed. The Physical Inventory Pallet (PINPAL) in combination with the shielded lift truck automates the inventory process and will significantly reduce personnel exposure.

16.3 Assets. There are many advantages to the Physical Inventory Pallet (PINPAL). This section covers the system's assets and defines the advantages of using the PINPAL as an inventory tool.

- The PINPAL is a portable self-contained unit, it requires no modifications to the magazine and requires no installation.

- The PINPAL enables site personnel to perform a complete inventory of magazine contents from inside a shielded lift truck and will significantly reduce personnel radiation exposure by an estimated $95 \%$.

- The PINPAL produces files containing a complete list of all magazine contents in a format that can be downloaded to the Pantex plant mainframe for use by the primary material control and accountability systems.

16.4 Limitations.

- The PINPAL is a site specific system and could not be readily used at other locations.

- The PINPAL does not provide continuous monitoring.

16.5 Projected Cost.

The PINPAL commercial hardware costs are approximately $\$ 65,000.00$ per unit. In-house fabrication of the support equipment costs are approximately $\$ 50,000.00$ per unit. The total cost per unit is approximately $\$ 115,000.00$.

\subsection{Supplier.}

- Sandia National Laboratories., Albuquerque, NM 87123. Contact: W.D. Morse (505) 845-9696, or Ivan G. Waddoups, (505) 844-1649. 


\section{COMPARISON OF TECHNOLOGICAL SYSTEMS}

Tables $3,4,5$ and 6 compare the attributes and the item monitoring techniques of the different systems.

Table 3

\begin{tabular}{|c|c|c|c|c|c|c|c|c|c|c|c|c|}
\hline \multicolumn{13}{|c|}{ ITEM MONITORING TECHNOLOGY COMPARISON } \\
\hline SYSTEM & DEVELOPER & WEIGHT & PRESENCE & ID & $\begin{array}{l}\text { AMBIENT } \\
\text { TEMPERATURE }\end{array}$ & $\begin{array}{l}\text { CANISTER } \\
\text { TEMPERATURE }\end{array}$ & RADIATION & BULGE & $\begin{array}{l}\text { INSTALLATION } \\
\text { REQUIREMENTS }\end{array}$ & RF & MOVEMENT & TAMPER \\
\hline METROX & Metrox Corporation & YES & YES & $\begin{array}{l}\text { YES } \\
\end{array}$ & YES & YES & NO & YES & $\mathrm{HIGH}$ & NO & YES & NO \\
\hline VSIS & $\begin{array}{l}\text { Sandia National } \\
\text { Laboratories }\end{array}$ & NO & YES & YES & YES & YES & NO & YES & $\mathrm{HIGH}$ & NO & YES & YES \\
\hline $\begin{array}{l}\text { WATCH } \\
\text { STAND ALONE }\end{array}$ & $\begin{array}{l}\text { Sandia National } \\
\text { Laboratories }\end{array}$ & NO & YES & $\begin{array}{l}\text { YES } \\
\end{array}$ & NO & NO & NO & NO & LOW & $900 \mathrm{MHz}$ & YES & YES \\
\hline $\begin{array}{l}\text { PAMTRAK } \\
\text { WITH } \\
\text { SUBSYSTEMS }\end{array}$ & $\begin{array}{l}\text { Sandia National } \\
\text { Laboratories }\end{array}$ & NO & YES & YES & NO & NO & NO & NO & MEDIUM & $\begin{array}{l}200 \mathrm{MHz} \\
400 \mathrm{MHz} \\
900 \mathrm{MHz}\end{array}$ & YES & YES \\
\hline $\begin{array}{l}\text { TAG } \\
\text { STAND ALONE }\end{array}$ & $\begin{array}{l}\text { Sandia National } \\
\text { Laboratories }\end{array}$ & NO & NO & YES & NO & NO & NO & NO & MEDIUM & $\begin{array}{l}200 \mathrm{MHz} \\
400 \mathrm{MHz}\end{array}$ & NO & NO \\
\hline VRIS & $\begin{array}{l}\text { Sandia National } \\
\text { Laboratories }\end{array}$ & NO & YES & $\overline{Y E S}$ & NO & NO & YES & NO & HIGH & NO & NO & YES \\
\hline EIVS & $\begin{array}{l}\text { Los Alamos National } \\
\text { Laboratories }\end{array}$ & NO & YES & NO & NO & NO & NO & NO & MEDIUM & NO & YES & NO \\
\hline LGVSS & $\begin{array}{l}\text { Oak Ridge Labs. } \\
\text { Bechtel National Inc. }\end{array}$ & NO & NO & NO & NO & NO & NO & NO & $\overline{\mathrm{HIGH}}$ & NO & $\overline{\text { YES }}$ & NO \\
\hline TCATS & $\begin{array}{l}\text { Sandia National } \\
\text { Laboratories }\end{array}$ & NO & YES & NO & NO & NO & NO & NO & MEDIUM & NO & $\overline{Y E S}$ & NO \\
\hline css & Westinghouse & YES & YES & "YES & YES & $\overline{Y E S}$ & NO & $\mathrm{NO}^{*}$ & HIGH & Optional & $\overline{Y E S}$ & "NO \\
\hline AIMS & $\begin{array}{l}\text { Sandia National } \\
\text { Laboratories }\end{array}$ & NO & YES & $\overline{Y E S}$ & NO & NO & NO & NO & Low & $900 \mathrm{MHz}$ & YES & $\overline{\text { YES }}$ \\
\hline SAMMS & Westinghouse & YES & YES & NO & NO & NO & NO & NO & HIGH & NO & YES & NO \\
\hline FOIDS® & $\begin{array}{l}\text { Mason \& Hanger } \\
\text { National, Inc. }\end{array}$ & NO & YES & YES & NO & NO & NO & NO & HIGH & NO & YES & YES \\
\hline GRADS & $\begin{array}{l}\text { Los Alamos National } \\
\text { Laboratories }\end{array}$ & $\overline{Y E S}$ & YES & $\begin{array}{l}\text { YES } \\
\end{array}$ & NO & NO & YES & NO & HIGH & $\overline{N O}$ & YES & YES \\
\hline PINPAL & $\begin{array}{l}\text { Sandia National } \\
\text { Laboratories }\end{array}$ & NO & NO & YES & NO & NO & NO & NO & LOW & NO & NO & NO \\
\hline
\end{tabular}

NOTE: See following page for explanation of Table 3.

* Still under development, may change.

${ }^{\star *}$ Does not measure individual canister weight. measures total weight of rack, more than one canister can be placed on rack. 


\section{Description of Table 3.}

These tables were provided as a means of quick reference and comparison of the different attributes of the systems discussed in this document. They are not meant to be the only source of information. For the reader to gain a clear understanding of the capabilities of each system and to better understand these tables. reading of the detailed section on each technology is essential.

In Column 3 the term "Weight" refers to:

In Column 4 the term "Presence" refers to:

In Column 5 the term "ID" refers to:

In Column 6 the term "Ambient Temperature" refers to:

In Column 7 the term "Canister Temperature" refers to:

In Column 8 the term "Radiation" refers to:

In Column 9 the term "Bulge" refers to:

In Column 10 the term "Installation Requirements" refers to

In Column 11 the term "RF" refers to:

In Column 12 the term "Movement" refers to:

In Column 13 the term "Tamper" refers to:
- Attribute measurement of the monitored item's weight.

- Does this system provide a weight measurement?

- Attribute measurement of the monitored item's presence.

- Does this system confirm that a monitored item is present?

- Attribute measurement of the monitored item's ID number.

- Does this system assign and monitor an item's ID number?

- Attribute measurement of the ambient temperature of the area where the item is stored. - Does this system measure the ambient temperature of the area where the item is stored?

- Attribute measurement of the monitored item's temperature.

- Does this system measure the temperature of the monitored item?

- Attribute measurement of the monitored item's radiation signature.

- Does this system provide the radiation signature of the monitored item?

- Attribute measurement of the monitored item's bulge.

- Does this system measure the bulge of the container being monitored?

- What is the level of installation required for this system? Hardwired systems are thought to require the highest amount of installation, and systems that use individual sensors that communicate using $\mathrm{RF}$ require the least.

- Systems that use radio frequencies to transmit data from sensors to the item monitoring control interface.

- Attribute measurement of the movement of a monitored item

- Does the system detect the movement of the monitored item?

- Does the system monitor its own hardware for signs of tampering? 
Table 4

\begin{tabular}{|c|c|c|c|c|c|c|c|c|c|}
\hline \multicolumn{10}{|c|}{ ITEM MONITORING TECHNOLOGY COMPARISON } \\
\hline SYSTEM & $\begin{array}{l}\text { COST PER ITEM } \\
\text { MONITORED }\end{array}$ & $\begin{array}{l}\text { COST PER } \\
\text { MONITORING } \\
\text { STATION }\end{array}$ & $\begin{array}{l}\text { SIGNAL } \\
\text { AUTHENTICATION }\end{array}$ & $\begin{array}{l}\text { ALARM } \\
\text { TYPE }\end{array}$ & $\begin{array}{l}\text { ALARM } \\
\text { RLLAY } \\
\text { CAPABILITY }\end{array}$ & $\begin{array}{l}\text { SYSTEM } \\
\text { SECURITY }\end{array}$ & $\begin{array}{l}\text { EVENT } \\
\text { LOGGING }\end{array}$ & $\begin{array}{l}\text { LOW } \\
\text { BATTERY } \\
\text { INDICATION }\end{array}$ & INVENTORY \\
\hline METROX & $1 \mathrm{~K}$ & N/A & NO & VISUAL & NO* & NONE & YES & $\mathrm{N} / \mathrm{A}$ & YES \\
\hline VSIS & $\$ 700$ & N/A & NO & AUDIBLE & YES & NONE & YES & N/A & YES \\
\hline $\begin{array}{l}\text { WATCH } \\
\text { STAND ALONE }\end{array}$ & $\$ 200$ & N/A & NO & VISUAL & NO & PASSWCRD & YES & YES & YES \\
\hline $\begin{array}{l}\text { PAMTRAK } \\
\text { WTH } \\
\text { SUBSYSTEMS }\end{array}$ & $\$ 300$ & $\mathrm{~N} / \mathrm{A}$ & NO & $\begin{array}{l}\text { VISUAL } \\
\text { AUDIBLE }\end{array}$ & NO* & PASSWCRD & YES & YES & YES \\
\hline $\begin{array}{l}\text { TAG } \\
\text { STAND ALONE }\end{array}$ & $N / A$ & $2 \mathrm{~K}$ & NO & VISUAL & NO & PASSWORD & YES & NO & N/A \\
\hline VRIS & $5 \mathrm{~K}$ & N/A & NO & VISUAL & YES & PASSWORD & YES & $\mathrm{N} / \mathrm{A}$ & YES \\
\hline EIVS & $\mathrm{N} / \mathrm{A}$ & $2 \mathrm{~K}$ & YES & $\begin{array}{l}\text { VISUAL } \\
\text { AUDIBLE }\end{array}$ & YES & PASSWORD & NO* & N/A & NO \\
\hline LGVSS & $?$ & N/A & NO & VISUAL & NO & NONE & YES & N/A & NO \\
\hline TCATS & N/A & $10 \mathrm{~K}^{*}$ & NO & $\begin{array}{l}\text { VISUAL } \\
\text { AUDIBLE }\end{array}$ & YES & NONE & YES & N/A & NO \\
\hline CsS & $\$ 700$ & N/A & NO & VISUAL & NO* & NONE* & $\mathrm{NO}^{*}$ & OPTIONAL & YES \\
\hline AIMS & $\$ 200$ & N/A & YES & AUDIBLE & YES & $\begin{array}{l}\text { Tamper Prot. } \\
\text { Enclosure }\end{array}$ & YES & YES & YES \\
\hline SAMMS & $?$ & $?$ & NO & $\begin{array}{l}\text { VISUAL } \\
\text { AUDIBLE }\end{array}$ & YES & NONE & YES & N/A & NO \\
\hline FOIDS $\otimes$ & $5 \mathrm{~K}$ & N/A & NO & $\begin{array}{l}\text { VISUAL } \\
\text { AUDIBLE }\end{array}$ & YES & PASSWORD & YES & N/A & YES \\
\hline GRADS & $?$ & $?$ & NO & $\begin{array}{l}\text { VISUAL } \\
\text { AUDIBLE }\end{array}$ & YES & PASSWORD & YES & N/A & YES \\
\hline PINPAL & $\mathrm{N} / \mathrm{A}$ & $115 \mathrm{~K}$ & NO & VISUAL & NO & NONE & YES & YES & N/A \\
\hline
\end{tabular}

NOTE: See following page for explanation of Table 4.

*Still under development, may change. 


\section{Description of Table 4.}

These tables were provided as a means of quick reference and comparison of the different attributes of the systems discussed in this document. They are not meant to be the only source of information. For the reader to gain a clear understanding of the capabilities of each system and to better understand these tables, reading of the detailed section on each technology is essential.

In Column 2 the term "Cost Per Item Monitored" refers to:

In Column 3 the term "Cost Per Monitoring Station" refers to:

In Column 4 the term "Signal Authentication" refers to:

In Column 5 the term "Alarm Type" refers to:

In Column 6 the term "Alarm Relay Capability" refers to:

In Column 7 the term "System Security" refers to:

In Column 8 the term "Event Logging" refers to:

In Column 9 the term "Low Battery Indication" refers to:

In Column 10 the term "Inventory" refers to:
The procurement cost per stored item, if the system monitors each item individually.

The procurement cost of a system that monitors an area containing more than one stored item, this is the cost per area.

Does the system use encrypted or otherwise encoded communication to confirm the accuracy and validity of data received from its sensors?

The method used by the system to alert an operator or security personnel that an alarm condition exists.

Does the system have a method of transfering alarm data to an inhouse security and accountability system.

Does the system have any type of security barriers to prevent access to the computer software or operating system?

Does the system have the ability to log events, such as alarms and changes to the system parameters either on hard disk or printer?

Does the system have the ability to indicate low battery status on its sensors? (This applies only to systems that use battery powered sensors.)

Can the data gathered by this system be used to monitor and confirm the inventory of the area being monitored? Does the system identify each container such that an inventory report can be generated? Our assumption is that is there is an ability to continuously individually monitor each item and correlate that data with item data, then an inventory is possible. 
Table 5

\begin{tabular}{|l|l|l|l|}
\hline \multicolumn{3}{|c|}{ INVENTORY PERIODS FOR ALTERNATE MEASURES } \\
\hline SyStem & $\begin{array}{l}\text { No Access Storage } \\
\text { Areas }\end{array}$ & $\begin{array}{l}1 \text { or } 2 \text { Access/Mo. } \\
\text { Storage Areas }\end{array}$ & $\begin{array}{l}>2 \text { Access/Mo. Storage } \\
\text { Areas }\end{array}$ \\
\hline METROX & 3 years & 2 years & 2 years \\
\hline VSIS & 2 years & 1 year & 1 year \\
\hline WATCH STAND ALONE & 2 years & 1 year & 1 year \\
\hline $\begin{array}{l}\text { PAMTRAK WITH } \\
\text { SUBSYSTEMS }\end{array}$ & 2 years & 1 year & 1 year \\
\hline TAG STAND ALONE & 6 months & 4 months & NA \\
\hline VRIS & 3 years & 2 years & 2 years \\
\hline EIVS & 2 years & 1 year & 6 months* \\
\hline LGVSS & 2 years & 1 year & 1 year \\
\hline TCATS & 2 years & 1 year & 6 months* \\
\hline CSS & 3 years & 2 years & 2 year \\
\hline AIMS & 2 years & 1 year & 1 year \\
\hline SAMMS & 2 years & 1.5 years & 1.5 years \\
\hline FOIDS $\otimes$ & 2 years & 1 year & 1 year \\
\hline GRADS & 3 years & 2 years & 2 years+ \\
\hline PINPAL & 2 months & 2 months & 2 months \\
\hline
\end{tabular}

NOTE: See following page for explanation of Table 5.

${ }^{\star}$ N/A for storage areas accessed $>5$ times per month. 


\section{Description of Table 5.}

These tables were provided as a means of quick reference and comparison of the different attributes of the systems discussed in This document. They are not meant to be the only source of information. For the reader to gain a clear understanding of the capabilities of each system and to better understand these tables, reading of the detailed section on each technology is essential.

In Column 2 the term "No Access Storage Areas" refers to:

In Column 3 the term " 1 or 2 Access/M̄o. Storage Areas" refers to:

In Column 4 the term "> 2 Access/Mo. Storage Areas" refers to:
A storage area (vault, igloo, magazine) that once material is placed into, no access is permitted.

A storage area (vault, igloo, magazine) that is accessed for any reason as many as two times per month

A storage area (vault, igloo, magazine) that is accessed for any reason more than two times per month.

Note: The time periods between inventories stated in Table 5 were determined using guidelines set by the Department Of Energy and are based on the assumption that no other inventory extension credits are taken.

Sources:

DOE memorandum dated July 21. 1992. "Guidance and Criteria for Reducing Nuclear Material Physical Inventory requirements."

DOE memorandum dated May 24. 1993. "Automated Nuclear Material Physical Inventory Guidance and Criteria." 
Table 6

\begin{tabular}{|c|c|c|c|c|c|c|}
\hline \multicolumn{7}{|c|}{ SYSTEM CONSIDERATIONS } \\
\hline System & $\begin{array}{l}\text { Cluttered } \\
\text { Area }\end{array}$ & Open Area & Old Vault & New Vault & $\begin{array}{l}\text { Maintenance } \\
\text { Requirements }\end{array}$ & Training \\
\hline METROX & $x$ & $\mathrm{X}$ & & $\underline{X}$ & $\mathrm{HIGH}^{\star \star}$ & MEDIUM \\
\hline VSIS & $\bar{x}$ & $x$ & & $x$ & $\mathrm{HIGH}^{\star \star}$ & MEDIUM \\
\hline $\begin{array}{l}\text { WATCH } \\
\text { STAND } \\
\text { ALONE } \\
\end{array}$ & $x$ & $\bar{x}$ & $\bar{x}$ & $\bar{x}$ & LOW & LOW \\
\hline $\begin{array}{l}\text { PAMTRAK } \\
\text { WITH } \\
\text { SUBSYSTEMS } \\
\end{array}$ & $\mathrm{X}$ & $\mathrm{X}$ & $\bar{x}$ & $\bar{x}$ & MEDIUM* & $\mathrm{HIGH}$ \\
\hline $\begin{array}{l}\text { TAG STAND } \\
\text { ALONE }\end{array}$ & & $\bar{x}$ & & $\bar{x}$ & LOW & LOW \\
\hline VRIS & & & & $\underline{x}$ & MEDIUM $^{\text {\#t }}$ & MEDIUM \\
\hline EIVS & & $\bar{x}$ & $x$ & $x$ & LOW & MEDIUM \\
\hline LGVSS & & $x$ & & $\bar{x}$ & LOW" & LOW \\
\hline TCATS & & $x$ & $\mathrm{X}$ & $x$ & LOW" & MEDIUM \\
\hline CSS & $x$ & $\mathrm{x}$ & & $\bar{x}$ & MEDIUM $^{\star \star}$ & MEDIUM \\
\hline AIMS & $x$ & $x$ & $x$ & $x$ & LOW & LOW \\
\hline SAMMS & $x$ & $\mathrm{x}$ & $x$ & $x$ & LOW $^{\star \star}$ & LOW \\
\hline FOIDS\& & $x$ & $x$ & & $x$ & LOW & MEDIUM \\
\hline GRADS & $x$ & $x$ & & $x$ & MEDIUM $^{\star \star}$ & MEDIUM \\
\hline PINPAL & & $x$ & $x$ & $x$ & MEDIUM & MEDIUM \\
\hline
\end{tabular}

NOTE: See following page for explanation of Table 6 .

* Dependent on type and number of subsystems.

** Opinion. subjective, based on complexity of system hardware. Under development, insufficient data for accurate conclusion.

$\star \star \star$ Opinion. subjective. based on data gathered from operational system. 


\section{Description of Table 6.}

These tables were provided as a means of quick reference and comparison of the different attributes of the systems discussed in this document. They are not meant to be the only source of information. For the reader to gain a clear understanding of the capabilities of each system and to better understand these tables, reading of the detailed section on each technology is essential.

In Column 2 the term "Cluttered Area" refers to:

In Column 3 the term "Open Area" refers to:

In Column 4 the term "Old Vault" refers to:

In Column 5 the term "New Vault" refers to:

In Column 6 the term "Maintenance Requirements" refer to:

In Column 7 the term "Training" refers to:
- Vaults where a large number of items are stored.

- Vaults where items are not readily visible because of items stored in front of them.

- Vaults where a small number of items are stored

- Vaults where all stored items are easily visible.

- Vaults where all stored material is accessible by site personnel without the necessity of moving other material

- Any vault where construction has been completed.

- Any vault where nuclear material is already stored.

- Any vault where construction has not been completed.

- Any vault that is still in the planning stages and construction has not begun.

- Any vault where construction has been completed where additional construction does not adversely affect plans for use.

- In most cases the systems described are prototypes or still in the development stages and insufficient data exists for conclusive analysis. The ratings given are opinions based on complexity of each system and study of many development and commercial systems.

- The amount of training required for site personnel to operate the system.

- Opinion based on the complexity of each system. 


\section{Distribution:}

1 HQ, US Dpt of Energy, SA-1

Office of Security Affairs

Attn.: General G. L. McFadden, Dir.

Washington, DC 20585

1 HQ, US Dpt of Energy, SA-10

Office of Safeguards and Security

Attn.: Nancy H. Holmes

Washington, DC 20585

1 HQ, US Dpt of Energy, SA-12

Policy, Standards, and Analysis Div.

Attn.: D. A. Jones, Director

Washington, DC 20585

1 HQ, US Dpt of Energy, SA.13

Field Operations Division

Attn.: J. C. Howell, Director

Washington, DC 20585

1 HQ, US Dpt of Energy, SA-14

Operations Division

Attn.: M. O. Combs, Director

Washington, DC 20585

1 US Dpt of Energy, SA-20

Office of Classification

Attn.: Bryan Siebert, Jr., Director

Washington, DC 20585

3 HQ, US Dpt of Energy, SA-121

Physical Security Branch

Attn: William J. Desmond, Chief

Darryl Toms

W. Lehman

Washington, DC 20585

1 HQ, US Dpt of Energy, SA-122

Personnel Security Policy,

Procedures, Analysis Branch

Attn.: A. B. Dalinsky, Chief

Washington, DC 20585

1 HQ, US Dpt of Energy, SA-123

Technical \& Ope:ations Security Branch Attn.: L. D. Wilcher, Chief

Washington, DC 20585
3 HQ, US Dpt of Energy, SA-124

Materials Control \& Accounting Branch

Attn.: D. W. Crawford, Chief

A. Whitworth

J. Crabtree

Washington, DC 2058E

1 HQ, US Dpt of Energy, S* 131

Assessment and Integration Branch

Attn.: B. Todd, Chief

Washington, DC 20585

1 HQ, US Dpt of Energy, SA-132

Weapons Safeguards \& Security Op. Br.

Attn.: E. E. Wagner

Washington, DC 20585

1 HQ, US Dpt of Energy, SA-133

Prnduction/Energy Sfgrds/Sec. Op. Br.

Attn.: A. J. Heysel, Chief

Washington, DC 20585

2 HQ, US Dpt of Energy, SA-134

Planning and Technology Dev. Br.

Attn.: G. Dan Smith, Chief

Carl A. Pocratsky

Washington, DC 20585

1 HQ US Dpt of Energy, SA-141

Physical Protection Branch

Attn.: C. Coker, Chief

Washington, DC 20585

1 HQ US Dpt of Energy, SA-142

Technical/Information Security Branch

Attn.: F. McCloud

Washington, DC 20585

1 US Dpt of Energy, AN-30

International Safeguards Division

Attn.: K. Sanders, Director

Washington, DC 20585

2 US Dpt of Energy, DP-42

Office of 'Weapons Complex Reconfig.

Attn: Jack F. Metzler

Bruce Birnbaum

Washington, DC 20585

1 US Dpt of Energy, DP-65

Office of RD\&T Facilities

Attn.: Ken Ferlic, Acting Director

Washington, DC 20585 
2 US Dpt of Energy, DP-68

Office of Field Security Oversight

Attn.: W. Hensley, Director J. Woods

Washingt,on, DC 20585

2 US Dpt of Energy, EH-4 Office of Security Evaluations

Attn.: G. S. Podonsky, Director T. Gaines

Washington, DC 20585

1 US Dpt of Energy, EH-4.3

Ciffice of Plans, Technology, \& Cert.

Attn.: V. J. Moskaitis

Washington, DC 20585

1 US Dpt of Energy, EM-10.1

Attn: M. Daugherty

Washington, DC 20585

3 US Dpt of Energy, AL

Central Training Academy

Attn.: S. Laktasic

D. Jewell

W. Strohm

PO Box 5400

Albuquerque, NM 87185-5400

1 US Dpt of Energy, AL

Nuclear Safeguards

Attn.: L. Perez, Branch Chief

PO Box 5400

Albuquerque, NM 87185-5400

1 US Dpt of Energy, BP

Attn: R. L. Windus, Security Officer

Portland, OR 97208

4 US Dpt of Energy, CH

Attn.: H. W. Kelley, Sfgrds \& Sec. Div.

C. Bingham, Dir., New Br. Lab.

Rod Martin, New Bruns. Lab.

C. Ahlberg

Argonne, IL 60438

2 US Dpt of Energy, ID

Safeguards and Security Division

Attn.: O. Larry Jones, Director

M. Brower

Idaho Falls, ID 83402
1 US Dpt of Energy, NV

Safeguards and Security Division

Attn.: R. Ramstad

Las Vegas, NV 89193-8518

2 US Dpt of Energy, OR

Safeguards and Security Division

Attn.: W. G. Phelps, Director

G. Proco

Oak Ridge, TN 87831-8570

1 US Dpt of Energy

Safeguards and Security Division

Attn.: D. J. Ornick, Director

New Orleans, LA 70123

2 US Dpt of Energy/PNR

Safeguards and Security Division

Attn.: J. A. Bullian, Director

E. Evosevic

West Mifflin, PA 15122

3 US Dpt of Energy/RF

Safeguards and Security Division

Attn.: R. J. Levernier, Director Jim Frank, SAIC

J. Steward

Golden, CO 80402-0928

2 US Dpt of Energy/RL

Operations Security Branch

Attn.: J. W. Wiley, Chief

Al Walker

Richland, WA 99352

2 US Dpt of Energy/SF

Safeguards and Security Division

Attn.: D. A. Ash, Director

D. McIntosh

Livermore, CA 94550

1 US Dpt of Energy

Safeguards and Security Division

Attn.: G. G. Stefani, Jr., Director

Schenectady, NY 12301

4 US Dpt of Energy/SR

Safeguards \& Engineering Proj. Br.

Attn.: K. H. Besecker

L. Brown

R. D. Rollins

T. Williams

Aiken, SC 29802 
$1 \quad$ US Dpt of Energy

Western Power Administration

Attn.: J. Christopher, Security Officer

Golden, CO 80401

2 US Dpt of Energy

Argonne National Laboratory

9700 South Cass Avenue

Attn.: K. W. Poupa

D. G. Erick

Argonne, IL 60430

2 US Dept. of Energy

Argonne National Laboratory

Attn.: Manny Sanchez, Mgr, Sfgds/Sec. Paul Henslee

Idaho Site, PO Box 2528

Idaho Falls, ID 83403-2528

2 US Dept of Energy

Brookhaven National Laboratory

Attn.: K. Dahms, Bldg. 703

J. Indusi, Bldg. 197C

53 Bell Avenue

Upton, NY 11973

1 US Dept. of Energy

Lawrence Livermore National

Laboratory

Attn.: Don Wentz, Dpty Mgr, Sfgds/Sec.

PO Box 808

Livermore, CA 94550

3 US Dept. of Energy

Los Alamos National Laboratory

Attn.: L. Runge/C. Ostenak,OS.

DO,G729

D. B. Smith/J. Tape, A-DO/SG

Neal Zack

PO Box 1663 M899

Los Alamos, NM 87545

2 Allied Signal, Inc.

Security Operations

Attn.: E. C. McGurren, Mgr, Security

Steve Zvacek, Sprvsr, Tech. Sec.

Kansas City, KS 64131-3095

2 Battelle Memorial Institute

Nuclear Services

Attn.: H. Toy, Manager

Neal Owens

Columbus, OH 43201
1 Bettis Atomic Power Laboratory

Westinghouse Electric Corporation

Attn.: W. C. Rogers, Mgr, Lab. Op. Sfgds

PO Box 79

West Mifflin, PA 15122-0079

1 Boeing Petroleum Services

Security Department

Attn.: J. Dollinger

New Orleans, LA 70123

2 EG\&G Idaho, Safeguards and Security

Attn.: Roger O. Cook, Sec. Alarms Mgr John Jones, Group Manager

Idaho Falls, ID 83415

2 EG\&G Mound, Technical Security

Attn.: Daniel Baker, Security Manager Melvin F. Duff, Safeguards

Miamisburg, OH 45342

1 EG\&G Rocky Flats

Technical Security

Attn.: Shirley C. Oblinger, Director Safety \& Health Division

Golden, CO 30402-0464

1 Fermi National Accelerator Laboratory

Attn.: R. Dorner

MS102

Batavia, IL 60150

1 Los Alamos National Laboratories

Nuclear Technology \& Engineering Div.

Advanced Nuclear Technology, N-2

Attn.: D.A. Close

P. O. Box 1663, MS J.562

Los Alamos, NM 87545

4 Martin Marietta Energy Systems

Y.12 Safeguards and Security

Attn.: $\quad$ C. A. Druit, Manager

Mike Fuller

W. Belew

R. Todd

Oak Ridge, TN 37831.8213 
2 Mason and Hanger-Silas Mason Co., Inc. Pantex Plant

Attn.: JJ Hallihan, Dir., Sfgrds \& Sec. W. L. Herr, Mgr.

Safeguards \& Sec. Tech \& Pl.

PO Box 30020

Amarillo, TX 79177-001

1 Mason and Hanger, Inc.

Attn: E. L. Wagner

2227 Drake Avenue Suite 2

Huntsville, AL 35805

1 Oak Ridge National Laboratory

Attn: M. H. Ehinger

Oak Ridge, 'TN 37831

1 Protection Technologies of Idaho Attn.: B. G. Essary, General Manager Idaho Falls, ID 83402

1 Raytheon Services, Inc., Nevada Attn.: Electronics Department,

Las Vegas, NV 89193-3838

1 Wackenhut Services, Inc.

New Orleans, LA 70123

1 Westinghouse Hanford Company

Hanford Patrol

Attn.: E. R. Saxon, Chief

Richland, WA 99352

2 Westinghouse Hanford Company

Security Applications Center

Attn: Don Six

Larry McRae

Richland, WA 99352

3 Westinghouse Idaho Nuclear Company

Safeguards and Security

Attn.: EL Goldman, Mgr, Sfgds \& Sec. L. Schenk R. C. Anderson

Idaho Falls, ID 83403

1 Westinghouse Materials Company of Ohio

Safeguards and Security

Attn.: J. M. Miller, Manager

Cincinnati, OH 45239
7 Westinghouse Savannah River Company

Attn.: JW Dorrycott, Div. Mgr, Sfgd/Sec. Mary Rodriguez, MC\&A Manager W. T. Arra

R. E. Gmitter

W. M. Rajczak

C. J. O. Cox

J. W. Jay

Aiken, SC 29802

1 Westinghouse Science \& Tech. Center Attn: Roger W. Cox

1310 Beulah Road

Pittsburgh, PA 15235-5098

MS0829 R. G. Easterling (12323)

MS0322 P. J. Eicker (02100)

MS0803 D. L. Crawford (1900NM)

MS1070 R. Bair (2200)

MS0511 G. N. Beeler (2500)

MS0329 J. G. Harlan (2512)

MS0985 J. H. Stichman (2600)

MS0469 P. A. Stokes (5004)

MS0570 C. W. Childers (5900)

MS0847 J. R. Gosler (5931)

MS0175 J. F. Hollister (7181)

MS0173 J. D. Martin (7400)

MS0181 R. K. McIntire (7401)

MS1114 F. Gallegos (7402)

MS1115 A. J. Villareal (7432)

MS0611 R. M. Workhoven (7433)

MS1116 J. A. Kaiser (7442)

MS1116 E. A. Marquez (7445)

MS1116 C. E. Robertson (7445)

MS9002 P. E. Brewer (8500)

Attn.: D. R. Charlesworth

MS9020 S. C. Gray (8536)

MS0567 D. L. Mangan (9208)

MS0656 J. C. Matter (9249)

MS0656 J. L. Shoeneman (9249)

MS0769 D. S. Miyoshi (5800)

MS0760 R. P. Syler (5805)

MS0768 J. W. Kane (5806)

MS0768 C. L. Schuster (5806)

MS0760 R. F. Davis (5808)

MS0760 S. K. Fletcher (9411)

MS0765 D. E. McGovern (5821)

MS0761 F. O. Luetters (5822)

MS0761 C. D. Jaeger (5822)

MS0781 D. J. Gangel (5831)

MS0781 D. C. Hanson (5833)

MS0780 S. Ortiz (5838)

10 MS0776 I. G. Waddoups (5845) 


\begin{tabular}{|lll} 
& & \\
& & \\
& & \\
& & \\
10 & MS0776 & J. A. Abbott (5845) \\
1 & MS0776 & D. A. Anspach (5845) \\
1 & MS0782 & J. F. Chapek (5848) \\
1 & MS1131 & B. J. Steele (5849) \\
1 & MS0765 & J. D. Williams (5861) \\
1 & MS0765 & H. D. Arlowe (5861) \\
1 & MS0765 & L. E. Predika (5861) \\
1 & MS0766 & J. R. Kelsey (9600) \\
1 & MS0767 & E. R. Hoover (9603) \\
1 & MS0767 & S. C. Roehrig (9604) \\
1 & MS0783 & S. H. Scott (9611) \\
1 & MS0790 & H. J. Abeyta (9612) \\
1 & MS1125 & B. C. Caskey (9616) \\
1 & MS1125 & W. D. Morse (9616) \\
1 & MS0775 & S. J. Weissman (9617) \\
5 & MS0899 & Technical Library (7141) \\
1 & MS0619 & Technical Publications (7151) \\
10 & MS1119 & Document Processing (7613-2) \\
& & for DOE/OSTI \\
1 & MS9018 & Central Technical Files (8523-2)
\end{tabular}


